\title{
TRABALHO EM EQUIPE DE SAÚDE E DE ENFERMAGEM: ANÁLISE SISTEMÁTICA DA LITERATURA
}

\author{
Dissertação apresentada à Escola de \\ Enfermagem da Universidade de São \\ Paulo para obtenção do título de Mestre \\ em Enfermagem. \\ Área de concentração: \\ Administração em Enfermagem
}

Orientadora:

Profa. Dra. Marina Peduzzi

SÃO PAULO

2008 
AUTORIZO A REPRODUÇÃO TOTAL OU PARCIAL DESTE TRABALHO, POR QUALQUER MEIO CONVENCIONAL OU ELETRÔNICO, PARA FINS DE ESTUDO E PESQUISA, DESDE QUE CITADA A FONTE.

Assinatura:

Data

Catalogação na Publicação (CIP)

Biblioteca "Wanda de Aguiar Horta"

Escola de Enfermagem da Universidade de São Paulo

Canoletti, Bianca.

Trabalho em equipe de saúde e de enfermagem: análise sistemática da literatura. / Bianca Canoletti. - São Paulo, 2008.

$138 \mathrm{p}$.

Dissertação (Mestrado) - Escola de Enfermagem da Universidade de São Paulo.

Orientadora: Prof ${ }^{a}$ Dr $^{a}$ Marina Peduzzi.

1. Administração de serviços de saúde 2. Profissionais de enfermagem 3. Profissionais de saúde 4. Trabalho em grupo 5. Trabalho (processos). I. Título. 
Nome: Bianca Canoletti

Título: Trabalho em equipe de saúde e de enfermagem: análise sistemática da literatura

Dissertação apresentada à Escola de Enfermagem da Universidade de São Paulo para obtenção do título de Mestre em Enfermagem.

Aprovada em

\section{Banca Examinadora}

Profa. Dra. Marina Peduzzi Julgamento:

Prof. Dr.

Julgamento:

Prof. Dr.

Julgamento:

Prof. Dr.

Julgamento:
Instituição: Escola de Enfermagem da USP Assinatura:

Instituição:

Assinatura:

Instituição:

Assinatura:

Instituição:

Assinatura: 
Agradeço todo o interesse, apoio e carinho da minha mãe - Solange - e do meu pai - Mario - nesse tempo todo de pesquisa, estudo, reuniões, falta de tempo e da minha paciência; e por acreditarem incondicionalmente em mim.

Às minhas amigas Milena, Andréa e Mileninha pela ajuda, pela paciência, por todo o apoio e pelas mensagens encorajadoras de que tudo daria certo. $E$ também a Bruna, por me dizer sempre: - calma, é assim mesmo, mas passa! À professora Marina Peduzzi, pelo encorajamento e confiança desde o começo, pela certeza depositada na minha capacidade. Por todo o apoio, os ensinamentos, a paciência, a compreensão e boa vontade.

Ao Aderaldo, meu fiel escudeiro da biblioteca da EEUSP, por localizar prontamente todo o material que precisei, sempre de maneira tão cordial.

Á Fundação de Amparo à Pesquisa do Estado de São Paulo - FAPESP - e ao Observatório de Recursos Humanos em Saúde da Organização Pan-Americana de Saúde - OPAS - pelo auxílio para o desenvolvimento deste estudo. 
“A única coisa que se pode fazer sem uma equipe é jogar golf!" 
Canoletti B. Trabalho em equipe de saúde e de enfermagem: análise sistemática da literatura [dissertação]. São Paulo: Escola de Enfermagem, Universidade de São Paulo; 2008.

\section{RESUMO}

A ferramenta do trabalho em equipe é proposta para organizar o trabalho em saúde e enfermagem como maneira de se responder às mudanças do modelo de atenção à saúde e do paradigma da atenção à saúde mental. Reconhecendo sua importância no contexto atual, realizou-se uma revisão sistemática da literatura acerca do trabalho em equipe na saúde e na enfermagem, com o objetivo de identificar a produção e analisá-la criticamente, segundo a quantidade, cronologia, procedência de nacionalidade, instituição de origem e o tipo de pesquisa; referencial teóricometodológico adotado; resultados e suas contribuições como base de conhecimento para a assistência e a gerência dos serviços de saúde. O referencial teórico utilizado foi o processo de trabalho, de Mendes-Gonçalves e Mehry, e o trabalho em equipe, de Peduzzi. Metodologicamente, o estudo seguiu o caminho da revisão sistemática, com a busca ativa de publicações em bancos de dados on line, através de descritores e palavras-chave relacionados ao trabalho em equipe. Embora a primeira busca tenha retornado uma grande quantidade de publicações (1837 artigos), após os diversos procedimentos para seleção da literatura pertinente, foram selecionadas 70 publicações. Os resultados mostram a dificuldade em pesquisar o tema nos bancos de dados, principalmente dada a ausência de definição dos termos trabalho em equipe e interdisciplinaridade; assim como a falta de rigor metodológico e conceitual das publicações. O trabalho em equipe é concebido como um processo grupal e interdisciplinar, no qual se observa sinergia positiva, coordenação, cooperação e responsabilidade coletiva, compartilhamento de objetivos comuns e interação entre os membros, possível através da comunicação. Os elementos identificados para caracterizar o trabalho em equipe, além daqueles (já) citados na concepção, incluem a autonomia profissional, a flexibilização da divisão do trabalho e a integralidade da atenção à saúde. A conclusão do estudo destaca a necessidade de aprofundamento de pesquisas teórico-empíricas sobre o tema para fundamentar sua abordagem teórica, e fornecer subsídios para a formulação de propostas que permitam melhorar a utilização prática do trabalho em equipe, assim como sua avaliação sistemática. 
PALAVRAS-CHAVE: 1. Administração de serviços de saúde 2. Profissionais de enfermagem 3. Profissionais de saúde 
Canoletti B. Working in teams of health and nursing: systematic review of literature [dissertation]. São Paulo (SP), Brasil: Escola de Enfermagem, Universidade de São Paulo; 2008.

\begin{abstract}
The tool of work as a team is proposed to organize the work in health and nursing as a way to answer to the changes of the model of primary health care and the paradigm of attention to mental health. Recognizing its importance in the current context, took place a systematic review of literature about the work as a team in health and nursing, with the objective of identifying the production and look at it critically, according to the quantity, chronology, nationality, institution of origin and the type of search; reference theoretical and methodological adopted; results and their contributions as a basis of knowledge for the care and management of health services. The theoretical reference used was the work process based in Mendez-Gonçalvez and Mehry, and work in teams, based in Peduzzi. Methodologically, the study followed the path of systematic review, with the active search for publications in databases online through descriptors and keywords related to teamwork. Although the first search has returned a large number of publications (1837 articles), after the various procedures for selecting the relevant literature, were selected 70 publications. The results include the difficulty in researching the topic in databases, particularly given the lack of definition of terms and interdisciplinary work in teams, as well as the lack of methodological rigor and conceptual of the articles. The work in teams was designed as a group and interdisciplinary process, which says positive synergy, coordination, cooperation and collective responsibility, sharing common objectives and interaction between members, possible through communication. The elements identified to characterize the work as a team, beyond those cited in the design, include a professional autonomy, the division of labour flexibility and comprehensiveness of health care. The conclusion of the study highlights the need for deepening of theoretical and empirical research on the issue to justify its theoretical approach, and provide subsidies for the formulation of proposals to improve the practical use of the work as a team, as well as its systematic assessment.
\end{abstract}

KEY-WORDS: 1 . teamwork 2. nursing professionals 3. health professionals 


\section{LISTA DE TABELAS}

Tabela 1 - Distribuição dos artigos identificados segundo descritores/ palavras-chave e bancos de dados 37

Tabela 2 - Distribuição dos artigos selecionados segundo descritores/ palavras-chave e bancos de dados 38

Tabela 3 - Distribuição das publicações sobre trabalho em equipe em saúde e enfermagem segundo ano de publicação 41

Tabela 4 - Distribuição das publicações sobre trabalho em equipe em saúde e enfermagem publicadas no Brasil, segundo local de publicação 42

Tabela 5 - Distribuição das publicações sobre trabalho em equipe em saúde e enfermagem, segundo país de publicação 43 


\section{SUMÁRIO}

1. INTRODUÇÃ

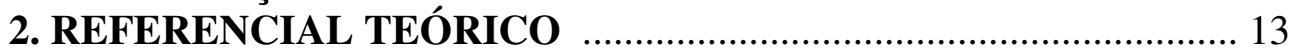

2.1 PROCESSO DE TRABALHO ....................................................... 13

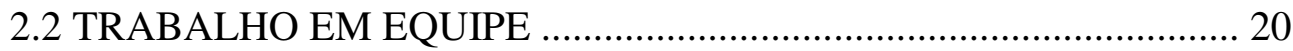

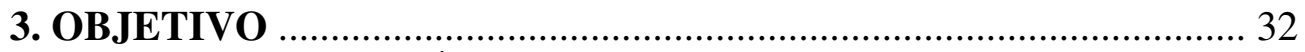

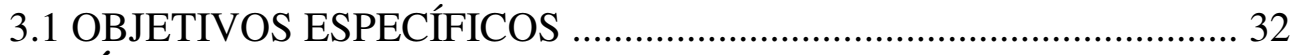

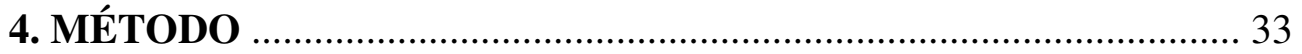

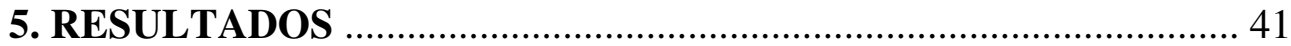

5.1 IDENTIFICAÇÃO DA PRODUÇÃO SOBRE TRABALHO EM EQUIPE NO CAMPO DA SAÚDE E DA ENFERMAGEM ..................... 41

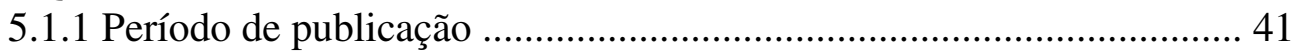

5.1.2 Local de publicação .......................................................................... 42

5.1.3 Área de concentração de pesquisa ................................................... 44

5.1.4 Tipo de publicação ............................................................................ 44

5.2 PRODUÇÃO IDENTIFICADA SEGUNDO REFERENCIAL TEÓRICO-METODOLOGICO ADOTADO ......................................... 45

5.3 RESULTADOS SOBRE AS CONCEPÇÕES E CARACTERÍSTICAS DE TRABALHO EM EQUIPE ............................................................ 46

5.3.1 Concepção de trabalho em equipe de saúde e enfermagem ............... 46

5.3.2 Características do trabalho em equipe de saúde e enfermagem ......... 49

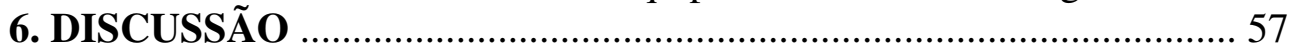

6.1 Dificuldades de busca e fragilidades teórico-conceituais e metodológicas

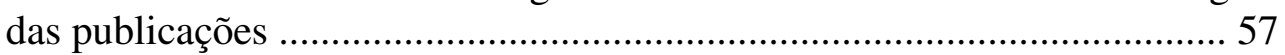

6.2 Aumento das publicações sobre o tema nas décadas de 1990 e 2000

6.3 Diferentes locais de publicação, com diferentes abordagens para o tema 60

6.4 Discussão do trabalho em equipe de enfermagem ............................... 61

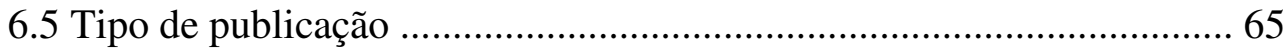

6.6 Concepção e respectivas características do trabalho em equipe ........... 67

7 CONSIDERAÇÕES FINAIS .......................................................... 81

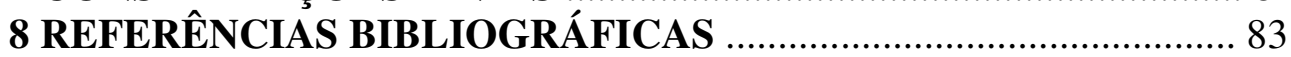

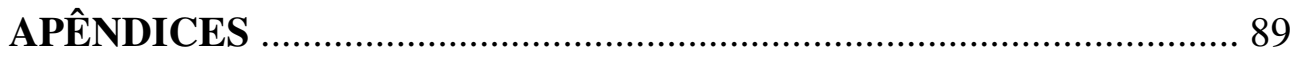

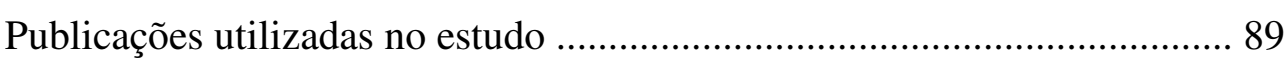

Sistematização dos resultados ............................................................... 93 


\section{TRABALHO EM EQUIPE DE SAÚDE E DE ENFERMAGEM: ANÁLISE SISTEMÁTICA DA LITERATURA}

\section{INTRODUÇÃO}

A experiência de desenvolver atividades em grupo, e a percepção de sua importância me acompanham desde a graduação, quando compreendi que em alguns grupos era possível produzir resultados melhores, e de forma mais prazerosa do que em outros.

Profissionalmente, iniciei minhas atividades em um hospital público de grande porte, que contava com um grupo de trabalho de aproximadamente 15 pessoas, nos turnos da manhã e da tarde. Heterogêneo, esse grupo de trabalho me permitiu observar que, de acordo com os profissionais que estavam presentes no plantão, o trabalho se tornava mais ou menos eficiente, as relações eram mais ou menos saudáveis, e principalmente, os resultados eram maiores ou menores.

Tal experiência me levou a questionar qual seria a importância do que eu até então chamava de equipe, no desenvolvimento de nossas atividades diárias, assim como quais seriam os elementos que poderiam ser trabalhados para facilitar o trabalho e nossos resultados.

Minha motivação veio, assim, da percepção da maneira como o processo grupal e o trabalho em equipe influenciam a prática de trabalho na saúde e na enfermagem, sua rotina diária, os resultados da assistência direta ao paciente, a gerência dos serviços e as relações interpessoais.

Embora seja um tema que permeia o trabalho em saúde, a discussão acerca do trabalho em equipe apresenta lacunas importantes, que precisam ser exploradas e aprofundadas, para que seja possível elaborar tecnologias capazes de melhorar e otimizar o processo de trabalho, tanto na saúde quanto na enfermagem.

O processo de trabalho em saúde é composto por profissionais de diversas áreas do conhecimento, que juntos buscam responder às complexas demandas e necessidades apresentadas pelos usuários dos serviços. Desenvolvido coletivamente, o 
trabalho em saúde procura utilizar a ferramenta do trabalho em equipe como forma de organizar as atividades.

Em torno de $60 \%$ do total de trabalhadores de saúde pertence à área da enfermagem, o que permite perceber a grande importância que essa área profissional representa para a qualidade da assistência prestada (Silva, Peduzzi, 2005).

Dessa forma, o aprofundamento dos estudos do trabalho em equipe enquanto ferramenta organizadora do processo de trabalho em saúde - no qual a enfermagem está inserida - e também do processo de trabalho em enfermagem torna-se um desafio que busca respostas. Assim, o problema de estudo é o trabalho em equipe na área da saúde e da enfermagem.

Procurando compreender o trabalho em equipe, inserido no contexto do processo de trabalho em saúde, e particularmente de trabalho em enfermagem, realizou-se uma revisão sistemática da literatura - nacional e internacional - que compõe bancos de dados on line, com uma análise bibliométrica e conceitual.

O referencial teórico que fundamentou o estudo compreendeu duas linhas gerais: o processo de trabalho em saúde e em enfermagem e o trabalho em equipe.

\section{REFERENCIAL TEÓRICO}


Foram trabalhados como referencial teórico estudos acerca do trabalho em equipe, sob a perspectiva dos processos de trabalho em saúde e em enfermagem.

\subsection{Processo de trabalho}

A concepção de trabalho em equipe adotada neste estudo foi fundamentada na teoria do processo de trabalho (Mendes-Gonçalves, 1992, 1994; Merhy, 1997). As contribuições de Mendes-Gonçalves (1992) formam o conjunto teórico essencial da análise do processo de trabalho em saúde, sendo complementadas pelos estudos de outros autores, conforme as citações referenciadas.

Entender de que maneira os indivíduos estão inseridos no contexto do trabalho, assim como a maneira através da qual as relações ocorrem, permite compreender ações e situações da realidade que interferem de forma decisiva na dinâmica do trabalho em saúde e na enfermagem.

A idéia de trabalho deve ser compreendida como um processo dinâmico e histórico; isto é, não se pode analisar o trabalho como uma atividade estanque no tempo e no espaço, mas sim como algo que está constantemente em movimento.

O processo de trabalho foi bastante alterado ao longo do tempo. Iniciando pelo trabalho do artesão - no qual o trabalhador era profundo conhecedor de todo o processo de produção, tanto em sua dimensão intelectual como manual -, até a divisão técnica do trabalho observada na modernidade, na qual cada indivíduo executa sua parcela de habilidade e conhecimento em uma etapa do processo produtivo.

Interessante observar que algumas atividades, embora consistam em trabalho, se desvinculam dessa idéia, seja pelo peso aparentemente maior de sua dimensão intelectual e sua especificidade técnica; seja por sua relação direta entre produtos e valores ideológicos e históricos; ou ainda pela posição social que permite aos seus agentes atingirem com a realização da atividade, a obtenção de maiores parcelas de riqueza e poder. Além disso, são atividades que permitem reproduzir representações 
sociais que auxiliam na manutenção da alienação humana em relação à sua natureza de trabalho humano e principalmente às suas potencialidades. $\mathrm{O}$ exemplo mais claro dessas atividades "desvinculadas" da idéia de trabalho é a atividade médica (MendesGonçalves, 1992).

O próprio autor apresenta uma concepção de trabalho como a situação na qual se transforma "algo" - o objeto do trabalho - em "outra coisa" - o produto do trabalho -, a partir de um objetivo, projeto anterior ou finalidade, utilizando-se energia, que é incorporada ao processo através de instrumentos específicos e necessários a cada situação especial de trabalho (Mendes-Gonçalves, 1992).

O conceito de trabalho não existe se desvinculado da utilização de energia. Para que haja a transformação do objeto em produto, é necessário que alguma parcela de energia seja incorporada ao processo, o que ao final diferencia o processo de trabalho dos acidentes naturais ou causais, nos quais podem ocorrer transformações, mas não podem ser denominados trabalho.

Outro aspecto importante para distinguir o processo de trabalho é a compreensão da finalidade. $\mathrm{O}$ homem precisa satisfazer as necessidades humanas para existir na natureza, e para tal, modificá-la. As necessidades são carecimentos que se modificam e se desenvolvem. Ao se intentar transformar um objeto em produto, observa-se que essa intenção nasceu a partir de uma necessidade, um carecimento de se obter o produto.

Essa necessidade gera um projeto que finalmente irá direcionar a transformação, ou o processo de trabalho. Assim, é a necessidade de se obter o produto, com uma dada finalidade, criadora do projeto e internalizada nele, que define o processo de trabalho enquanto ação transformadora. O sentido do trabalho percorre o processo do início à conclusão.

A perda da finalidade do trabalho traz como conseqüência a alienação, uma vez que o trabalho não é direcionado pelo projeto, mas simplesmente acontece através da transformação que se utiliza de energia. É nesse processo chamado alienação que o trabalhador apenas desempenha sua função, sem conseguir, no entanto, compreender em que fase do todo suas atividades se encaixam, e nem qual a importância delas no processo de trabalho e produção. 
Concebendo o trabalho como um processo, observa-se que pode ser compreendido como um ciclo de processos subseqüentes, isto é, o processo de trabalho torna-se um ciclo repetitivo de processos. Como se repete sistematicamente, a cada volta do ciclo ocorrem mudanças que tornam o processo mais produtivo, sendo possível produzir o mesmo trabalho em menos tempo, ou, inversamente, é possível produzir uma quantidade maior de trabalho no mesmo tempo gasto anteriormente.

A partir dessa análise, resta a dúvida do que pode ser considerado objeto de trabalho. Nesse sentido, faz-se necessário observar primeiramente que o homem e a natureza são a parte e o todo de um mesmo conjunto. O homem natural é diferente de homem social, capaz de pensar diferentes fases do mesmo processo e planejá-lo de acordo com seus carecimentos atuais e futuros.

Assim, as partes do todo apresentam em si potencialidades, qualidades que permitem sua transformação em produtos específicos. Essas qualidades devem ser evidenciadas de maneira a tornarem-se claras quanto ao seu interesse para a efetivação do processo de transformação, sendo que as demais potencialidades, apesar de existirem, tornam-se nulas. É esse olhar diferenciado com base em determinadas concepções de necessidades e as potencialidades para a sua satisfação que permite delimitar, recortar um dado objeto de trabalho.

De outra forma, é possível compreender que o objeto de trabalho não existe naturalmente, mas é definido, isso sim, de acordo com o recorte que se faz. O recorte do objeto de trabalho pode conter o projeto com os resultados almejados e a eficácia dos instrumentos, o que possibilita a satisfação de uma dada necessidade.

Para que a energia seja incorporada no processo de transformação do objeto em produto, são necessários utensílios que permitam incorporar a utilizar, de fato, essa energia. Esses utensílios são denominados instrumentos de trabalho, ou seja, artigos capazes de sintetizar as potencialidades do que existe antes nos projetos que se deseja depois.

Finalmente, pode-se entender força de trabalho como sendo o conjunto de qualidades humanas ativadas com o objetivo de transformar, para que o trabalho ocorra. É composta tanto pela energia mecânica quanto pela energia intelectual necessárias para que o processo aconteça. 
Ao longo do tempo, porém, o trabalho manual foi gradativamente sendo separado do trabalho intelectual no processo de produção, ficando este último - o trabalho intelectual - com a parcela mais "nobre" e vantajosa do trabalho, aquela através da qual torna-se mais fácil a obtenção de poder e riqueza.

Especificamente na Enfermagem, a divisão do trabalho que originou as categorias de auxiliares de enfermagem, técnicos de enfermagem e enfermeiros, segue a mesma lógica descrita acima: parte da separação entre a dimensão intelectual e manual do trabalho e, portanto, do parcelamento de um trabalho originário em práticas parcelares e específicas (Ciampone, Peduzzi, 2005).

Para se entender o processo de trabalho nas sociedades, retoma-se, como já foi dito anteriormente, que o homem é um ser social, que se expressa, produz e se reproduz em grupo, sendo os próprios grupos responsáveis pela determinação das necessidades geradoras dos processos de trabalho, e estes são também responsáveis pela sociabilidade dos indivíduos, uma vez que raramente o homem é capaz de concluir completamente o processo de trabalho sozinho.

Assim, numa situação de grupo, não se fala em necessidade individual, mas sim em necessidade social, que pode ser compreendida como a generalização das necessidades dos indivíduos que compõe o grupo, aqui chamado de sociedade. Já as necessidades sociais específicas da saúde devem englobar necessidades individuais para que possam ser consideradas legítimas. Dessa forma, os objetos de trabalho se modificam de acordo com as necessidades sociais, e de acordo com o momento histórico.

Como processo, o trabalho em saúde se diferencia por sua especificidade, uma vez que seu produto é imediatamente consumido no próprio ato de produção do serviço, ou seja, não há possibilidade de armazenamento concreto.

Através da História, o processo de trabalho em saúde se alterou de acordo com as necessidades das sociedades. Na Grécia Clássica, o processo de trabalho em saúde trouxe grandes inovações, tais como a análise clínica - tal como concebida na época das condições de saúde, com a instituição do diagnóstico e do prognóstico, determinados pelos médicos da época. Porém essas inovações somente eram experimentadas por seus cidadãos, quais sejam os homens livres. Aos outros - escravos, artesãos e mulheres - o trabalho em saúde era desenvolvido por homens com pouco 
preparo técnico, que podem ser compreendidos como os precursores do cirurgiãobarbeiro da idade média. Nessa época a doença era concebida como uma reação natural e espontânea ao desequilíbrio do homem com a natureza.

Já na idade média, por vezes considerada época de trevas em relação aos avanços científicos revelados na Grécia, a doença foi compreendida como uma provação pela qual necessariamente era preciso passar para se alcançar o paraíso. Dessa forma, o trabalho em saúde perde sua intenção de cura, para tornar-se observador e suporte para o sofrimento na busca pela vida eterna.

A modernidade iniciada com o período do mercantilismo permite uma nova ênfase na racionalidade, que procura dar conta das necessidades sociais de saúde, com uma nova concepção. Nesse período os corpos humanos passam a ser concebidos como a sede da força de trabalho, não mais desenvolvida por escravos, mas agora pertencente a homens livres, que podem vender temporariamente sua força para ser consumida nos processos de trabalho. Enquanto mercadoria, a força de trabalho deve estar disponível em quantidade e qualidade suficientes para suprir a nova dinâmica do processo de produção.

É a partir dessa análise que se compreendem as vertentes de atenção à saúde no capitalismo: controlar e evitar a ocorrência de doenças para preservar a capacidade para o trabalho, e recuperar a força de trabalho incapacitada pela doença. Essas são, assim, as necessidades de saúde no capitalismo (Mendes-Gonçalves, 1992).

A primeira necessidade de saúde na ótica capitalista - o controle da doença - é visto como fenômeno coletivo, com base na epidemiologia, cujos dois pilares principais são a possibilidade de prever a quantidade de casos das doenças em determinado período de tempo e espaço, e a possibilidade de determinar fatores associados ao aparecimento das doenças. Assim, constituem-se como instrumentos de trabalho o próprio saber da epidemiologia, o saneamento básico e a educação em saúde.

O modelo epidemiológico revela vantagens, como a perspectiva racional para o uso de recursos humanos e materiais, com o cálculo dos custos e benefícios. Dessa forma, o momento mais intelectual do trabalho em saúde passa do individual para o coletivo, sendo que o planejador em saúde pode ser médico ou não em sua formação profissional, mas certamente não o será em seu trabalho, abrindo o campo para outros indivíduos tecnicamente competentes para planejar a atenção à saúde. 
A segunda necessidade de saúde no período capitalista - recuperar a força de trabalho - é vista a partir do modelo clínico biológico, no qual o trabalho em saúde é preponderantemente o trabalho do médico, através do arsenal diagnóstico e terapêutico, farmacológico e outras práticas clínicas. O modelo clínico torna-se dominante porque a medicina produz uma concepção de doença e de saúde, como ausência de doença, centrada no conhecimento científico da anatomia, fisiologia e patologia, e na intervenção no corpo do indivíduo; portanto, com base em valores e concepções com foco no indivíduo e no individualismo, e no tecnicismo e cientificismo (MendesGonçalves, 1992).

No modelo clínico - epidemiológico é possível observar que as práticas de saúde referem-se às necessidades sociais, e a atenção a essas necessidades é planejada - ou deveria ser - a partir de dados fornecidos pela sociedade, e igualitariamente a todos os seus cidadãos.

Porém, o que se observa é a necessidade social de consumo dos serviços de saúde, isto é, a redução da saúde ao consumo, seja de serviços de assistência ou de produtos que previnem a doença, como exercícios, remédios protetores e dietas especiais. A consequiência direta desse processo é a redução do indivíduo ao consumo constante, de acordo com a lógica de mercado, que quanto maior o consumo da assistência, maior, ou melhor, será a saúde.

Observa-se, dessa forma, uma inversão do modelo clínico - do qualitativo para o quantitativo - e do modelo epidemiológico - proteção do indivíduo da doença para que sua força de trabalho possa ser exaustivamente consumida, excluindo a saúde de suas possibilidades mais amplas e abrangentes em relação a outras esferas de vida para além do trabalho, como a qualidade de vida.

De volta ao modelo clínico, para se compreender a atual divisão do trabalho em saúde, é preciso analisar que o trabalho do médico também divide-se em suas dimensões manual e intelectual, sendo que nesse contexto seu trabalho resume-se no cuidado com a recuperação do corpo do indivíduo. Para tanto, fez-se necessário espaço - o hospital moderno - e infra-estrutura que auxilie o profissional médico em sua prática, e assim surgem as "novas" profissões da área da saúde. A partir disso, tem-se a divisão técnica e social do trabalho no campo da saúde. 
É possível perceber que essa análise do processo de trabalho é complexa e histórica, pois parte das necessidades científico-tecnológicas de especialização do conhecimento, e também da dinâmica social de organização da prestação de serviço de saúde em um dado momento histórico, na direção das subdivisões do trabalho, englobando tarefas cada vez mais manuais, e aumentando, assim, a desigual valoração social das diferentes categorias de trabalhadores, que geram as diversas categorias profissionais em saúde (Peduzzi, 1998).

\subsection{Trabalho em equipe}

De acordo com Bergamini (1982), embora os indivíduos sejam tecnicamente capazes de desenvolver tarefas sozinhos, não o fazem porque têm a necessidade social de agirem em grupos sociais. Assim, os sujeitos estão constantemente se reunindo em grupos, formais ou informais, para satisfazerem suas necessidades de segurança, status, auto-estima, associação, poder e facilitação do alcance de suas metas individuais (Matheus, 1995; Munari, 1997; Ingram, Desombre, 1999; Robbins, 2001).

Nas relações de trabalho, embora essa dinâmica seja válida, se torna mais complexa pelo fato de que os indivíduos não escolhem seus grupos, mas são neles inseridos de acordo com suas responsabilidades e atividades dentro da instituição. Esses grupos são denominados grupos formais, uma vez que não são compostos de acordo com as afinidades pessoais, mas sim de acordo com uma estrutura formal de trabalho (Ingram, Desombre, 1999; Robbins, 2001).

Já os chamados grupos informais são aqueles compostos a partir das escolhas pessoais dos indivíduos, de acordo com suas afinidades, que se formam naturalmente dentro dos ambientes formais. São os grupos de amigos de uma empresa, os colegas de escola, enfim, aqueles grupos que respondem pelas necessidades sociais dos sujeitos (Ingram, Desombre, 1999; Robbins, 2001). 
Embora os termos grupo e equipe sejam largamente utilizados para denominar um conjunto de sujeitos, é importante considerar que tanto o grupo quanto a equipe definem um conjunto de pessoas que desenvolvem suas tarefas de acordo com um objetivo comum definido pelo conjunto, de maneira que o resultado não seja simplesmente a soma das habilidades individuais de cada membro (Robbins, 2001; Abreu et al., 2005). Ambos são trabalhos coletivos, que congregam profissionais interagindo entre si e articulando suas ações. O que diferencia o trabalho em grupo do trabalho em equipe seria a situação de trabalho, a dinâmica do processo. $\mathrm{O}$ grupo pode existir sem a necessidade de produzir resultados - como os grupos de amigos - mas a equipe sempre estará pautada na dinâmica do processo de trabalho, com a preocupação de produzir resultados.

A equipe deve ser organizada de forma coesa, a partir de um processo de maturidade do grupo, no qual cada agente se sinta responsável pelo trabalho coletivo (Bergamini, 1982). Tanto o processo de planejamento como a tomada de decisão são desenvolvidos por todos os agentes do grupo, sendo que a tarefa de liderar a equipe é alternada entre seus membros, de acordo com as necessidades do trabalho, assim como a partir do grau de maturidade da equipe e de seus membros.

$\mathrm{Na}$ busca de tornarem-se eficientes e eficazes, as equipes devem percorrer o caminho em direção à maturidade, estudada por autores como Bergamini (1982) e Robbins (2001). De acordo com esses autores, as equipes caminham por diversas etapas do desenvolvimento humano em grupo, para criar uma "cultura" que permita sua atuação plena enquanto equipe.

A maturidade das equipes ocorre a partir de estágios de desenvolvimento. Segundo Robbins (2001), estes estágios são: a) formação - caracterizado por uma fase de incerteza acerca dos objetivos do grupo e da determinação de suas regras de comportamento. Essa fase se encerra no momento em que os agentes se percebem enquanto parte da equipe; b) tormenta - é uma fase de conflitos entre a existência do grupo e os limites a individualidade de cada membro. Também é o estágio no qual se configura a imagem do líder; c) normalização - na busca pela maturidade, o grupo começa a demonstrar coesão e identidade grupal; d) desempenho - os agentes da equipe transferem seus esforços em conhecer e compreender os outros para o desenvolvimento da atividade para o qual a equipe foi formada. 
De acordo com Bergamini (1982) a maturidade dos grupos se desenvolve em três etapas, segundo as necessidades dos indivíduos. Tais etapas são: inclusão, que corresponde à formação do grupo; controle, relacionada à determinação das posições dentro do grupo, assim como suas relações de poder, e finalmente a fase de afeição, na qual os agentes estão inseridos no grupo como seus membros e preparados para desenvolver suas atividades, de forma a agir colaborativamente na busca dos objetivos determinados.

O alcance da maturidade da equipe pode ser reconhecido, a partir dessas duas análises, no momento em que os indivíduos do grupo se reconhecem como membros da equipe sentem-se responsáveis tanto pelos seus fracassos quanto pelos seus sucessos, participam da tomada de decisão e principalmente, possuem clareza quanto à comunicação das informações relevantes para o trabalho da equipe (Ingram, Desombre, 1999; Wasch, 2005).

Aqui se entende em particular o trabalho em equipe, que se constitui objeto e referencial desta pesquisa, visto que se realiza uma revisão crítica da literatura sobre o tema, com base em alguns estudos já consagrados no país (Peduzzi, 1998; 2001; 2007b; Fortuna et al., 2005).

Segundo Peduzzi (1998), o termo equipe deriva da palavra francesa "esquif", cujo significado se relacionava com filas de barcos amarrados uns aos outros e rebocados por homens ou cavalos. Como os homens que puxavam os barcos trabalhavam coletivamente na busca de um objetivo comum - rebocar a fila de barcos amarrados - compartilhando sua tarefa, acabou-se por utilizar o termo equipe de trabalhadores para designar o trabalho coletivo, compartilhado, de vários trabalhadores no desenvolvimento de uma tarefa, compreendida como a meta comum do grupo.

Como se referiu anteriormente, desde sua formalização enquanto profissão no século XIX, e principalmente a partir da década de 1950, o trabalho da enfermagem - a prestação do cuidado de modo contínuo - é desempenhado por diversos agentes, cujas atividades vão desde o trabalho assistencial ao trabalho gerencial, sendo, portanto, desempenhado coletivamente.

É a partir da década de 1950 que começa a ser denominado trabalho em “equipe" (Ciampone, Peduzzi, 2005). As publicações pioneiras acerca da enfermagem enquanto trabalho em equipe são da década de 1950, e versam sobre a assistência de 
saúde coletiva a gestantes (Munari, 1997). A proposta de equipe se justificaria na tentativa de organizar o trabalho de maneira a racionalizar a utilização dos recursos disponíveis para a assistência à saúde.

Apesar de proposto a décadas, o termo "trabalho em equipe" é utilizado na literatura indistintamente tanto para denominar o conjunto de agentes de uma mesma instituição, caracterizados como equipe apenas por trabalharem juntos, como para denominar a possibilidade de trabalho cooperativo e integrado, no qual os saberes são articulados em busca de metas comuns (Fortuna et al., 2005).

Segundo Peduzzi (2001), o "trabalho em equipe consiste numa modalidade de trabalho coletivo que se configura na relação recíproca entre as intervenções técnicas e a interação dos agentes” (p.103). Para Fortuna et al. (2005), o trabalho em equipe pode ser compreendido como "uma rede de relações entre pessoas, rede de relações de poderes, saberes, afetos, interesses e desejos, em que é possível identificar processos grupais. Trabalhar em equipe equivale a se relacionar” (p.264).

A origem da concepção de trabalho em equipe na área da saúde está relacionada à três vertentes: a busca estratégica pela integração, no campo da medicina preventiva, nas décadas de 1950 a 1970; a adoção do conceito da multicausalidade do processo saúde-doença; e as alterações no processo de trabalho, a partir das mudanças da finalidade do trabalho, seus objetos de intervenção e as novas tecnologias em saúde (Peduzzi, 2006).

A atualidade nos remete à importância do trabalho em equipes compostas por profissionais diversos, principalmente a partir da implantação do Sistema Único de Saúde - SUS - e do Programa de Saúde da Família - PSF. Tanto a equipe de enfermagem como a equipe de saúde, da qual a enfermagem é participante, obedecem a uma mesma diretriz ou idéia reguladora - a integralidade da saúde, que busca no trabalho em equipe a resposta às necessidades de saúde na modalidade de atenção integral à saúde.

Embora uma equipe de trabalho possa, de forma sumária e restrita, ser definida como um grupo de pessoas trabalhando com uma meta comum, não se pode deixar de compreender que tais grupos apresentam diferenças relevantes se analisados à luz da idéia de equipe. Peduzzi (2001) nos auxilia a entender essa diferenciação quando trabalha os conceitos de equipe agrupamento e equipe integração. 
A equipe agrupamento se configura em um conjunto de pessoas que, desempenham esforços individuais para planejar e decidir acerca de objetivos que auxiliem cada membro no desenvolvimento de sua área de responsabilidade (Peduzzi, 2001). Não se percebe a articulação entre os agentes, mas sim a justaposição das ações dos agentes agrupados. Dessa forma, os projetos de cada área de atuação são independentes do todo, sendo cada qual complementado pelos demais, retornando à idéia de plena autonomia técnica dos agentes, enfatizando o caráter de especificidade do trabalho (Peduzzi, 2001).

Embora traga benefícios, a organização do trabalho em equipe expõe a diferente valoração social dada ao trabalho intelectual, desenvolvido principalmente pelos profissionais médicos, e dentro da enfermagem pelo enfermeiro, e ao trabalho manual, desenvolvido pelos demais profissionais de saúde e, na enfermagem, pelos técnicos e auxiliares de enfermagem. Embora não haja diferença no que se refere à necessidade técnica dos trabalhos intelectual e manual, socialmente essa diferença de valor representa um entrave no desenvolvimento das equipes compostas por profissionais de diversas áreas do conhecimento (McCalling, 2001).

Já a equipe integração pode ser considerada um grupo onde todos os membros se envolvem no processo de trabalho de maneira a determinar e compartilhar objetivos e metas comuns, o que resulta em projetos desenvolvidos pelos diferentes profissionais de forma interdependente e complementar, colaborando entre si no exercício da autonomia técnica. A ênfase do trabalho, na equipe integração está, dessa forma, relacionada a articulação das ações e a interação dos profissionais (Peduzzi, 2001).

Assim, o trabalho em equipe expressa uma possibilidade real de alcançar a integração de diferentes áreas profissionais e disciplinares, incluindo suas intervenções técnicas e a interação dos diferentes agentes - profissionais (Schofield, Amodeo, 1999). Peduzzi $(1998 ; 2001)$ reitera que é por meio da relação entre trabalho e interação que os agentes da equipe são capazes de construir projetos comuns, que respondam às necessidades de atenção integral dos usuários dos serviços de saúde.

A comunicação entre os membros de uma equipe de trabalho, e especificamente nas equipes de saúde, revela-se como a chave necessária à solução de diversos problemas, como a discussão dos valores, da filosofia e dos objetivos da equipe, e o 
planejamento de suas ações e dos recursos necessários ao seu trabalho (Wiecha, Pollard, 2004; McCalling, 2001).

Segundo Peduzzi (1998; 2001; 2007b), a comunicação e o diálogo constituem-se como dimensões essenciais para a integração do trabalho em equipe. É a partir da comunicação que a interação dos agentes torna-se possível, assim como a articulação dos trabalhos especializados com a interação dos agentes da equipe, sendo que sem interação não se pode falar em trabalho em equipe.

Assim, a dimensão comunicativa é considerada intrínseca ao trabalho em equipe, é o seu denominador-comum. É através da mediação da linguagem que a articulação das atividades, a integração dos saberes técnicos e a interação dos agentes torna-se possível (Peduzzi, 1998; 2001).

Os agentes que compõe a equipe de trabalho apresentam como característica a capacidade de elaborar conjuntamente a linguagem, objetivos, propostas e projetos comuns, isto é, a elaboração de uma cultura comum à equipe de trabalho, desde a concepção até a execução do trabalho (Peduzzi, 1998; 2001; Ingram, Desombre, 1999). O ambiente propício para a eficiência da equipe é aquele onde a comunicação é clara, freqüente e aberta (Wasch, 2005).

Portanto, uma equipe representa, para além de relações de trabalho, relações de saberes, poderes e principalmente, relações interpessoais, o que configura duas dimensões de uma equipe: a articulação das ações executadas pelos diversos profissionais que a compõem e a interação destes agentes (Peduzzi, 2001; Fortuna et al., 2005; Peduzzi, Ciampone, 2005).

Segundo Peduzzi e Ciampone (2005), o trabalho em equipe eficiente exige certas competências que devem ser constantemente desenvolvidas, tais como "o aprender a viver junto, a viver com os outros, a conviver (...) aprender a questionar o próprio conhecimento, aprender a aprender com o outro (...). Implica, em última instância, em trabalhar o autoconhecimento e a auto-estima” (p. 15).

Assim, embora muito se fale acerca do termo equipe, sua utilização se restringe àquele conjunto de sujeitos que trabalham em busca do alcance de uma meta comum determinada por eles mesmos, que articulam suas ações de acordo com seus diferentes saberes e experiências, e interagem entre si, de maneira que seus esforços estejam em sinergia, isto é, os esforços da equipe são maiores do que simplesmente a soma dos 
esforços individuais (Lorimer, Manion, 1996; Ingram, Desombre, 1999; McCalling, 2001; Abreu et al., 2005; Wasch, 2005).

São características indispensáveis das equipes a colaboração e a cooperação na interação de seus agentes, assim como a articulação e a interdependência de suas ações e projetos, visando um objetivo comum (Ciampone, Peduzzi, 2005).

Importante ressaltar, porém, que quando se fala em integração dos profissionais e potencialização de suas competências, não se fala em equalização de saberes, isto é, os diferentes profissionais possuem conhecimentos diferentes que se completam e cooperam entre si, mas não são uniformizados ou simplesmente somados (Peduzzi, 1998; 2001).

O trabalho em equipe revela-se complexo, uma vez que congrega em si as necessidades dos usuários do serviço, da própria instituição, bem como os desejos e a individualidade de cada membro da equipe. Isto posto, não se pode negligenciar o fato de que embora o trabalho seja de equipe, esta é composta por indivíduos com diferentes histórias de vida, saberes e formações diversas. Matheus (1995) pontua a importância dos indivíduos sentirem-se satisfeitos em desenvolver suas atividades, e essa satisfação está intimamente ligada ao reconhecimento do indivíduo pela equipe, assim com a possibilidade de alcançar suas metas individuais.

Essa situação gera conflitos, mas também pode estimular a criatividade, conduzindo a equipe na direção de uma tomada de decisão mais consciente e consistente, através da análise dos problemas sob as várias perspectivas trazidas pelos diversos profissionais da equipe (Robbins, 2001; Wiecha, Pollard, 2004; Fortuna et al., 2005; Peduzzi, Ciampone, 2005).

Dessa forma, percebe-se que o trabalho em equipe não pode ser considerado uma atividade automática ou natural da capacidade técnica ou profissional dos sujeitos, mas sim uma qualidade constantemente desenvolvida como propriedade coletiva, na qual as habilidades necessárias ao trabalho em equipe eficaz devem ser constantemente desenvolvidas e amadurecidas (Matheus, 1995; McCalling, 2001).

Assim, na atualidade observa-se o interesse das instituições em promover o trabalho em equipe. Esse interesse está relacionado ao fato de que as equipes eficientes podem facilitar o trabalho e melhor o desempenho dos indivíduos por conter em si 
diferentes competências e experiências. Além disso, as equipes podem ser mais flexíveis que os indivíduos isolados, reagindo melhor às situações de mudança, tão rápidas e vitais nos dias atuais (Robbins, 2001).

A partir da década de 1990, a busca pelo cuidado integral em saúde tem se tornado mais freqüente (McCalling, 2001). No Brasil, é com a implantação do Sistema Único de Saúde e principalmente com a implantação do Programa de Saúde da Família, em 1994, que apresenta o trabalho em equipe como pressuposto e diretriz operacional para a reorganização do processo de trabalho em saúde, que o conceito de trabalho em equipe, assim como sua importância tornam-se pontos vitais para se atingir o sucesso na área da saúde (Peduzzi, 2006; 2007a). O modelo assistencial atual em saúde baseia-se, assim, na estruturação do trabalho em equipes (Abreu et al., 2005).

Com a mudança do paradigma do processo saúde-doença para o modelo de atenção integral, a equipe de saúde torna-se questão central da prestação de cuidados, pois atende a busca pela integralidade da saúde - promoção, prevenção, recuperação e reabilitação (Peduzzi, 2006).

Trabalho em equipe, para além da integração dos agentes e da articulação das ações, exige o reconhecimento e o entendimento das práticas dos demais profissionais. O reconhecimento de que o conhecimento do outro é útil e indispensável ao atendimento das demandas apresentadas pelos usuários e população converge com a idéia de integralidade da atenção à saúde, pois o processo saúde-doença é apreendido em suas diversas dimensões. A integralidade é a principal justificativa que motiva o trabalho em equipe (Peduzzi, 2007a).

De acordo com Pinheiro (2006), a integralidade da atenção à saúde obedece a três conjuntos de sentidos: como prática médica adequada - compreendendo o sujeito para além de sua queixa inicial -, como modelo de organização das práticas de saúde articulando as demandas e superando a fragmentação das ações de saúde -, e como estratégia política para atenção a problemas de saúde, de acordo com o novo paradigma de assistência à saúde do SUS, atendendo ao princípio da universalidade. A autora defende que, dessa forma, a integralidade é "concebida como uma construção coletiva, que ganha forma e expressão no espaço de encontro com os diferentes sujeitos implicados na produção do cuidado em saúde".

De acordo com Mattos (2004), a atenção integral em saúde busca uma lógica ampliada para o atendimento das necessidades de saúde, que contemple tanto a esfera da 
prevenção quanto a esfera da assistência. O que significa dizer que a responsabilidade profissional, na atenção à saúde, está tanto em responder à demanda espontânea que trouxe o usuário até o serviço, quanto utilizar a oportunidade do encontro entre usuário e equipe de saúde para agir na oferta de ações preventivas. Esse conjunto de ações preventivas e assistenciais deve ser, portanto, oferecido por uma equipe de trabalho, capaz de responder às diferentes necessidades.

Ainda de acordo com Mattos (2004), "o que caracteriza a integralidade é obviamente a apreensão ampliada das necessidades, mas principalmente essa habilidade de reconhecer a adequação de nossas ofertas ao contexto específico da situação no qual se dá o encontro do sujeito com a equipe de saúde" (p. 1414).

Peduzzi (2006) corrobora com a concepção de integralidade da atenção à saúde como "a apreensão e resposta ampliada e contextualizada para as necessidades de saúde dos usuários e população de um dado território".

Essa maneira de compreender a atenção em saúde implica em se construir, a partir da relação dialógica uns com os outros, - equipe de saúde e usuário do serviço um projeto terapêutico individualizado para cada usuário e um projeto comum de trabalho para a equipe.

Assim, o trabalho em equipe responde à busca pela integralidade do cuidado, uma vez que se coloca como alternativa frente à fragmentação da assistência, e nesse sentido, relaciona-se com a quebra da divisão rígida do trabalho em saúde, com a coresponsabilização dos profissionais pelos problemas e suas soluções, assim como com a busca pela superação da inércia e da burocracia do trabalho (Almeida Filho, 1997; Peduzzi, 1998; 2007b; Peduzzi, Ciampone, 2005).

Dessa forma, justifica-se também pela diminuição dos custos decorrentes da otimização da assistência especializada e integral. Os custos da assistência podem, num primeiro momento, aumentar, em função dos esforços para estruturar e alcançar a eficiência das equipes, porém o trabalho em equipe claramente definida, reduz os custos da assistência integral em saúde (Ingram, Desombre, 1999; McCalling, 2000).

Há, portanto, duas justificativas para o trabalho em equipe: a atenção integral em saúde; e a racionalização dos serviços e o controle dos custos (Peduzzi, 2007b).

O trabalho em equipe é compreendido como modalidade de trabalho coletivo, composto por diferentes profissionais, que também contempla as relações entre as 
diferentes disciplinas ou áreas do conhecimento, sendo que a multidisciplinaridade, a interdisciplinaridade e a transdisciplinaridade aparecem como uma maneira de responder à necessidade de recomposição dos trabalhos especializados (Peduzzi, 1998; 2001; Schofield, Amodeo, 1999). Tais conceitos são por vezes utilizados como sinônimos e no senso comum perdem suas particularidades e suas potencialidades na implantação da equipe (Almeida Filho, 1997; Schofield, Amodeo, 1999).

A equipe multidisciplinar diz respeito a um conjunto de profissionais com formação em diferentes disciplinas, envolvidos em um mesmo projeto, porém desenvolvendo seu trabalho de maneira independente, isolada. Na multidisciplinaridade se observa que as diferentes disciplinas tratam da mesma questão, sem apresentar relações entre os profissionais envolvidos, determinando a justaposição das disciplinas, numa situação de trabalho na qual a cooperação é ausente e a coordenação é administrativa (Almeida Filho, 1997; Schofield, Amodeo, 1999; Wiecha, Pollard, 2004; McCalling, 2001; Irribary, 2003).

A equipe interdisciplinar se configura quando os esforços dos diferentes profissionais são coordenados e interdependentes na assistência em saúde (Schofield, Amodeo, 1999; Wiecha, Pollard, 2004; McCalling, 2001; Irribary, 2003). O trabalho interdisciplinar observa relações recíprocas entre os profissionais, com possibilidades de crescimento mútuo. As ações são coordenadas pela disciplina mais próxima da temática central, procurando mediar e integrar os discursos, direcionando as relações de poder à horizontalização (Almeida Filho, 1997).

As equipes interdisciplinares, nas quais o planejamento da assistência é realizado com a participação de todos os profissionais da equipe de maneira ativa, apresenta maior facilidade em solucionar problemas, uma vez que pode contar com diversas disciplinas e seus pontos de vista específicos (McCalling, 2001; Wasch, 2005). Segundo McCalling (2001). As equipes interdisciplinares e transdisciplinares podem contribuir para a redução dos custos da assistência em saúde, embora as evidências empíricas acerca de seus benefícios ainda sejam escassas.

Finalmente, no trabalho em equipe transdisciplinar, a integração das disciplinas é característica singular, tendendo a horizontalização das relações de poder, borrando as fronteiras entre as disciplinas, sendo que a coordenação da equipe é assegurada pela finalidade do próprio projeto (Almeida Filho, 1997). Irribary (2003) define que o 
trabalho transdisciplinar pode ser compreendido como o "diálogo e a cooperação entre as diferentes áreas do conhecimento" (p. 490), procurando explicar os fenômenos que não podem ser compreendidos pelo domínio de uma disciplina única. Dessa forma, busca recolocar o homem no "centro do conhecimento".

\section{OBJETIVO}

Analisar criticamente a literatura nacional e internacional sobre trabalho em equipe de saúde e enfermagem.

\subsection{Objetivos específicos}

@ Identificar a produção sobre trabalho em equipe no campo da saúde e da enfermagem, e analisá-la segundo a quantidade, cronologia, procedência de nacionalidade, instituição de origem e tipo de pesquisa;

C Analisar a produção identificada no campo da saúde e da enfermagem segundo o referencial teórico-metodológico adotado; 
C Analisar a produção identificada segundo os resultados de pesquisa e de reflexão crítica;

@ Analisar de forma crítica a produção identificada em relação à sua contribuição como base de conhecimento para a assistência e a gerência de serviços de saúde.

\section{MÉTODO}

Neste estudo realizou-se uma revisão sistemática da literatura acerca do trabalho em equipe na saúde e na enfermagem. As pesquisas de revisão bibliográfica têm o objetivo de reunir em si as pesquisas de outros autores, que podem ser localizadas em bancos de dados, sejam estes impressos ou eletrônicos, na intenção de embasar teoricamente determinado assunto. Permitem que o conhecimento seja aprofundado, aperfeiçoando teorias e subsidiando mudanças no cotidiano que permeiam a realidade do objeto de estudo, assim como permitem a divulgação do conhecimento conceitual relacionado ao tema.

Segundo Silveira (2005), as revisões de literatura exigem que sejam seguidos padrões que assegurem sua qualidade metodológica, quais sejam: "uso de métodos para assegurar a análise precisa e objetiva, análise da teoria, resultados, métodos, sujeitos e variáveis de estudo, fornecer ao leitor o máximo de informações possíveis sobre os estudos revisados e não somente os principais" (p. 42). 
As pesquisas que se propõem a realizar um levantamento bibliográfico têm três caminhos metodológicos a seguir, quais sejam a revisão integrativa, a revisão narrativa e a revisão sistemática.

A revisão integrativa se propõe a sintetizar os resultados de pesquisas científicas finalizadas, elaborando conclusões globais acerca do objeto e conhecendo os pesquisadores mais engajados no tema. Exige os mesmos padrões de rigor, clareza e replicação que são utilizados nos estudos que analisa. Nesta modalidade de revisão deve-se declarar com clareza o assunto ou tema estudado, incluir todos os estudos encontrados, e do contrário, justificar os métodos de amostragem e critérios de inclusão utilizados (Silveira, 2005).

A revisão narrativa é a análise de uma ampla gama de artigos, com o objetivo de "descrever e discutir o desenvolvimento" de determinado assunto ou do objeto de estudo, seja de maneira teórica ou conceitual, de modo a apresentar o "estado de arte" do tema abordado (Rother, 2007). Sua particularidade em relação aos demais tipos de revisão bibliográfica é a ausência de informações relativas às fontes de informação, a metodologia de busca ou os critérios de seleção e análise. Segundo Rother (2007), são importantes na medida em que permitem ao leitor se apoderar ou atualizar seu conhecimento acerca de determinado assunto. São estudos qualitativos que não abrem espaço para a reprodução de seus dados.

Já a revisão sistemática da literatura, utilizada neste estudo, se propõe a uma revisão planejada, com o objetivo de atender a questões específicas, determinadas no início da pesquisa e denominada como a questão de investigação, a partir de uma metodologia explicitada e sistemática de identificação, seleção e análise crítica do material (Rother, 2007). Esta modalidade de revisão produz trabalhos originais desenvolvidos com rigor metodológico que permitam sua reprodução, evitando tendenciosidades e inferências.

A revisão sistemática é o estilo de revisão da literatura mais utilizado na prática baseada em evidências, nos estudos quantitativos, mas também pode ser utilizada em estudos qualitativos (Galvão, Sawada, Trevizan, 2004). A recomendação de desenvolvimento de uma revisão sistemática pode ser definida de acordo com as seguintes etapas, como apresentam Rother (2007) e Galvão, Sawada e Trevizan (2004): formulação da pergunta, localização dos estudos, avaliação crítica dos estudos, coleta de 
dados, análise e apresentação dos dados, interpretação dos dados, aprimoramento e atualização da revisão.

A aplicação da revisão sistemática da literatura nos estudos de natureza qualitativa é recomendada quando se deseja atingir maior rigor metodológico no desenvolvimento da pesquisa. A utilização da revisão sistemática no estudo de quadro qualitativo tem a preocupação de limitar o viés do estudo; porém por ser metodologicamente rigorosa, apresenta grande dificuldade em sua realização; embora seja esse mesmo rigor que demonstre a importância em se desenvolver pesquisas qualitativas com metodologia de revisão sistemática.

Para o delineamento do estudo, foi definida como pergunta norteadora a questão: quais as concepções e respectivas características do trabalho em equipe na saúde e na enfermagem presentes na literatura? A definição da pergunta da pesquisa é uma etapa fundamental para o delineamento do estudo. Segundo Rudio (2004), o rigor e a validade de uma pesquisa estão intimamente ligados ao delineamento preciso do problema de estudo.

Definir o conceito que se deseja estudar implica diretamente no rigor metodológico de uma pesquisa. Segundo Rudio (2004), “além de ser a representação da coisa em alguém, o conceito é o meio que o indivíduo tem para reconhecer esta coisa (ou outra qualquer da mesma espécie), compreendendo-a, tornando-a inteligível para si". É de acordo com o conceito pré-definido do objeto de estudo que se realiza a análise dos dados da pesquisa e a proposição de suas conclusões. O conceito bem definido deve apresentar um conjunto de tudo que se sabe sobre o fenômeno, sobretudo aquilo aprendido empiricamente, englobando em si todas as suas características próprias.

Os conceitos apresentam características particulares para que possam ser bem definidos, e a principal é a clareza, que pode ser definida como o embasamento necessário para que, dentre vários, se consiga reconhecer um fenômeno específico - o objeto de estudo - a partir de sua definição. Rudio (2004) apresenta a definição de conceitos como “dizer o que a coisa é, sob o ponto de vista da nossa compreensão".

Para que o conceito definido seja claro, obedecendo ao rigor metodológico exigido pela revisão sistemática da literatura, faz-se necessário definir todas as idéias do 
conceito, procurar não definí-lo utilizando-se idéias contrárias, evitar as ambigüidades, buscando a simplicidade e a clareza (Rudio, 2004).

O levantamento bibliográfico de busca dos artigos pertinentes à questão de estudo foi realizado no período de janeiro à março de 2007, nos bancos de dados Lilacs, BDEnf e MedLine, que compõe a Biblioteca Virtual em Saúde da Bireme www.bireme.br -, e Dedalus, que reúne o acervo da USP - www.ee.usp.br/ biblioteca/whorta/index.htm.

Não foi determinado um recorte de tempo de publicação na busca pelos artigos, uma vez que o levantamento bibliográfico preliminar, realizado para construir o embasamento teórico deste estudo, revelou uma escassez de publicações sobre o tema.

Os critérios de inclusão dos registros pesquisados foram: artigos publicados em periódicos, nacionais e internacionais e que tratam do tema trabalho em equipe como objeto de estudo.

Para a exclusão dos artigos, foram adotados os critérios de publicações como teses e dissertações, pela dificuldade de acesso mais restrito às respectivas Universidades em que foram defendidas, e pela recomendação atual de publicação destas em periódicos que viabilizem sua divulgação; publicações como resumos de trabalhos apresentados em congressos, também pela dificuldade de acesso.

Embora num primeiro momento tenha sido pensado em excluir registros conforme apresentado a seguir - que não apresentassem resumo no levantamento, esse critério foi abandonado, uma vez que se percebeu que o título de alguns registros, embora sem resumo, fazia clara referência ao trabalho em equipe como objeto de estudo.

Foram pesquisadas as palavras-chave: trabalho em equipe, trabalho em equipe + gestão, trabalho em equipe + relações interpessoais, trabalho em equipe + Programa de Saúde da Família, e os descritores: equipe de assistência ao paciente; e patient care team.

A dificuldade em se replicar um estudo bibliográfico está exatamente na ausência de regras claras que uniformizem os descritores e as palavras chaves dos diversos bancos de dados. Observam-se diferenças importantes entre os bancos de dados, no que diz respeito ao rol de periódicos incluídos, a metodologia de busca e 
principalmente na determinação dos descritores e palavras-chaves que deverão ser utilizados. Essas diferenças dificultam a busca e a replicação dos estudos bibliográficos.

Identificou-se um viés de seleção, acarretado pelo recorte da busca, conseqüente das limitações e dificuldades da utilização da metodologia de revisão sistemática a estudos qualitativos.

Embora a busca inicial tenha identificado uma grande quantidade de registros, observou-se que apenas uma minoria tomava o trabalho em equipe na saúde ou enfermagem como objeto de estudo, ou seja, como tema central de análise e discussão. No levantamento nos bancos de dados on line, observou-se que a palavra chave trabalho em equipe é utilizada pela maioria dos registros para descrever ou denominar a situação de trabalho na qual diversos profissionais dividem o mesmo espaço e as mesmas informações. Entretanto, percebe-se a ausência de rigor na definição e na utilização do termo equipe.

A primeira busca ativa nos bancos de dados, procurando localizar o maior número de publicações que centrassem o foco do estudo na questão do trabalho em equipe, foi realizada com a aplicação de refinamentos de busca. Foram utilizados os limites de idioma (português/ inglês), tendências, administração/ organização, recursos humanos e descritor de assunto. Esses limites foram utilizados para as palavras-chave trabalho em equipe, trabalho em equipe + gestão, trabalho em equipe + relações interpessoais e trabalho em equipe + Programa de Saúde da Família.

Como a busca do descritor equipe de assistência ao paciente e das palavraschave trabalho em equipe + relações interpessoais e trabalho em equipe + Programa de Saúde da Família, acrescidas dos refinamentos acima citados, não retornaram registros, optou-se por buscar as mesmas sem os limites impostos, na intenção de obter o máximo de cobertura da literatura publicada sobre o assunto. Assim, o descritor equipe de assistência ao paciente; e as palavras-chave trabalho em equipe + relações interpessoais e trabalho em equipe + Programa de Saúde da Família foram também pesquisados sem os limites impostos.

Já para o descritor patient care team não foi localizado nenhum registro, sendo então realizada a busca sem o limite de descritor, porém mantendo-se os mesmos limites apresentados acima, ou seja, limites de idioma (português/ inglês), tendências, administração/ organização, recursos humanos. 
Os registros encontrados na busca ativa de artigos através dos bancos de dados eletrônicos totalizaram 1837 publicações (tabela 1).

Tabela 1 - Distribuição dos artigos identificados segundo descritores/ palavras-chave e bancos de dados, São Paulo - 2007

\begin{tabular}{lccccc}
\hline \multicolumn{1}{c}{ Descritor de assunto/ Banco de Dados } & Lilacs & BDEnf & MedLine & Dedalus & Total \\
Trabalho em equipe & 13 & 3 & 0 & 112 & 128 \\
Trabalho em equipe + gestão & 39 & 16 & 0 & 10 & 65 \\
$\begin{array}{l}\text { Trabalho em equipe + relações interpessoais } \\
\text { (com limites) }\end{array}$ & 0 & 0 & 0 & 1 & 1 \\
$\begin{array}{l}\text { Trabalho em equipe + relações interpessoais } \\
\text { (sem limites) }\end{array}$ & 29 & 20 & 0 & 0 & 49 \\
Trabalho em equipe + PSF (com limites) & 0 & 0 & 0 & 6 & 6 \\
Trabalho em equipe + PSF (sem limites) & 62 & 9 & 0 & 0 & 71 \\
Patient care team (sem descritor e com limites) & 106 & 13 & 0 & 0 & 119 \\
Equipe de assistência ao paciente & 0 & 0 & $542(1996-2006)$ & 28 & 1398 \\
\hline Total & 249 & 61 & 1370 & 157 & 1837 \\
\hline
\end{tabular}

Os resumos dos 1837 registros localizados foram lidos, e a partir da leitura foram selecionados aqueles cujo título e/ou resumo colocavam o trabalho em equipe como o objeto de estudo, ou como uma de suas questões centrais de análise. Desta forma, os artigos selecionados se reduziram a um total de 391 publicações (tabela 2).

Tabela 2 - Distribuição dos artigos selecionados segundo descritores/ palavras-chave e bancos de dados, São Paulo - 2007

\begin{tabular}{lccccc}
\hline \multicolumn{1}{c}{ Descritor de assunto/ Banco de Dados } & Lilacs & BDEnf & MedLine & Dedalus & Total \\
\cline { 2 - 6 } $\begin{array}{l}\text { Trabalho em equipe } \\
\text { Trabalho em equipe + gestão }\end{array}$ & 39 & 16 & 0 & 112 & 128 \\
$\begin{array}{l}\text { Trabalho em equipe + relações interpessoais } \\
\text { (com limites) }\end{array}$ & 0 & 0 & 0 & 0 & 55 \\
$\begin{array}{l}\text { Trabalho em equipe + relações interpessoais } \\
\text { (sem limites) }\end{array}$ & 8 & 6 & 0 & 0 & 14
\end{tabular}




\begin{tabular}{lcccc|c} 
Trabalho em equipe + PSF (com limites) & 0 & 0 & 0 & 6 & 6 \\
Trabalho em equipe + PSF (sem limites) & 13 & 6 & 0 & 0 & 19 \\
Patient care team (sem descritor e com limites) & 27 & 4 & 0 & 0 & 31 \\
Equipe de assistência ao paciente & 0 & 0 & $49(1996-2006)$ & 28 & 137 \\
\hline Total & 100 & 35 & 109 & 147 & 391
\end{tabular}

Após a exclusão das repetições entre os diversos bancos de dados pesquisados, nos vários descritores/ palavras-chave, assim como os registros de teses, dissertações e capítulos de livros, finalizou-se com um total de 71 publicações, que deveriam ser obtidas para leitura integral e análise sistemática.

A etapa seguinte - obtenção dos artigos selecionados - foi realizada entre abril a junho de 2007, através da busca ativa dos artigos na biblioteca da Escola de Enfermagem da Universidade de São Paulo (EEUSP), e solicitada a busca daqueles artigos não localizados através do serviço de comutação bibliográfica da EEUSP.

Foram localizados 59 artigos, lidos entre abril e agosto de 2007. Os 12 artigos restantes não foram localizados na busca através do serviço de comutação bibliográfica, pois não foram encontrados exemplares disponíveis no Brasil. Assim sendo, foi solicitada a sua aquisição pela biblioteca mediante pagamento com recursos da pesquisa principal a qual o presente estudo está vinculado ${ }^{1}$. Foram localizados 11 artigos internacionais no período de 20 de dezembro de 2007 a 20 de janeiro de 2008, sendo os dois restantes não localizados na busca pela biblioteca, totalizando 70 artigos para análise.

Os artigos foram separados entre nacionais (40) e internacionais (31), sendo que 70 foram lidos, 30 internacionais e 40 nacionais; e também de acordo com o conteúdo que apresentam, se fazem referência ao trabalho em saúde de maneira geral (60) ou especificamente ao trabalho em enfermagem (10). É interessante observar que 18 artigos analisados se referem à saúde mental, todos na área da atenção à saúde, e nove se relacionam com o Programa de Saúde da Família, sendo oito na área da atenção à saúde e um na área da enfermagem.

\footnotetext{
${ }^{1} \mathrm{O}$ presente estudo está vinculado à pesquisa principal intitulada: “Análise das atividades educativas de trabalhadores e equipes de saúde e enfermagem: características, levantamento de necessidades e resultados esperados", que conta com auxílio da Fundação de Amparo à Pesquisa do Estado de São Paulo - FAPESP - e do Observatório de Recursos Humanos da Organização Pan-Americana de Saúde - OPAS / Ministério da Saúde.
} 
Os artigos foram analisados através da leitura reiterada, e sistemática, à luz das categorias de análise pré-determinadas, com base nas características do trabalho em equipe definidas por Peduzzi (1998; 2001), quais sejam: comunicação entre os profissionais; elaboração de um projeto assistencial comum; especificidade dos trabalhos especializados; flexibilização da divisão do trabalho e autonomia profissional de caráter interdependente.

Também foram analisados com base na concepção de integralidade da saúde, ou atenção integral à saúde, que representa a origem e a principal justificativa do trabalho em equipe de saúde, segundo os estudos de Peduzzi (2006), Pinheiro (2006) e Mattos (2004); assim como foram analisados com base no trabalho multidisciplinar, interdisciplinar e transdisciplinar, de acordo com Irribary (2003) e Almeida - Filho (1997).

Os artigos foram estudados sistematicamente, com base nas categorias acima referidas, de modo a extrair de cada um as concepções e respectivas características do trabalho em equipe. As concepções e características apreendidas foram, então discutidas à luz do referencial teórico que embasa este estudo, qual seja o processo de trabalho e o trabalho em equipe, incluindo a integralidade da atenção à saúde e a interdisciplinaridade.

\section{RESULTADOS}

Os resultados da revisão, com base na leitura sistemática dos artigos selecionados, são apresentados a seguir.

5.1 Identificação da produção sobre trabalho em equipe no campo da saúde e da enfermagem 


\subsubsection{Período de publicação}

Do total de 70 artigos analisados, observou-se que o período de publicação inicia-se na década de 1970, com um artigo publicado em 1975.

A década de 1980 contribui com cinco artigos, sendo dois artigos publicados em 1984, um artigo em 1987 e dois artigos em 1988.

Na década de 1990 tem-se a publicação de 24 artigos, distribuídos conforme se apresenta na tabela 3. Na área da enfermagem, observou-se três publicações, uma em 1990, desenvolvida nos Estados Unidos da América (EUA) e duas em 1995, uma desenvolvida nos Estados Unidos da América e outra em São Paulo.

Na década de 2000 observa-se o crescimento de estudo do trabalho em equipe, pois neste período foram identificados 40 artigos referentes ao tema (tabela 3). $\mathrm{O}$ ano mais expressivo foi 2005, com 14 publicações. Especificamente em relação às publicações que fazem referência ao trabalho em equipe na enfermagem, observou-se sete publicações, sendo uma publicação em 2002, duas em 2003, duas em 2004, uma em 2005 e uma em 2006.

Tabela 3 - Distribuição das publicações sobre trabalho em equipe em saúde e enfermagem segundo ano de publicação, São Paulo - 2007

\begin{tabular}{|c|c|c|c|c|c|c|c|c|c|c|c|c|c|c|c|}
\hline 1990 & 1991 & 1992 & 1993 & 1994 & 1995 & 1996 & 1997 & 1998 & 1999 & 2000 & 2001 & 2002 & 2003 & 2004 & 20052006 \\
\hline 1 & - & 1 & 4 & 3 & 5 & 2 & 2 & 4 & 2 & 3 & 3 & 3 & 5 & 6 & 14 \\
\hline
\end{tabular}

\subsubsection{Local de publicação}

De acordo com o local de publicação dos textos selecionados, observou-se que 40 artigos são resultado de estudos brasileiros, em sua maioria desenvolvidos em parceria com universidades.

O Estado que mais publicou sobre o trabalho em equipe como objeto central de análise foi São Paulo, com 25 publicações. Dezoito artigos foram desenvolvidos em parceria com a Universidade de São Paulo (10 artigos da Escola de Enfermagem, quatro 
artigos da Escola de Enfermagem de Ribeirão Preto, um artigo da USP Bauru, um artigo da Faculdade de Saúde Pública e dois artigos da Faculdade de Medicina de Ribeirão Preto); dois artigos da Universidade Estadual de Campinas; dois artigos da Universidade do Estado de São Paulo; um artigo da Universidade São Camilo; um artigo da Escola Paulista de Medicina (UNIFESP) e um artigo em parceria com a Secretaria Municipal de Saúde de Amparo (Tabela 4).

Segue-se a São Paulo o Estado do Rio de Janeiro, com quatro publicações, sendo uma pela Escola de Enfermagem Anna Nery, uma pelo Instituto de Assistência dos Servidores do Estado do Rio de Janeiro (IASERJ), uma pela Universidade Federal do Rio de Janeiro e uma desenvolvida a partir de uma parceria entre autores da Universidade Federal Fluminense e da Universidade Federal do Rio de Janeiro (Tabela $4)$.

A Universidade Federal de Goiás publicou um artigo e a Universidade Federal da Bahia publicou dois artigos. O Estado do Mato Grosso contribui com um artigo, sem especificar a instituição que o desenvolveu, o Estado de Minas Gerais publicou um artigo, desenvolvido pela Sociedade Mineira de Terapia Intensiva, e a Universidade Estadual de Maringá, no Paraná também publicou um artigo. O Estado do Rio Grande do Sul contribuiu com dois artigos, sendo um desenvolvido pela Universidade Federal do Rio Grande do Sul e um pela Universidade Livre Brasileira (ULBRA). Houve um artigo com a citação de desenvolvimento na Região Sul do Brasil, sem especificar o Estado nem a instituição que o desenvolveu e dois artigos sem menção do local ou instituição de desenvolvimento (Tabela 4).

Em relação à literatura internacional, foram localizadas 30 publicações, sendo 11 artigos desenvolvidos nos Estados Unidos da América, três artigos na Inglaterra e quatro artigos no Canadá. Os países França, Holanda, Austrália, Escócia e Suécia contribuíram com um artigo cada, e também identificou-se um artigo desenvolvido a partir de uma parceria entre Holanda e Canadá. Em seis artigos não houve citação do local de desenvolvimento do estudo (tabela 5).

Especificamente em relação aos artigos relacionados ao trabalho em equipe de enfermagem, tem-se cinco artigos publicados em São Paulo, um no Paraná, um em Goiás, um na Região Sul, sem especificação do Estado, e dois nos EUA, sendo um em Nova York e um em Minesota. 
Tabela 4 - Distribuição das publicações sobre trabalho em equipe em saúde e enfermagem publicadas no Brasil, segundo local de publicação, São Paulo 2007

\begin{tabular}{lcc}
\multicolumn{1}{c}{ Local } & N & \% \\
\hline São Paulo & 25 & 62,5 \\
Rio de Janeiro & 4 & 10 \\
Rio Grande do Sul & 2 & 5 \\
Bahia & 2 & 5 \\
Mato Grosso & 1 & 2,5 \\
Minas Gerais & 1 & 2,5 \\
Paraná & 1 & 2,5 \\
Região Sul & 1 & 2,5 \\
Goiás & 1 & 2,5 \\
Sem local & 2 & 5 \\
\hline Total & $\mathbf{4 0}$ & $\mathbf{1 0 0}$
\end{tabular}

Tabela 5 - Distribuição das publicações sobre trabalho em equipe em saúde e enfermagem, segundo país de publicação, São Paulo - 2007

\begin{tabular}{lcc}
\multicolumn{1}{c}{ País } & N & \% \\
\hline Brasil & 40 & 57 \\
EUA & 11 & 16 \\
Canadá & 4 & 5,7 \\
Inglaterra & 3 & 4,3 \\
França & 1 & 1,4 \\
Holanda & 1 & 1,4 \\
Austrália & 1 & 1,4 \\
Escócia & 1 & 1,4 \\
Suécia & 1 & 1,4 \\
Holanda / Canadá & 1 & 1,4 \\
Sem local & 6 & 8,6 \\
\hline Total & $\mathbf{7 0}$ & $\mathbf{1 0 0}$
\end{tabular}

\subsection{3 Área de concentração de pesquisa}


Dos 70 artigos analisados, apenas 10 se referiram à área específica do trabalho em equipe na enfermagem, sendo os demais (60) relacionados ao trabalho em equipe na área da saúde.

É interessante observar que 18 artigos analisados se referiram à saúde mental, todos na área da atenção à saúde, e nove se relacionaram com o Programa de Saúde da Família, sendo oito na área da atenção à saúde e um na área da enfermagem.

\subsubsection{Tipo de publicação}

De acordo com o tipo de publicação, os artigos lidos foram classificados como desenvolvimento de pesquisa empírica, qualitativa ou quantitativa, revisão bibliográfica, relato de experiência, reflexão crítica - quando apresentam explicitamente o referencial teórico no qual se apóiam - e ensaio - quando a reflexão, embora pertinente e importante à discussão do tema, não deixa explícito o referencial teórico adotado.

Dessa forma, as publicações se dividiram em: ensaio (22), relato de experiência (12), reflexão crítica (10), pesquisa empírica qualitativa (15), pesquisa empírica quantitativa (7) e revisão da literatura (4).

\subsection{Produção identificada segundo o referencial teórico-metodológico}

Observa-se que a grande maioria dos textos analisados - 49 (70\%) - não expõe diretamente o referencial teórico utilizado. Vinte e uma publicações apresentaram explicitamente o referencial teórico no qual se apóiam, sendo 10 artigos de pesquisa qualitativa, dois de pesquisa quantitativa e nove textos de reflexão crítica.

Os estudos sobre trabalho em equipe, desenvolvidos por Marina Peduzzi, e os estudos do processo de trabalho em saúde, de Ricardo Bruno Mendes-Gonçalvez e Emerson Elias Merhy foram os referenciais mais citados, em 4 artigos cada um. O referencial de modelo de gestão colegiada e co-gestão de Gastão Wagner Souza 
Campos, o Grupo Operativo de Pichon-Riveri, o Materialismo Histórico-Dialético e os estudos sobre interdisciplinaridade foram referidos por dois artigos cada.

Foram citados por apenas um artigo os seguintes referenciais teóricos: reabilitação psicossocial, conceito de disciplina e suas derivações, filosofia da gestão pela qualidade total, análise institucional, reforma psiquiátrica, agir comunicativo de Habermmas e teoria das representações sociais, composição das equipes de educação especial, controle social de Maria do Carmo Alves Albuquerque Carvalho e características da equipe de Antônio César Amaru.

\subsection{Resultados sobre as concepções e as características de trabalho em equipe}

A análise do material coletado buscou identificar as concepções sobre o tema, e as características do trabalho em equipe.

Como apresentado anteriormente, entende-se por concepção a maneira como o artigo define o trabalho em equipe e por características os elementos que podem ser distinguidos no conceito e permitem compreende-lo. Assim, as características referemse a um conjunto de elementos que qualificam o trabalho em equipe e são essenciais para o seu reconhecimento.

\subsubsection{Concepção de trabalho em equipe de saúde enfermagem}

Quanto às concepções expressas na literatura sobre trabalho em equipe de saúde e/ou enfermagem, os resultados mostraram que embora o termo equipe seja usado em um grande número de artigos para denominar uma situação na qual diferentes profissionais, da mesma área de atuação ou de áreas distintas, trabalham em um ambiente comum, com a possibilidade de acesso às mesmas informações, sem 
necessariamente compartilhar ou planejar algo comum, apenas quatro publicações fizeram essa distinção explicitamente (artigos 29, 34, 42, 64).

Embora seja uma característica do trabalho em equipe, a sinergia positiva também apareceu como concepção do trabalho em equipe, sendo esta compreendida como a situação na qual os resultados obtidos são maiores do que a soma dos resultados individuais, o que torna a produção mais eficiente e eficaz (artigos 1, 34, 46, 50, 63, 69).

"Equipe gera sinergia positiva através de um esforço coordenado" (artigo 1; Abreu et al., 2005 - p. 204).

"Equipes de saúde bem organizadas são uma entidade sinérgica, seus efeitos são maiores que a soma das contribuições individuais dos membros da equipe" (artigo 46; Petersson, 2005 - p. 160).

Algumas publicações apresentaram uma concepção de equipe no sentido de um esforço coordenado e de cooperação entre os membros, e da responsabilidade coletiva acerca das decisões e atividades da equipe (artigos 1, 6, 10, 15, 16, 35, 41, 51, 56).

"Uma equipe pode ser definida como um grupo de duas ou mais pessoas que reconhecem objetivos comuns e coordenam seus esforços para atingí-los" (artigo 6; Brown, 1995 - p. 5).

"Um grupo de profissionais só configura uma equipe, quando opera de modo cooperativo, convergindo seus objetivos para uma dada situação, de forma a haver complementaridade e não soma ou superposição" (artigo 10; Campos, 1992 - p. 255).

Outras publicações apontaram que a equipe compartilha o planejamento, os propósitos do trabalho, os objetivos, as normas e as propostas que são comuns à equipe (artigos 6, 15, 31, 42, 45, 67, 69).

"O foco do trabalho em equipe é baseado no esforço coletivo na busca de objetivos e metas comuns" (artigo 1; Abreu et al., 2005 - p. 204).

O trabalho em equipe também foi definido como a interação entre os agentes, compreendida como a relação entre os profissionais, de maneira a facilitar o processo de 
trabalho, melhorando a qualidade tanto da assistência prestada quanto das condições de trabalho dos profissionais (artigos 13, 15, 37, 45, 66).

"O trabalho em equipe consiste numa modalidade de trabalho coletivo, que se configura na relação recíproca entre as intervenções técnicas e a interação dos agentes" (artigo 54; Peduzzi, 2001 - p. 103).

"É justamente a relação recíproca entre estas duas dimensões complementares - trabalho e interação - que caracteriza o que denominamos de trabalho em equipe" (artigo 13; Peduzzi, Ciampone, 2000 - p. 144).

Dentre os artigos nos quais se destacou a dimensão interativa ou comunicativa do trabalho em equipe, também se observou que em alguns o trabalho em equipe foi concebido como um processo grupal, uma vez que se compõe de um conjunto de sujeitos interagindo na busca de metas comuns, através de relações interpessoais (artigos 20, 37).

"Equipe de saúde como uma rede de relações entre pessoas, rede de relações de poderes, saberes, afetos, interesses e desejos, onde é possível identificar processos grupais. Trabalhar em equipe equivale a se relacionar" (artigo 20; Fortuna et al., 2005 - p. 264).

"Consideramos o trabalho em equipe em saúde como uma rede de relações (de trabalho, de poder, de afeto, de gênero, etc) entre pessoas, produzidas permanentemente no dia-a-dia, com múltiplas possibilidades de significados, de encontros e desencontros, satisfações e frustrações, lágrimas e sorrisos" (artigo 37; Matumoto et al., 2005 - p. 14).

Também foi concebido como um trabalho interdisciplinar e transdisciplinar (artigos 20, 21, 44), no qual se observa o compartilhamento e a integração entre as diferentes disciplinas.

"O conceito de equipe multiprofissional atuando em modelo interdisciplinar é bastante interessante ao sugerir a possibilidade de interpenetração do conhecimento para suprir as necessidades do paciente" (artigo 5; Bourgneth, 2004 - p. 57). 
“Uma equipe será transdisciplinar quando sua reunião congregar diversas especialidades com a finalidade de uma cooperação entre elas sem que uma coordenação se estabeleça a partir de um lugar fixo. É claro que isso gera, de saída, um problema. Como evitar a verticalidade de uma coordenação? Isto é, como evitar que uma especialidade se torne uma espécie de juiz no processo de tomada de decisão? Ora, a transdisciplinaridade deve ser encarada como meta a ser alcançada e nunca como algo pronto, como um modelo aplicável e como um desafio que serve de parâmetro para que todos os membros da equipe estejam atentos para eventuais cristalizações e centralização do poder” (artigo 25; Irribary, 2003 - p. 488).

\subsubsection{Características do trabalho em equipe de saúde e enfermagem}

O trabalho em equipe foi considerado força de coesão por dois artigos $(3,69)$, e força inoperante por um artigo (3).

Foram consideradas características fundamentais ao trabalho da equipe o reconhecimento e a valorização, de um lado, de cada membro por parte do grupo e, de outro, de cada membro em relação ao grupo; motivação; respeito; criatividade; suporte/apoio; responsabilidade, compromisso e cooperação; coordenação de esforços (artigos 26, 31, 35, 69).

Além desses, foi apontada a importância em manter o foco do trabalho na produção de resultados (artigo 13).

A integração da equipe expressa na articulação das ações e na interação dos agentes, foi reconhecida como elemento essencial à caracterização do trabalho em equipe (artigos $11,13,15,35,39,48,50,55,58$ ).

Se fosse possível isolar apenas uma característica que pudesse ser considerada unanimidade entre os artigos analisados, esta certamente seria a comunicação. A maioria (36 publicações: 1, 2, 10, 13, 14, 15, 16, 18, 20, 25, 27, 29, 31, 32, 34, 35, 38, $39,40,41,44,45,50,53,54,55,56,57,59,31,62,34,65,67,69,70)$ dos artigos analisados citou a dimensão comunicativa como a chave que permite o trabalho em equipe, porém com diferentes concepções de comunicação. 
Esta foi, por um lado, compreendida como atitude comunicativa, de construção de espaço para troca e crescimento, busca por soluções eficientes e viáveis de maneira transparente e igualitária (artigos 1, 10, 13, 15, 25, 31, 35, 45, 54, 57, 59, 65, 69), e de outro lado, como espaço para troca de informação e de cristalização de antigas idéias e modelos (artigos 14, 20, 27, 29, 32, 34, 39, 39, 40, 41, 44, 50, 53, 55, 56, 61, 62, 64, 70). Quatro publicações citaram a comunicação como característica do trabalho em equipe, sem a preocupação de explicar de que maneira faz parte dele (artigos 2, 16, 18, 67). Duas publicações fizeram uma discussão mais aprofundada do processo de comunicação concebido como prática comunicativa na dinâmica do processo de trabalho em equipe (artigos 45, 59).

A comunicação para o trabalho em equipe foi condição essencial ao seu desenvolvimento e funcionamento. É através da comunicação que a equipe é capaz de buscar a eficiência e a eficácia (artigos 31, 56). Diz-se que a comunicação é "o denominador comum ao trabalho em equipe" (artigos 13, 45, 57).

A comunicação no contexto do trabalho em equipe pode ser entendida como um processo intrínseco ao trabalho, desenvolvido continuamente em seu contexto, nesse sentido, "será um agir comunicativo aquele em que o fim é definido e alcançado por um processo participativo e de intervenção" (artigo 45; Peduzzi, 2001 - p. 107). Apesar disso, é importante destacar que em alguns contextos de trabalhos ditos de equipe, a comunicação ocorre externamente ao trabalho, ou ainda de maneira estritamente pessoal (artigo 45).

A comunicação é considerada fundamental para o alcance da interação entre os membros da equipe e permite que os conhecimentos e idéias sejam expostos e discutidos entre todos, procurando formular as melhores hipóteses e condutas pertinentes a cada caso particular (artigos 1, 10, 15, 35, 44, 45, 69); "quando as mentes interagem, novas idéias surgem" (artigo 69; Wiecha, Pollard, 2004 - p. 3).

Uma comunicação ineficaz e permeada por ruídos - medo, insegurança, informações falsas, ausência de informação, relações de poder desigual - é paralisante e predispõe os membros da equipe ao erro (artigos 20, 59, 62, 65, 67).

Algumas publicações (artigos 1, 4, 5, 8, 10, 11, 12, 20, 26, 27, 31, 43, 53, 59, 62) analisadas referiram a importância das reuniões para o trabalho em equipe. Contudo, estudos apontaram um conflito entre reunião de equipe e comunicação, pois a existência de reuniões regulares entre os membros da equipe seria a garantia de que a dimensão 
comunicativa do trabalho em equipe está sendo positivamente atingida (artigos 1, 5, 8, $11,12,26,27,62)$, ainda que nos demais momentos do processo de trabalho não existam atitudes ou espaços que permitam o fluxo efetivo das informações, assim como as trocas entre os agentes e o crescimento profissional da equipe. O conflito reside na interpretação que as reuniões de equipe seriam, por excelência, espaço de comunicação entre os profissionais, o que justificaria a ausência de prática comunicativa nos demais espaços e momentos do processo de trabalho em saúde.

A possibilidade das equipes de reconstruir saberes fragmentados pela especialização foi apontada como característica do trabalho em equipe, trazendo consigo a questão do reconhecimento de diferenças técnicas, respeito a autonomia técnica das profissões, conjugada com a flexibilização do trabalho, na direção de se construir um projeto assistencial comum, de acordo com a necessidade de se atender a integralidade da atenção à saúde, ou seja, os autores apontaram que o planejamento deve ser baseado nas necessidades de saúde dos usuários (artigos 11, 15, 31, 37, 45).

Os artigos que trabalham a saúde mental apresentaram a participação do usuário do serviço como membro da equipe, como alternativa à organização tradicional do trabalho em saúde na direção do cuidado do sujeito e não da doença, ou seja, da atenção integral à saúde (artigos 39, 43, 56). Um artigo que analisa a atenção à saúde também assinalou que para se alcançar a integralidade é necessário que o usuário do serviço seja participante do processo, e não apenas espectador deste (artigo 15).

A comunicação pode apresentar resultados positivos na qualidade da atenção integral, por permitir a interação e articulação através da discussão de idéias e condutas diversas trazidas pelo recorte específico de cada profissional envolvido, de acordo com as necessidades singulares observadas (artigos 13, 16, 45, 56, 59).

Os artigos analisados referiram que as equipes contribuem para a integralidade da atenção à saúde na medida em que são capazes de recompor os trabalhos especializados, reconstituir a unidade do saber perdido com a ultra-especialização, integrar as diferentes habilidades, abordando com olhares específicos e complementares as necessidade de saúde e de saúde mental (artigos 1, 10, 18, 20, 31, 37, 40, 44, 69). "Na busca pela integralidade da assistência, a atuação de um único profissional não é suficiente" (artigo 40; Mishima et al., 2000 - p. 69).

A equipe multidisciplinar foi referida em relação à necessidade da atenção integral, uma vez que não há um saber único que possa fundamentar as respostas às 
múltiplas dimensões das necessidades de saúde. Porém, duas publicações apontaram que a equipe multidisciplinar não garante a atenção integral, sendo apenas uma ferramenta para que esta se desenvolva (artigos 22, 44).

Dessa forma, o trabalho em equipe não resolveria o problema da atenção integral, mas agindo de maneira a reconstituir os saberes parcelares criados pela especialização do conhecimento, contribuiria para um olhar global sobre as necessidades dos sujeitos (artigo 2).

A integralidade na atenção à saúde estaria diretamente relacionada com o grau de integração da equipe, e esta será maior ou menor na medida em que sejam também maiores ou menores as interações dos agentes e a articulação das ações desenvolvidas na busca por um projeto assistencial comum, no qual todos são agentes e responsáveis pelas decisões e resultados (artigos 55, 59).

Os artigos analisados apresentaram pouca diferenciação entre os termos multidisciplinar, interdisciplinar e transdisciplinar, porém, apenas três explicitaram que usaram os termos como sinônimos (artigos 2, 10, 55).

A multidisciplinaridade foi concebida como as relações nas quais os profissionais se aproximam para compartilhar informações e conhecimentos que os auxilie, independentemente dos demais, a buscar soluções para as necessidades observadas; comumente coordenadas de maneira tradicional, através de relações verticalizadas, com o objetivo de otimizarem recursos (artigos 42, 43, 67). Embora as publicações que fazem referência à equipe multidisciplinar apontem para a cooperação e o compartilhamento entre os profissionais, não apresentaram contribuições no sentido do questionamento das fronteiras entre as disciplinas e não apontaram para o trabalho de forma interdependente, o que diferencia a multidisciplinaridade da interdisciplinaridade (artigos 39, 42, 67). A equipe multidisciplinar foi apontada como o princípio diretivo de um dos modelos de atenção em saúde apresentado num dos artigos analisados, porém sem especificar suas características ou concepções (artigo 22).

A questão da interdisciplinaridade se mostrou intimamente ligada ao trabalho em equipe, e pôde ser caracterizada, segundo os resultados deste estudo, de diferentes maneiras: através da intensidade das trocas entre os profissionais e da relação entre as disciplinas, resultando em crescimento, transformação bilateral, colaboração e partilhar de informações e decisões, interação entre os profissionais e horizontalização das relações de poder (artigos 1, 39); através de uma "atitude interdisciplinar" que 
corresponderia a reconhecer as especificidades de uma disciplina ou área do conhecimento e as demais áreas, o que leva ao reconhecimento das limitações de intervenção e as diferentes maneiras de se abordar a mesma questão. E ainda, compromisso e responsabilidade com as soluções, decisões e resultados alcançados por todos (artigos 39, 44, 61). Apenas dois artigos referiram a necessidades de se incluir o usuário do serviço na composição da equipe interdisciplinar (artigos 60, 69).

Publicações assinalam dificuldades para a interdisciplinaridade, tais como: a hierarquia e as relações desiguais entre as diferentes disciplinas ou áreas do conhecimento com a hegemonia do saber biomédico na área da saúde (artigos 47, 61); a ausência de interação entre os membros da equipe e conseqüentemente um voltar-se para a área específica, não permitindo que as fronteiras entre as disciplinas sejam flexibilizadas.

Por fim, a questão da transdisciplinaridade foi apontada como um objetivo audacioso para o trabalho em equipe, visto que foi caracterizada como a articulação de distintas disciplinas e responsabilidades (artigo 9), "trabalhar através da fronteiras disciplinares tradicionais, na direção da 'liberdade de papéis', tomar todas as decisões com consenso da equipe" (artigo 31; Lopes, 1993 - p. 106).

Como referido acima, a autonomia profissional também foi apresentada como característica do trabalho em equipe (Campos, 1999; Peduzzi, 2001).

O artigo de Campos (1999) apresentou uma instituição na qual a assistência é organizada a partir de equipes de referência para um determinado número de usuários com apoio matricial, isto é, áreas específicas que dão suporte às equipes de referência. Esta publicação aponta para a necessidade de valorizar a autonomia dos profissionais da equipe de referência, que é a responsável pelo usuário e tem a possibilidade de acionar as equipes de suporte e apoio matricial quando julgar que sua especificidade técnica atende às demandas sentidas, e que superam a competência da equipe de referência (artigo 9).

O artigo de Peduzzi (2001) apresentou, com base em pesquisa empírica, três diferentes concepções de autonomia profissional: autonomia plena, na qual o profissional entende usufruir de total independência na execução das intervenções, ou seja, julga e decide sozinho de acordo com a sua competência técnica; a concepção de autonomia com interdependência, no qual o profissional toma em consideração o julgamento e as decisões dos demais integrante das equipes na sua própria avaliação e 
decisão; e a alienação da autonomia profissional, na qual o profissional mostra um estranhamento em relação a sua esfera de autonomia no trabalho. A chamada autonomia plena foi apresentada no material analisado como o planejamento ou a atuação individual, que independe da equipe (artigo 45).

A hegemonia médica foi observada como dificultadora do trabalho em equipe e conseqüentemente da integração das ações, saberes e profissionais, interferindo na autonomia (artigo 2).

Diferentemente da administração tradicional, as mudanças organizacionais que promovem a integração, com a horizontalização das relações e o compartilhamento das decisões, interfere positivamente no aumento da autonomia profissional (artigos 25, 49, 66).

A flexibilização da divisão do trabalho também apareceu como característica do trabalho em equipe, porém com divergência de opiniões sobre este aspecto (artigos 20, 40, 45, 59, 61, 62). Uma publicação apontou para a necessária divisão formal do trabalho, uma vez que cada profissional tem conhecimentos específicos e deve atuar em sua esfera de saber (artigo 20). Outros defenderam a idéia de que a divisão formal é negativa, pois dificulta a integração dos agentes e a busca pela integralidade, culminando na alienação do profissional acerca de sua atividade numa esfera global (artigos 40, 59).

$\mathrm{Na}$ direção da defesa da flexibilidade no trabalho em equipe, uma publicação apontou que a flexibilização pode conviver com as especificidades, na medida em que apenas as fronteiras de cada área são borradas, na qual coexistem as ações privativas e as ações de execução indistinta. Porém, para que haja flexibilidade é preciso que haja, antes de tudo, integração entre os profissionais (artigo 45).

Em publicação que analisou o trabalho em equipe de enfermagem, observou-se uma citação que defende a divisão do trabalho como algo importante, sem, no entanto, abrir mão da flexibilidade (artigo 62).

A elaboração de um projeto assistencial comum foi compreendida como elemento básico para o trabalho em equipe na saúde, sendo caracterizada pelo foco nas necessidades singulares de cada usuário, de acordo com a disponibilidade de recursos e tempo, através de um processo comunicativo e de interação dos profissionais (artigos 9, 13, 44, 59). Somente torna-se possível através das discussões em equipe, e a partir do conhecimento, pelos membros da equipe, dos contratos firmados entre eles acerca de 
sua cultura particular (artigos 26, 37, 39, 44, 59). A elaboração do projeto assistencial comum é dificultada pela sobrecarga de trabalho (artigo 59), e pode ser facilitada pela flexibilização da divisão do trabalho e pelo partilhar da tomada de decisão (artigo 59). 


\section{Discussão}

6.1 Dificuldades de busca e fragilidade teórico-conceitual e metodológica das publicações sobre trabalho em equipe de saúde e enfermagem

Identificaram-se dificuldades na realização da busca bibliográfica de publicações cujo foco central é a problematização do trabalho em equipe na saúde e na enfermagem. Embora um elevado número de citações tenha retornado da busca inicial através dos descritores e das palavras-chave utilizadas, a literatura que aborda o trabalho em equipe como discussão central foi escassa, corroborando os estudos de Schofield e Amodeo (1999).

A maior dificuldade observada na busca foi a utilização imprecisa do termo trabalho em equipe nas publicações em saúde e enfermagem, que é apresentado nas publicações sem rigor conceitual ou definição. Também apareceram sem definição precisa ou distinção as diferentes denominações - multiprofissional, interprofissional, multidisciplinar, interdisciplinar, transdisciplinar (Ciampone, Peduzzi, 2000; Peduzzi, 2001; 2007b; Miller, Freeman, Ross, 2001; Abreu et al., 2005; Silva Peduzzi, 2005).

A definição clara e consistente de termos utilizados em estudos científicos é considerada pré-requisito para sua avaliação rigorosa (Schofield, Amodeo, 1999). A utilização dos termos grupo e equipe como sinônimos faz com que ambos tornem-se vagos na conceituação de qualquer estudo (McCalling, 2001; Peduzzi, 2007b).

Além da fragilidade conceitual, a revisão da literatura permitiu perceber a falta de rigor metodológico na condução dos estudos acerca do tema (Wiecha, Pollard, 2004). Observaram-se objetos de estudo e desenhos de pesquisa - campo de estudo, população, procedimentos de coleta de dados e de análise do material empírico - marcantemente diferentes, o que impede a comparação entre os estudos e a formulação de uma discussão teórica profundamente embasada em dados empíricos.

Houve, também, uma completa falta de propostas de avaliação sistemática do tema, nas publicações analisadas. Nenhuma delas propôs a avaliação do trabalho em equipe. A ausência de processos de avaliação formal do trabalho em equipe pode, em 
parte, ser compreendida pela dificuldade de avaliar suas complexas características, em especial a dimensão subjetiva e intersubjetiva presente na comunicação e interação dos sujeitos que compõem a equipe. Ou seja, reside na falta de modelos e propostas que tornem possível a avaliação da forte dimensão subjetiva sob a qual está apoiado o trabalho em equipe (Peduzzi, 2007b). Retoma-se, aqui, a fragilidade conceitual e teórico-metodológica das publicações acerca do tema, com a ausência de termos definidos que embasem e permitam desenvolver um processo de avaliação consistente do trabalho em equipe.

A ausência de avaliação merece destaque uma vez que todo trabalho, inclusive o trabalho em equipe, deve ser continuamente avaliado, de maneira que seja possível melhorá-lo constantemente.

A ausência de rigor metodológico, assim como a fragilidade conceitual impedem avanços no conhecimento e a melhoria do trabalho em equipe na prática.

Para além das dificuldades conceituais, a busca sistemática pelos bancos de dados on line apresentou importantes obstáculos, quais sejam as grandes diferenças entre os bancos de dados, no que se refere ao tipo de periódico que os compõem e os mecanismos de busca. A seleção de descritores e palavras-chave constituiu-se um dos maiores entraves, embora haja consenso entre as bibliotecas em relação aos descritores disponíveis, nem sempre os autores se utilizam deles, lançando mão do uso das palavras-chave para qualificar a publicação. O problema reside, então, no fato de que as palavras-chave são imprecisas e dependem puramente da escolha do autor, sendo este o responsável pela escolha da palavra que melhor represente seu trabalho (Silva, Peduzzi, 2005).

6.2 Aumento das publicações sobre o tema nas décadas de 1990 e 2000

Chamou a atenção o fato de haver uma tendência ascendente no número de publicações sobre trabalho em equipe na saúde e também na enfermagem, a partir da década de 1990 e, sobretudo na década de 2000 (Miller, Freeman, Ross, 2001; Silva, 
Peduzzi, 2005). Tal fato levou à reflexão sobre as mudanças ocorridas nesse período, tanto no exterior quanto no Brasil.

Por um lado, o trabalho em equipe começa a ser valorizado, no exterior, por se apresentar como alternativa promissora à melhoria da relação custo-benefício na atenção à saúde, racionalizando os recursos necessários e diminuindo os custos da assistência, com a mudança das políticas de saúde e respectivos modelos de atenção à saúde (Miller, Freeman, Ross, 2001). Os autores propõem equipes de atendimento às emergências e ao paciente crítico, assim como nas unidades fechadas, como centros operatórios e unidades intensivas (artigos internacionais 24, 26, 48, 54, 55, 56, 60, 64, 69, e nacional 45).

Por outro lado, no Brasil, essa valorização do trabalho em equipe é alavancada em grande parte pelos esforços em se implantar o Sistema Único de Saúde - SUS - e em particular o Programa de Saúde da Família - PSF -, no qual o trabalho em equipe é visto como ferramenta básica da atenção primária à saúde (Ciampone, Peduzzi, 2000; Abreu et al., 2005; Rosa, Labate, 2005).

De acordo com a Lei Federal $n^{\circ}$ 8.080, de 1990, que trata da implantação do SUS, são princípios norteadores do novo modelo de atenção universalidade, ou a garantia de atenção à saúde a todo cidadão; eqüidade, qual seja a garantia da assistência à saúde de acordo com a complexidade de cada caso, e integralidade, que procura compreender o usuário do serviço de saúde como "um ser integral, bio-psico-social que deverá ser entendido com esta visão integral por um sistema de saúde também integral, voltado a promover, proteger e recuperar a saúde" (Brasil, 1990, p. 10).

Para garantir que esses princípios diretivos sejam atingidos, o processo de implementação da política pública do SUS propõe a ferramenta do trabalho em equipe como forma de alcançar, em especial, a atenção integral em saúde.

Assim, observa-se que é após a implantação do SUS, e principalmente do PSF, que a discussão em torno do trabalho em equipe ganha força, no país, colocando a equipe na lista dos temas que devem ser aprofundados na atenção à saúde (Abreu et al., 2005).

As mudanças de paradigma impostas pela reforma psiquiátrica também são responsáveis pela ampliação da discussão do trabalho em equipe, uma vez que a área da saúde mental percebeu precocemente que o trabalho em equipe é estratégia vantajosa na busca por uma compreensão integral do usuário, de maneira a atender suas complexas 
necessidades de saúde, impossíveis de serem respondidas por apenas um profissional ou área do conhecimento (Bichaff, 2006).

6. 3 Diferentes locais de publicação, com diferentes abordagens para o tema

Embora o número de publicação nacionais e internacionais tenha sido próximo 40 artigos brasileiros e 30 artigos internacionais - chama a atenção o volume de publicações nacionais desenvolvidas no eixo São Paulo - Rio de Janeiro, 29 artigos nacionais (72\%). No exterior, se destacam EUA, 11 artigos (16\%).

Como referido anteriormente, as publicações internacionais destacaram a discussão do tema trabalho em equipe a partir da perspectiva do custo-efetividade da assistência e da redução dos custos (Jackson et al., 1993; Porter, 1988; Schull et al., 2001; Schweikhart, Smith-Daniels, 1996; Sherman, 1990; Slande-Dew et al., 1993; Wiecha, Pollard, 2004).

As publicações nacionais pautaram-se na necessidade de mudanças de paradigma da atenção à saúde na perspectiva da atenção integral. Esta mudança leva ao debate em torno da necessidade de um modelo assistencial, em especial de um modelo de atenção básica, que atenda ao princípio da integralidade, sendo o trabalho em equipe característica nuclear da atenção básica (Mattos, 2004; Rosa, Labate; 2005).

Os artigos nacionais também se pautaram na mudança do paradigma da atenção à saúde mental, fortalecida pela reforma psiquiátrica, a partir da década de 1970 (Matumoto et al., 2005), com a necessidade do trabalho em equipe para responder às suas complexas demandas, obrigando-se a encontrar alternativas para organizar sua prática.

Embora a integralidade e o custo-efetividade sejam perspectivas diferentes que culminaram na necessidade de se discutir o trabalho em equipe, entende-se que essas abordagens são complementares e devem ser observadas em conjunto na busca pela compreensão do trabalho em equipe na saúde e na enfermagem. A complementaridade dessas abordagens será retomada adiante. 
6.4 Discussão do trabalho em equipe de enfermagem

Embora apenas 10 publicações refiram-se ao trabalho em equipe na enfermagem, o que representa $14 \%$ do total de publicações analisadas, 21 publicações têm autorias de profissionais enfermeiros (10 artigos da Escola de Enfermagem da USP, quatro artigos da Escola de Enfermagem da USP de Ribeirão Preto, um artigo da Faculdade São Camilo, um artigo da Universidade Estadual de Maringá, um artigo da Universidade Federal de Goiás, um artigo da Escola Ana Nery da Universidade Federal do Rio de Janeiro, um artigo da Universidade Federal do Rio Grande do Sul e enfermeiras da Região Sul e dois artigos de enfermeiras americanas, um de Nova York e um de Minesota). Dentre essas 21 publicações desenvolvidas por enfermeiros, 11 abordaram a equipe multiprofissional e interdisciplinar, e 10 publicações trataram da equipe de enfermagem.

Isso mostra o interesse dos profissionais e docentes de enfermagem em discutir o trabalho em equipe multiprofissional, no qual a área está inserida (Abreu et al., 2005).

Contudo, chamou a atenção o número reduzido dessas publicações, pois desde a institucionalização ou profissionalização da enfermagem, em meados do século XIX, o trabalho da enfermagem é desenvolvido coletivamente, de modo a assegurar a continuidade do tratamento e do cuidado hospitalar; portanto, os profissionais da área poderiam ter desenvolvido um saber sobre o que, desde os anos 1960, denomina-se como trabalho em equipe de saúde (Munari, 1997; Peduzzi, 2006; 2007b).

De acordo com os resultados desta revisão, foi possível observar que os profissionais enfermeiros tratam a realidade do trabalho em equipe na enfermagem como uma situação dada, estabelecida, que não apresenta a necessidade de ser discutida, uma vez que está consolidada no trabalho de enfermagem (Peduzzi, Ciampone, 2005).

Outro aspecto que pode estar relacionado à escassez de publicação sobre o trabalho em equipe de enfermagem, refere-se à precocidade com que a enfermagem começou a discussão do trabalho em equipe, na década de 1950, nos EUA, no período da Guerra Fria, como alternativa para o gerenciamento dos cuidados hospitalares, frente à escassez de mão-de-obra de enfermagem. (Almeida, Rocha, 1986; Peduzzi, Ciampone, 2005). Porém, de modo contraditório, a proposta do trabalho em equipe de enfermagem, ao invés de aprofundar o estudo e a prática de integração dos componentes 
da equipe, deu lugar à intensificação do estudo sobre a liderança em enfermagem, exercida pelo enfermeiro em relação aos demais trabalhadores de enfermagem com menor qualificação profissional.

Na década de 1970, com a crise econômica percebida mundialmente, cresceu a necessidade de uma atenção hospitalar curativa de baixo custo, que atendesse à demanda de suprir a mão de obra do processo produtivo (Rozendo, 1995; Peduzzi, Ciampone, 2005). No âmbito dos hospitais, observou-se a necessidade de manipulação das lideranças para se obter e manter a cooperação entre os trabalhadores, atendendo a racionalização do custo-benefício da assistência e possibilitando o retorno da mão-deobra, agora restabelecida, ao mercado de trabalho. Ao atenuar conflitos e garantir a ordem estabelecida, as lideranças passam a desenvolver o que Rozendo (1995) denominou "mito da liderança" na enfermagem.

A questão da liderança é abordada por Rozendo (1995) como tema carente de discussão teórica crítica na enfermagem, visto que é compreendida como fenômeno mítico, com o objetivo de controlar os agentes e manter as relações de poder do enfermeiro sobre os demais componentes do que é denominado "equipe de enfermagem”. A ausência de análise crítica da prática de enfermagem coloca a liderança do enfermeiro como fenômeno inquestionável.

Desta forma entende-se que a enfermagem abraçou as questões relacionadas à liderança da equipe de enfermagem, dando como pressuposto a configuração de equipes de trabalho, sem atentar para a necessidade de promover e dar sustentação à integração dos membros da equipe, o que não ocorre automaticamente em decorrência de uma situação comum de trabalho, na qual os profissionais de enfermagem dividem entre si as ações de cuidado a uma mesma clientela em um mesmo local e turno de trabalho, mas sim com base em intervenções que visam articulação e integração das ações e agentes (Rozendo, 1995; Peduzzi, 2001; Peduzzi, Ciampone, 2005).

Também se pode compreender a escassez de produção científica sobre o trabalho em equipe na enfermagem como a expressão da busca prioritária, por um lado, do reconhecimento profissional do enfermeiro e, de outro, da definição da atuação dos diferentes agentes que compõe a enfermagem no contexto da atenção à saúde. Ambas as buscas estão relacionadas à heterogeneidade da prática de enfermagem, na qual convivem categorias profissionais diferentes, porém executando trabalhos equivalentes - em especial os auxiliares e técnicos de enfermagem -, de modo que os usuários e a 
população não reconhecem as distinções entre os trabalhadores de enfermagem (Peduzzi, 2001).

A busca pelo reconhecimento da atuação do enfermeiro, por sua vez, está expressa, sobretudo nas estratégias corporativas de fazer reconhecer e legitimar as atividades privativas do profissional, previstas na Lei do Exercício Profissional de Enfermagem (COREN-SP, 2007), assim como o saber específico de enfermagem que fundamenta as ações privativas. Entende-se que a prioridade atribuída ao processo de busca de reconhecimento profissional e de diferenciação dos agentes de enfermagem, obscurece o debate, os estudos e as publicações acerca do trabalho em equipe de enfermagem, que passam para um segundo plano ou mesmo são tratados como se estivessem consolidados no processo de trabalho em enfermagem.

Entende-se que a prioridade atribuída a busca do reconhecimento profissional da enfermagem, em detrimento de outros aspectos da prática tais como as contradições inerentes a sua heterogeneidade, está relacionada a escassez da produção teórica sobre trabalho em equipe na enfermagem e esta, por sua vez, também se expressa na fragilidade do debate sobre a integralidade no cuidado de enfermagem. Nesse sentido, Antunes (1991) refere que: "formado para assistir e domesticado para controlar, o enfermeiro também perde o rumo da integralidade da assistência ao usuário".

Entretanto, na enfermagem, o trabalho em equipe foi difundo como um instrumento básico de trabalho. Isto porque a área da enfermagem, como referido anteriormente é, desde sua profissionalização, organizada de acordo com a divisão do trabalho manual e intelectual, com a composição de diversos trabalhadores de enfermagem atuando juntos, sob a supervisão do profissional enfermeiro, o que viria a ser denominado como trabalho em equipe a partir dos anos 1950 (Almeida, Rocha, 1986; Matheus, 1995; Peduzzi, Ciampone, 2005).

$\mathrm{Na}$ atualidade, no Brasil, a enfermagem se compõe dos enfermeiros profissionais com graduação de nível superior, cuja atribuição predominante está na esfera gerencial e dimensão intelectual do trabalho de enfermagem -, e dos auxiliares e técnicos de enfermagem - com educação profisssional de nível médio que atuam predominante na assistência e no cuidado direto aos usuários, mais intensamente reconhecida como atinente à dimensão manual e operacional do trabalho de enfermagem. 
O trabalho coletivo na enfermagem, realizado de forma individualizada por cada profissional e hierarquizada, com subordinação dos auxiliares e técnicos ao profissional enfermeiro e, portanto com intensa separação entre a concepção e a execução do trabalho, é denominado constante e inadvertidamente como trabalho em equipe, ainda que não se configure como tal, uma vez que a estratégia de trabalho em equipe procura horizontalizar as relações de poder, promovendo a interdependência na articulação das ações e a interação dos profissionais.

Embora concebido como instrumento básico para sua prática, a discussão do trabalho em equipe na enfermagem desde a sua proposição, na década de 1950, até a atualidade, não foi aprofundada.

\subsection{Tipo de publicação}

As publicações foram classificadas como ensaios - discussões que não apresentam quadro teórico explícito -, relatos de experiência, revisão de literatura, pesquisa empírica, qualitativa ou quantitativa, e reflexão crítica, essa última quando a publicação apresentou explicitamente o referencial teórico sobre a qual estava apoiada.

A maioria das publicações, ou seja, 38 registros (54\%), foram ensaios, relatos de experiência e revisão de literatura, de modo que predominam as publicações sem nenhum rigor em relação à delimitação e apresentação do quadro teórico e dos conceitos adotados. As pesquisas empíricas totalizaram $22(31,4 \%)$ publicações, restando apenas $10(14,3 \%)$ publicações classificadas como reflexões críticas teoricamente fundamentadas.

Como apontado anteriormente, a ausência de explicitação do quadro teóricoconceitual, ou mesmo de definição de termos, que é fundamental para a consistência e coerência na análise de um tópico, compromete os argumentos apresentados a favor da implementação do trabalho em equipe, bem como a própria formulação de propostas para a prática, que incluem a prática em equipe (Peduzzi, Ciampone, 2005).

Quarenta e nove publicações (70\%), não fizeram referência ao seu quadro teórico. Isto evidenciou que o tema trabalho em equipe tem sido tratado com superficialidade, visto a ausência de embasamento teórico-metodológico coerente e 
consistente que, por sua vez, acarreta a ausência de rigor conceitual, bem como as contradições e a fragilidade observada na produção.

Do total de publicações que expuseram claramente o referencial teórico, 10 são reflexões críticas e 11 são pesquisas empíricas. Contudo, nem todas as pesquisas empíricas apresentaram claramente o referencial teórico no qual foram apoiadas. Conforme foi apresentado anteriormente nos resultados, cinco artigos de pesquisa qualitativa e cinco artigos de pesquisa quantitativa não declararam o quadro teórico adotado.

Em relação às publicações desenvolvidas por enfermeiros, as que analisaram questões atinentes à equipe multiprofissional e interdisciplinar, o fizeram com base em diferentes abordagens teóricas. Dois artigos utilizaram o referencial do processo de trabalho em saúde, que concebe as diferentes práticas profissionais que integram o campo da saúde como práticas articuladas entre si e articuladas com outras práticas sociais num dado contexto social, político-econômico e cultural. Esta abordagem parte da premissa que as práticas profissionais não podem ser tratadas como um processo isolado que decorre dos avanços do conhecimento de cada área de per si. As demais publicações utilizaram as abordagens teóricas de Peduzzi, acerca do trabalho em equipe (quatro publicações), grupo operativo de Pichon-Riveri (três publicações), e ainda reabilitação psicossocial (uma publicação), controle social de Carvalho (uma publicação), agir comunicativo de Habermmas (uma publicação), materialismo histórico-dialético (uma publicação) e interdisciplinaridade (uma publicação). Três artigos não apresentaram quadro teórico explícito.

As 10 publicações desenvolvidas por enfermeiros que analisam o trabalho em equipe de enfermagem, por sua vez, utilizaram como referencial o materialismo histórico-dialético (uma publicação), as características da equipe de Amaru (uma publicação), a gestão pela qualidade total (uma publicação) e a dinâmica de grupo (uma publicação). Seis publicações não apresentaram quadro teórico explicitado.

6.6 Concepção e respectivas características do trabalho em equipe

A literatura evidenciou que a proposta do trabalho em equipe foi um consenso entre os profissionais da área da saúde e da enfermagem. Entretanto, o conceito de 
trabalho em equipe não foi consenso, pois a maior parte da literatura se manteve no campo da retórica.

As concepções de trabalho em equipe identificadas neste estudo incluíram as características de sinergia positiva; esforços coordenados, cooperação e responsabilidade coletiva; compartilhamento de objetivos e metas comuns; interação entre os agentes que compõe a equipe; processo grupal e trabalho interdisciplinar e transdisciplinar.

A sinergia positiva foi analisada como concepção e também como característica, ou seja, elemento que permite reconhecer o conjunto do trabalho em equipe, foi também apontada como concepção. Sinergia positiva se conceitua como a situação na qual o resultado dos esforços dos trabalhadores ou profissionais envolvidos no processo de trabalho é maior do que seriam os resultados dos esforços individuais somados. $\mathrm{Na}$ situação específica do trabalho em equipe, os sujeitos que trabalham interativamente como equipe são capazes de produzir mais do que a somatória de seus resultados individuais, o que tem por conseqüência maior eficácia e eficiência do processo de trabalho quando este é organizado partir das equipes (McCalling, 2001; Wiecha, Pollard, 2004; Abreu et al., 2005).

É a relação sinérgica entre os membros da equipe que possibilita a um número reduzidos de profissionais serem capazes de atender a demandas maiores, e de maneira eficiente, do que seriam capazes individualmente.

A literatura não apresenta uma discussão sobre as relações sinérgicas para além da retórica, isto é, não expõe uma discussão que seja embasada em evidências empíricas. Contudo, com base na experiência prática da pesquisadora e autora do estudo, é possível perceber a sinergia das equipes, por exemplo, quando se observa o processo de trabalho em diferentes unidades de internação de um mesmo serviço hospitalar. Há unidades nas quais o mesmo número de profissionais concluem suas atividades de maneira mais eficiente e eficaz do que em outras unidades, mantidas as mesmas características do trabalho e da clientela. Nesta linha de exemplos, a mesma unidade que conta com uma equipe sinérgica apresenta redução significativa de sua produção na situação na qual um de seus membros não se encontra no plantão, sendo substituído por outro sujeito estranho à equipe, mesmo que este não seja estranho aos membros da equipe enquanto trabalhadores da mesma instituição. 
As ações no trabalho em equipe devem ser coordenadas cooperativamente na busca pela garantia do fluxo de informações por todos os membros da equipe, e dos esforços na elaboração do plano assistencial comum. Mase, já em 1975, propunha que um trabalho somente se configura como equipe quando existe cooperação.

Lorimer e Manion (1996) adicionam a importância da responsabilidade coletiva das equipes na tomada de decisão voltada para os resultados, com o aumento significativo da qualidade da assistência, a manutenção de relações interpessoais saudáveis tanto entre os membros da equipe quanto destes com os demais colaboradores da organização no qual se inserem.

A cooperação, a coordenação e a responsabilidade coletiva são elementos difíceis de ser mensurados devido a sua forte dimensão intersubjetiva; embora também tenham sido identificados como elementos indispensáveis na caracterização do trabalho em equipe.

Os esforços coordenados, cooperativos, identificados como característica do trabalho em equipe, são compreendidos como a disponibilidade para auxiliar o outro no desenvolvimento de suas atividades, de maneira a facilitar o trabalho. Ao participar da concepção e do desenvolvimento do trabalho do outro, o sujeito co-responsabiliza-se pelas atividades, definindo a responsabilidade coletiva do trabalho em equipe.

Irribary (2003) defende a coordenação e a cooperação como elementos indispensáveis ao trabalho em equipe interdisciplinar.

A interação dos agentes que compõe a equipe de trabalho é considerada questão central que permite a um grupo qualquer se configurar como equipe. Possível por meio da comunicação, a interação é a prática que permite aos sujeitos compartilharem informações e saberes, de modo a recompor os trabalhos especializados e as disciplinas, e trabalhar na busca pelas soluções possíveis das necessidades de saúde, a partir da abordagem da integralidade (Peduzzi, 2001). A interação é o meio que permite à equipe definir e implementar seu projeto assistencial comum de trabalho, na busca pela integralidade da atenção à saúde.

O trabalho em equipe na saúde e na enfermagem foi concebido como processo grupal, no qual um conjunto de sujeitos trabalha coletivamente, a partir de objetos de trabalho comuns, de acordo com objetivos e metas também comuns. Apresentam inter- 
relações ou interações entre os profissionais, processos comunicativos eficientes e articulação interdependente das ações dos diversos profissionais envolvidos.

Segundo Peduzzi (1998), uma das características que diferencia o grupo da equipe é que no último existem relações orientadas por atividades e funções, ou seja, pelo próprio trabalho, sendo os grupos caracterizados por relações de convivência e trocas informais. Esse caráter independente do processo grupal o diferencia do trabalho em equipe, conceitualmente um processo com relações de trabalho interdependentes, permeadas pela comunicação (Ciampone, Peduzzi, 2005).

Concebido também como trabalho interdisciplinar, na perspectiva da busca pela integralidade da atenção à saúde, o trabalho em equipe foi compreendido como a situação na qual as disciplinas envolvidas no processo de trabalho interagem entre si, compartilhando seus conhecimentos específicos na busca pela compreensão ampla de problemas complexos, que não podem ser solucionados por um saber único.

As publicações analisadas mostram que a observação de olhares diversos e específicos sobre uma mesma questão possibilita uma compreensão mais ampla que determina soluções, aperfeiçoa a utilização dos recursos disponíveis e responde com eficiência a problemas complexos, como normalmente se apresentam as questões em saúde (Irribary, 2003).

O trabalho em equipe é concebido como interdisciplinar quando há uma situação de trabalho na qual profissionais de diferentes áreas do conhecimento se propõe a interagir interdependentemente na busca por soluções mais amplas para as complexas necessidades de saúde dos usuários e população, recompondo saberes perdidos com a especialização do conhecimento que fragmentou a assistência (Ciampone, Peduzzi, 2005).

O trabalho em equipe na atenção à saúde exige, dessa forma, a abordagem multiprofissional, que pode ser interdisciplinar ou transdisciplinar, de acordo com o grau de interação entre os profissionais e de integração entre as disciplinas que a compõe (Irribary, 2003).

Será o nível de integração profissional que assegurará os resultados alcançados pela equipe multiprofissional de atenção à saúde, em relação à integralidade, a qualidade da assistência, à elaboração de um plano assistencial comum, e em relação ao custo-efetividade da assistência. 


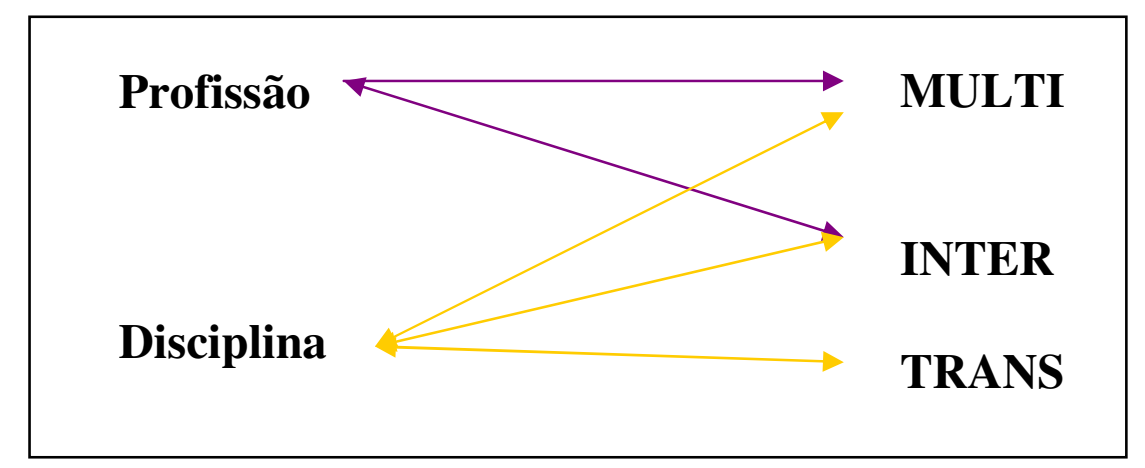

Figura 1 - Possibilidades de relação integrativa entre as profissões e disciplinas,

São Paulo - 2008

É possível distinguir dois tipos de integração na terminologia do trabalho em equipe: das profissões e das disciplinas. A primeira, integração das profissões, diz respeito aos processos operacionais, à interdependência das áreas profissionais da saúde que pode ser expressa na articulação das ações e interação dos agentes (Peduzzi, 1998, 2001; Irribary, 2003). Assim sendo, a integração das profissões pode apresentar-se multiprofissional ou interprofissional (Figura 1).

Já a segunda terminologia, refere-se à integração das disciplinas, entendidas como ciências, ou a interação entre as diferentes áreas do conhecimento e especialidades (Miller, Freeman, Ross, 2001; Irribary, 2003, Peduzzi, 2007b). Dessa forma, a denominação do trabalho em equipe enquanto integração de disciplinas ou áreas de conhecimento podem ser denominadas multidisciplinares, interdisciplinares ou transdisciplinares, com um grau de integração ascendente que parte da multidisciplinaridade, para a interdisciplinaridade, e desta para a transdisciplinaridade (Figura 1).

A identificação de características permitiu avançar na análise conceitual do trabalho em equipe, para além do referencial teórico utilizado, embora um conjunto amplo de características dificulte as pesquisas empíricas.

Foram identificadas, neste estudo, nove características do trabalho em equipe: 1) sinergia positiva; 2) coordenação, cooperação e responsabilidade coletiva; 3) interação entre os agentes; 4) foco nos resultados; 5) autonomia profissional; 6) flexibilização da divisão do trabalho; 7) comunicação; 8) integralidade da atenção à saúde; 9) elaboração de projeto assistencial comum - objetivos comuns.

Em pesquisa recente, Peduzzi (2007b) identifica um conjunto de 14 características do trabalho em equipe: comunicação entre os profissionais; 
compartilhamento de finalidades e objetivos; compartilhamento da abordagem dos pacientes; construção de uma linguagem comum; elaboração de um projeto assistencial comum; articulação entre as ações e disciplinas; cooperação e colaboração; responsabilidade e accountability; reconhecimento do papel dos demais profissionais; complementaridade e interdependência; preservação das especificidades; desigual valoração social dos trabalhos especializados; flexibilidade da divisão do trabalho e autonomia profissional.

Assim, é possível observar que o presente estudo corrobora com as características apontadas por Peduzzi (2007b) de modo que ambas pesquisas ampliam a consistência de seus respectivos resultados.

O foco do trabalho na produção de resultados é apresentado como característico do trabalho em equipe. Conforme analisado por Peduzzi (2001), o foco nos resultados faz parte da tensão gerada no interior das equipes entre a necessidade de promover a integração dos profissionais e a necessidade de produção, no contexto do processo de trabalho.

O processo de trabalho, como apresentado no referencial teórico, está pautado na transformação que produz resultados, sendo essa a finalidade do trabalho - a produção.

Assim, se o que diferencia o grupo da equipe é a dinâmica de trabalho, então o trabalho em equipe deve ser caracterizado por focar-se na produção de resultados. Como apresentado anteriormente, os resultados esperados para o trabalho em equipe podem ser compreendidos a partir de duas linhas gerais: - redução dos custos da assistência, e - assistência integral em saúde. Embora tensas quando confrontadas, entende-se que essas duas dimensões são complementares, convergindo na direção da melhoria da eficácia e eficiência da atenção integral à saúde dos usuários e população

Apesar da necessidade e importância de aprofundamento na análise da tensão acima referida para a compreensão do trabalho em equipe de saúde e enfermagem focado em resultados, esta discussão não será aprofundada nos limites deste estudo, devendo ser mais analisada em pesquisas posteriores.

Concebida como a liberdade de julgamento e tomada de decisão, a autonomia profissional é embasada pelo conhecimento técnico (Peduzzi, 2001), compondo também o conjunto de características do trabalho em equipe. 
De acordo com os artigos analisados, na dinâmica do trabalho em equipe, cada profissional participa da construção do projeto comum com a finalidade de auxiliar na atenção a particularidades específicas de sua área de atuação (Jackson et al., 1993), contribuindo para que a assistência seja integral e de acordo com as necessidades observadas.

Dessa forma, a autonomia profissional seria compreendida como um exercício cotidiano a ser continuamente conquistado (Spiri, Leite, 2004), na busca pela preservação e pelo compartilhamento da autonomia, e pela interdependência dos profissionais no processo de trabalho em equipe (Peduzzi, Ciampone,2005).

A flexibilização da divisão do trabalho foi reconhecida como característica do trabalho em equipe e para a sua abordagem, retoma-se o referencial de Peduzzi, que conceitua o trabalho em equipe como a interação dos agentes e a articulação das ações.

Não se pode rejeitar, nem tampouco aceitar totalmente, a divisão social e técnica do trabalho, pois esta constitui um processo histórico que, por um lado aliena o profissional por não permitir que conheça o projeto e/ou produto do trabalho e, por outro lado, é mantido por parcelar o processo de trabalho, aumentando a produtividade. Assim, a flexibilização é desejável a partir da divisão do trabalho já dada (Mishima et al., 2000).

A comunicação foi o elemento mais reconhecido pelos artigos analisados como característico do trabalho em equipe. Como dito anteriormente, foi o denominador comum dos artigos que problematizaram o trabalho em equipe, o que mostra sua relevância na análise do tema. Possibilitando a interação dos agentes e a articulação das ações no trabalho da equipe, a dimensão comunicativa é compreendida como a chave que permite o trabalho em equipe (Peduzzi, 2007b).

A questão da comunicação é discussão essencial do trabalho em equipe, uma vez que permite a integração dos profissionais, o que favorece a execução do processo de trabalho e a coesão da equipe, tornando-se, assim, um círculo no qual a comunicação favorece a integração das ações e dos profissionais, que por sua vez, favorece a comunicação (Rivera, 1996).

Houve publicações que trataram a comunicação com ausência de rigor conceitual na sua discussão, referindo-se a ela como a simples troca de informação entre os profissionais, tendendo a ampliar e cristalizar a fragmentação que compromete a assistência e o cuidado de enfermagem e de saúde. 
A equipe de trabalho deve ser compreendida como unidade integrada, que permite o fluxo horizontal de informações e intervenções, que devem ser de conhecimento de todos os membros da equipe. Isto configura uma prática que busca o entendimento mútuo entre os agentes, o que, por sua vez, pode acarretar a articulação dos saberes e das disciplinas, na direção do atendimento das necessidades de saúde dos usuários do serviço. Através da integração entre os profissionais da equipe, as condutas são decididas de acordo com cada caso singular e com o projeto comum de trabalho (Hadley et al., 1997; Oliveira, Spiri, 2006).

Dessa forma, o planejamento do projeto assistencial comum é visto como sinalizador da integração da equipe, sendo possível através do processo comunicativo (Peduzzi, 2001).

Outra característica da comunicação, abordada pelas publicações analisadas, foi a necessidade de eliminar os ruídos - medo, insegurança, informações falsas, ausência de informação, relações de poder desiguais - e o cuidado para que as informações não se percam e sejam transmitidas igualmente a todos os membros da equipe (Campos, 1992).

Pode-se dizer que a comunicação é efetiva quando capaz de gerar modificações nas áreas envolvidas no processo de trabalho, proporcionando a possibilidade de crescimento e troca entre seus membros, tanto de informações quanto de experiências (Campos, 1992).

Dessa forma, torna-se essencial problematizar e compreender a dimensão comunicativa no trabalho em equipe na tentativa de buscar e conhecer a cultura comum da equipe, os consensos que possibilitam a prática.

A linguagem, verbal e não-verbal, que serve como meio para a comunicação, torna-se responsável por mediar simbolicamente as decisões, a cooperação e principalmente a articulação das ações e a interação dos agentes no processo de trabalho em equipe.

As reuniões foram apontadas, nas publicações, como importante espaço para a comunicação das equipes. Por um lado, como espaço para reafirmar antigas idéias e propostas, e socializar projetos individuais - o que Peduzzi (1998) caracteriza como comunicação externa o trabalho, e por outro lado, como espaço para troca e crescimento dos membros, o que permite o melhor desempenho da equipe, e a elaboração de um projeto assistencial comum. 
Conforme apontado por Scherer, Scherer e Campos (2007), as reuniões de equipe devem ser compreendidas como espaços privilegiados para a discussão e reflexão da equipe acerca de sua prática profissional, possibilitando seu crescimento, assim como a coesão e a melhoria da interação de seus membros.

As reuniões de equipe podem ser espaços para a discussão e resolução de conflitos; porém, quando as relações de poder tornam-se super dimensionadas e promovem a intimidação dos membros de menor poder hierárquico, não é mais possível discutir e tomar decisões coletivamente, e as reuniões perdem sua razão de ser.

Na literatura analisada, apenas Sadigursky (2002) aponta para a necessidade de avaliação sistemática e crítica das reuniões de equipe, o que permitiria garantir momentos de crescimento para a equipe como um todo. Embora pouco discutida, a necessidade de avaliação sistemática da dimensão comunicativa e das reuniões regulares, é questão central na avaliação geral do trabalho da equipe, assim como de seus resultados.

Quanto à construção de um projeto comum da equipe, também apontada como característica do trabalho em equipe, percebeu-se que a produção analisada não apresentou distinção entre os termos projeto e objetivos, que são utilizados como sinônimos. Porém, há diferenças conceituais importantes entre esses dois termos.

Os objetivos são pontuais e específicos para a ação que se deseja concretizar, sem apresentar a esperada articulação das ações nem a interação dos agentes. Há objetivos relacionados aos pacientes, aos funcionários e à própria instituição, compondo as metas necessárias para a consolidação do projeto.

Faz-se necessário compreender que tanto os objetivos dos trabalhadores e da instituição quanto os objetivos dos usuários dos serviços de saúde são relevantes, porém a atenção às necessidades de saúde dos usuários do sistema de saúde constitui a atividade fim da atenção à saúde, sendo, portanto, o objeto do projeto assistencial comum (Campos, 1992).

O projeto é intersubjetivo, amplo, compõe-se de vários objetivos e ações para que sua finalidade seja atingida, sendo este o ponto que auxilia na caracterização do trabalho em equipe. O projeto situa-se no limite das possibilidades e necessidades observadas, sendo compreendido, dessa forma, como a finalidade do trabalho (Peduzzi, 2001). Embora a literatura cite poucas vezes a elaboração de um projeto comum, muito se fala acerca dos objetivos comuns da equipe, centrados nas necessidades dos usuários; 
sendo importante, portanto, valorizar a preocupação dos autores em relação aos objetivos comuns do trabalho em equipe.

$\mathrm{Na}$ prática, a produção analisada apresentou situações nas quais o projeto comum é apenas uma realidade utópica, sendo que as ações não condizem com os acordos firmados, as relações são tensas, as condutas são individualizadas de acordo com a visão específica de cada profissional, e o usuário é apenas comunicado do planejamento quando este está pronto.

A integração que se observa na equipe está no sentido de auxiliar cada profissional a alcançar seus objetivos assistenciais. Não houve citações acerca do planejamento de um projeto assistencial comum, o qual deveria ser a maneira como a equipe interdisciplinar organiza seu trabalho, recompondo os diferentes olhares e expressando a integração da equipe (Peduzzi, Ciampone, 2005).

A busca pela integralidade da atenção à saúde foi identificada como elemento característico do trabalho em equipe. A atenção à saúde foi compreendida, nas publicações analisadas, como um círculo vicioso - quando busca somente a relação custo-benefício da assistência -, ou virtuoso, na atenção das necessidades de saúde do sujeito de maneira integral. No entanto, neste estudo entende-se esse aspecto como dinâmica complementar entre a racionalização dos serviços de saúde e a atenção integral às necessidades de saúde dos usuários. Ocorre que ambas podem ser orientadas por racionalidades distintas, a tal ponto que geram conflitos, tensões ou mesmo contradições entre a eficiência dos serviços e eficácia para os usuários.

Entretanto, essas duas dimensões do trabalho em equipe - custo-efetividade e integralidade - podem ser complementares, como foi apontado anteriormente. Embora esse aspecto ainda não tenha sido amplamente discutido na literatura, Peduzzi (1998, 2001) faz uma discussão acerca da tensão que existe no trabalho em equipe que, por um lado deve promover a integração dos agentes e das ações, e por outro lado, deve produzir resultados a partir da abordagem da atenção integral em saúde.

Na busca pela integralidade da atenção à saúde, a ferramenta do trabalho em equipe torna-se fundamental, na medida em que permite recompor os saberes fragmentados pela especialização dos saberes da assistência em saúde. O trabalho em equipe é instrumento para auxiliar no aprendizado constante, identificação de nós críticos, e base para ações que melhorem a qualidade da assistência. Numa visão mais 
global, a integralidade seria a finalidade do trabalho em equipe (Peduzzi, 2001; Peduzzi, Ciampone, 2005).

A utilização da ferramenta trabalho em equipe na busca pela integralidade da atenção à saúde se expressa como uma possibilidade de recomposição dos trabalhos super especializados, de acordo com a necessidade de diversos olhares na abordagem de um mesmo problema. Campos (1999) defende que o trabalho organizado em equipes de referência e suporte de apoio matricial atendem muito bem à questão da integralidade por permitir a recomposição dos trabalhos.

Alguns artigos analisaram as equipes de trabalho sob a perspectiva da organização formal dentro das instituições, respondendo às suas demandas, normas e objetivos. O trabalho em equipe seria, dessa forma, um meio de expressão da dinâmica social da organização e dos indivíduos inseridos nela.

O modelo de organização de uma instituição seja de saúde ou de outro setor, está intimamente relacionado com a dinâmica do trabalho. Isso porque a organização do trabalho, a hierarquia e o estilo gerencial condicionam e determinam comportamentos e posturas, influenciando negativamente a cooperação, através da sobrecarga de trabalho; ou facilitando a integração e a articulação dos diferentes níveis de poder, sendo estes objetivos de busca constante (Matheus, 1995).

As estruturas tradicionais de gerenciamento - verticalizadas e centralizadas -, são consideradas, segundo o material analisado, dificultadoras da integração dos profissionais, favorecendo o descompromisso e a alienação destes (Campos, 1999; Peduzzi, Ciampone, 2005).

A distribuição de poder dentro da equipe, assim como a diferente valoração social do trabalho, foram apontados como característica que pode dificultar o trabalho em equipe (Peduzzi, 2001; Oliveira, Bottaro, Alessi, 2003).

Os artigos cujo foco central foi o Programa de Saúde da Família, ou a Saúde Mental apontam a importância de incluir o usuário na tomada de decisão e elaboração do plano assistencial comum (artigo 15, 39, 44, 69). A inclusão do usuário na equipe interdisciplinar auxilia na atenção integral às necessidades observadas, com efeitos positivos na adesão e responsabilidade do usuário no cuidado em saúde (Wiecha, Pollard, 2004). Porém, em algumas situações práticas apresentadas, as decisões foram tomadas no interior da equipe, sendo o usuário apenas comunicado, legitimando-as (artigo 15). 
A questão do surgimento e do enfrentamento de conflitos, no contexto do trabalho em equipe também foi abordada por algumas publicações, embora tenham trazido conceitos e visões divergentes, tais como a idéia de que os conflitos podem aparecer e devem ser resolvidos no interior da equipe; e outras como a defesa de que nas equipes maduras e eficientes os conflitos não ocorrem.

É importante salientar que o conflito, no contexto do trabalho em equipe, é uma situação real e comum, devendo ser trabalhada com vistas à sua solução e à busca pelo crescimento da equipe como um todo. A situação de conflito dentro de uma equipe pode ser considerada situação positiva, uma vez que possibilita a integração e o crescimento da equipe e de seus membros, durante o processo de negociação e resolução do conflito (Miller, Freeman, Ross, 2001).

Segundo Spagnol (2006), as escolas clássicas da administração consideravam o aparecimento dos conflitos no contexto do processo de trabalho como situações negativas, de disfunção. Já na escola estruturalista, o reconhecimento de que os conflitos estão presentes em todas as organizações, e que precisam ser conhecidos e trabalhados, aponta para a positividade do conflito, uma vez que pode ser situação geradora de mudanças.

A comunicação é fundamental na busca pela resolução dos conflitos gerados no interior da equipe, assim como na busca pelas melhores soluções aos problemas observados.

Valores e atitudes, como respeito, compromisso e motivação, assim como a presença de objetivos claros, que possibilitem a união dos objetivos coletivos e individuais, respeitando as diferenças, permitem que as equipes sejam capazes de solucionar os problemas e conflitos percebidos de maneira mais saudável e efetiva do que individualmente, possuindo ainda a vantagem de contar com o comprometimento dos membros com as decisões, que por serem compartilhadas são de responsabilidade da equipe, coletivamente (artigo 26, 48).

Outra questão relevante em relação ao enfoque gerencial, abordada na seleção dos artigos analisados, foi a liderança (Miller, Freeman, Ross., 2001). Apontou-se a importância de se definir claramente o estilo de liderança que será utilizado, assim como a figura do líder, que será escolhido a partir de suas habilidades específicas para o alcance dos objetivos e metas, de acordo com o momento vivido pela equipe (Campos, 1992; Lopes, 1993; Matheus, 1995). 
O trabalho desenvolvido pelas equipes é sempre mais complexo e desafiante do que um único indivíduo ou área do conhecimento possa realizar sozinho. A organização do trabalho em equipe é capaz de responder aos desafios com mais facilidade, e se o faz de maneira eficiente e eficaz, trabalhando os conflitos em busca de um trabalho integrado, resta ao líder exercer pouco sua função de controlador do processo, e mais a função de mentor das ações e das direções (McCalling, 2001; Miller, Freeman, Ross, 2001; Wasch, 2005).

$\mathrm{Na}$ equipe, não se observa a figura de um chefe formal, mas de um líder, sendo que esta liderança pode alternar-se de um membro para outro, de acordo com o momento de trabalho, seja para um processo de mudança, a superação de um conflito ou a elaboração de novas tarefas (Fortuna et al., 2005). Na enfermagem, a questão do líder torna-se complexa, uma vez que essa tarefa está, de antemão, determinada ao enfermeiro (Ciampone, Peduzzi, 2005).

Também é esperado que o líder eficiente na gestão do trabalho em equipe facilite a compreensão das políticas e procedimentos organizacionais pelo grupo de trabalho, e auxilie a equipe a inserir-se no contexto da instituição para que seja por ela valorizada (Wasch, 2005).

De forma esquemática, Lorimer e Manion (1996) enumeram algumas competências necessárias aos líderes de equipes. São elas: foco nos objetivos, criação de uma imagem clara do futuro que se deseja alcançar, comunicação clara e efetiva, compreensão da equipe, sendo modelo para seu desenvolvimento, delegação de autoridade e responsabilidade para a tomada de decisão, manutenção de relações interpessoais saudáveis, cuidado consigo mesmo e finalmente o gerenciamento das mudanças e a facilitação para que estas ocorram.

São características preconizadas para o líder de uma equipe facilitar a comunicação, o alcance dos objetivos, tanto individuais quanto coletivos, a cooperação entre os membros e o reconhecimento mútuo entre os membros da equipe entre si, e também entre equipe e instituição (Lopes, 1993), favorecendo a integração e a coesão da equipe (Miller, Freeman, Ross, 2001).

A liderança emerge como característica do trabalho em equipe, e pode ser compreendida a partir das ações do líder, que deve ser capaz de extrair do grupo de agentes o máximo que eles podem desenvolver, visualizando o todo e cada um, assim 
como suas qualidades singulares que podem ser potencializadas em favor do grupo (Miller, Freeman, Ross, 2001; Wasch, 2005).

A liderança pode promover a interação dos agentes e a articulação das ações a partir da manutenção de um ambiente colaborador, da confiança entre os indivíduos e do gerenciamento de recursos e prioridades para o alcance da meta determinada (Miller, Freeman, Ross, 2001; Wasch, 2005).

\section{Considerações Finais}

Estudar a literatura sobre o trabalho em equipe permite aprofundar a discussão conceitual sobre o tema, criando subsídios que permitam melhorar a prática, e conseqüentemente a assistência em saúde.

A banalização do termo equipe é uma conclusão importante desse estudo, buscando trazer a atenção para a necessidade de se estudar e fundamentar a compreensão que os profissionais da saúde têm acerca do assunto. A ausência de rigor conceitual dificulta as pesquisas e a busca de publicações relevantes nos bancos de dados.

As mudanças do modelo de atenção em saúde, no Brasil, com a implantação do SUS e do PSF, tem como resultado o aumento das publicações sobre trabalho em equipe, sobretudo nas décadas de 1990 e 2000, fundamentadas e impulsionadas pela busca da integralidade na atenção à saúde, princípio diretivo do novo modelo.

Internacionalmente, o impulso para a discussão do tema é a busca pela otimização da relação custo-efetividade da assistência; dimensão esta que pode ser considerada complementar à busca pela atenção integral, a partir da abordagem do trabalho em equipe focado na produção de resultados.

Chama atenção a escassez de publicações sobre o trabalho em equipe de enfermagem. O trabalho em equipe multiprofissional foi abordado por enfermeiros com contribuições de significativa importância para o debate e prática do tema, porém os estudos que abordam especificamente o trabalho em equipe na área representam escassa produção. Algumas explicações possíveis para esse fato estão relacionadas ao reconhecimento do trabalho em equipe como situação "natural" da enfermagem, visto 
sua institucionalização com base na divisão do trabalho; a precocidade na abordagem do tema na área, nos anos 1950, e a sua centralização da discussão da temática da liderança, e finalmente, a priorização corporativa da busca pelo reconhecimento profissional em detrimento do aprofundamento da discussão e prática da equipe de enfermagem que integra enfermeiros, auxiliares e técnicos de enfermagem.

Assim, entende-se que como instrumento básico para o trabalho da enfermagem, o conhecimento e a prática do trabalho em equipe devem ser aprofundado.

A concepção de trabalho em equipe, e suas respectivas características, analisadas neste estudo, fortalecem pesquisas anteriores e permitem subsidiar conceitualmente estudos posteriores. Em especial a característica do trabalho em equipe como esforços coordenados, cooperativos e responsabilidade coletiva merecem especial atenção como aspecto a ser avaliado e aprofundado posteriormente.

A revisão da literatura permite concluir pela necessidade de construção de tecnologia, no sentido estrito do temo como ciência da técnica e no sentido lato como modos de atenção à saúde e de cuidado de enfermagem, que atendam à diretriz do trabalho em equipe, para além da discussão retórica, uma vez que essa estratégia de organização do trabalho em saúde e em enfermagem se configura como uma diretriz do modelo assistencial vigente que aponta para maior eficácia e eficiência dos serviços prestados à população e usuários. Coloca-se assim, a necessidade de criar meios e métodos que permitam avaliar e melhorar a dinâmica do trabalho em equipe em saúde e enfermagem, de modo a refletir em melhorias diretas nos resultados da atenção à saúde e dos cuidado de enfermagem. 


\section{Referências bibliográficas}

Abreu de LO, Munari DB, de Queiroz AL, Fernandes CN. O trabalho de equipe em Enfermagem: revisão sistemática da literatura. Rev Bras Enferm. 2005;58(2):203-7.

Almeida Filho N. Transdisciplinaridade e saúde coletiva. Ciência \& saúde coletiva. 1997;II(1/2):5-20.

Almeida MCP, Rocha SMM (organizadores). O trabalho de enfermagem. São Paulo: Cortez; 1986.

Antunes MJM. O ensino da administração de enfermagem nas escolas públicas da região sudeste. Rev Paul Enfermagem. 1991;10(2):58-67.

Bergamini CW. Psicologia aplicada à administração de empresas: psicologia do comportamento organizacional. São Paulo: Atlas; 1982.

Bichaff R. O trabalho nos centros de atenção psicossocial: uma reflexão crítica das práticas e suas contribuições para a consolidação da reforma psiquiátrica. [tese] São Paulo: Escola de Enfermagem. Universidade de São Paulo; 2006.

Bourghnet L. Considerações sobre o processo de reabilitação. Acta Fisiátrica. 2004;11(2):55-9.

Brasil. Ministério da Saúde. Secretaria Nacional de Assistência à Saúde. ABC do SUS Doutrinas e princípios. Ministério da Saúde. Secretaria Nacional de Assistência à Saúde. Brasília: Secretaria Nacional de Assistência à Saúde; 1990.

Brown A. Tds in operating department nursing. The role of the patient advocate. $\mathrm{Br} \mathbf{J}$ Theatre Nurs. 1995;5(2):5-6,8.

Campos MA. O trabalho em equipe multiprofissional: uma reflexão crítica. J Bras Psiq. 1992;41(6):255-257.

Campos GWS. Equipes de referência e apoio especializado matricial: um ensaio sobre a reorganização do trabalho em saúde. Cienc saúde coletiva. 1999;4(2):393-403. 
COREN-SP. Principais Legislações para o exercício da enfermagem. Conselho Regional de Enfermagem de São Paulo: São Paulo; 2007.

Crevelim MA, Peduzzi M. Participação da comunidade na equipe de saúde da família: é possível estabelecer um projeto comum entre trabalhadores e usuários? Cienc saúde coletiva. 2005;10(2):323-31.

Fortuna CM, Mishima SM, Matumoto S, Pereira MJB. O trabalho de equipe no programa de saúde da família: reflexões a partir de conceitos do processo grupal e de grupos operativos. Rev Latino-am Enfermagem. 2005; 13(2):262-8.

Galvão CM, Sawada NO, Trevizan MA. Revisão sistemática: recurso que proporciona a incorporação das evidências na prática da Enfermagem. Rev Latino-am Enfermagem. 2004;12(3):549-59.

Hadley TR, Turk R, Vasko S, McGurrin MC. Community Treatment teams: an alternative to state hospital. Psychiatric quarterly. 1997;69(1):77-90.

Ingram H, Desombre, T. Teamwork in health care - lessons from the literature and from good practice around the world. Journal of Management in Medicine. 1999;13(1):51-58.

Irribary IN. Aproximações sobre a transdisciplinaridade: algumas linhas históricas, fundamentos e princípios aplicados ao trabalho de equipe. Psicologia: reflexão e crítica. 2003;16(3):483-490.

Jackson G, Gater R, Goldberg D, Tantam D, Loftus L, Taylor H. A new community mental health team based in primary care. A description of the service and its effect on service use in the first year. Br J Psiquiatry. 1993;162:375-84.

Lopes RLM. Modalidades de equipe na assistência à pessoa especial. Rev Baiana Enf, Salvador. 1993;6(2):103-109.

Lorimer W, Manion J. Team-based organizations - leading the essential transformation. PFCA review. Spring, 1996.

Mase DJ. Profissionalism and the health care team. J allied health. 1975;4(2):25-32. 
Matheus MCC. O trabalho em equipe: um instrumento básico e um desafio para a Enfermagem. Rev Esc Enfermagem USP. 1995;29(1):13-25.

Mattos RA. A integralidade na prática (ou sobre a prática da integralidade). Cad Saúde Públ. 2004;20(5):1411-16.

Matumoto S, Fortuna CM, Mishima SM, Pereira MJB, Domingos NAM. Supervisão de equipes no PSF: reflexões acerca do desafio da produção de cuidados. Interface comum saúde educ. 2005;9(16):9-24.

McCalling A. Interdisciplinary practice - a matter of teamwork: an integrated literature review. Journal of clinical nursing. 2001;10:419-28.

Mendes-Gonçalves RB. Práticas de saúde: processo de trabalho e necessidades. CEFOR; 1992.

Mendes-Gonçalves RB. Tecnologia e organização social das práticas de saúde. São Paulo: Hucitec; 1994.

Merhy EE. Em busca do tempo perdido: a micropolítica do trabalho vivo em saúde. In: Merhy, EE; Onocko, R (org). Agir em saúde: um desafio para o público. São Paulo: Hucitec; 1997.

Miller C, Freeman M, Ross N. Interprofessional practice in health and social care challenging the shared learning agenda. Arnold: London; 2001.

Mishima SM, Villa TCS, Silva EM, Pinto IC, Almeida MCP. O velho trabalho em equipe pode ganhar cara nova? Uma perspectiva do trabalho gerencial. Saúde em debate. 2000;24(54):66-74.

Munari DB. Processo grupal em Enfermagem: possibilidades e limites. Rev Bras Enferm. 1997;50(1):37-52. 
Oliveira EM, Spiri WC. Programa de Saúde da Família: a experiência de equipe multiprofissional. Rev Saúde Pública. 2006;40(4):727-33.

Peduzzi M. Equipe multiprofissional de saúde: a interface entre trabalho e interação [Tese]. Campinas: Faculdade de Ciências Médicas, Universidade Estadual de Campinas; 1998.

Peduzzi M. Equipe multiprofissional de saúde: conceito e tipologia. Rev Saúde Pública. 2001;35(1):103-9.

Peduzzi M. Trabalho em equipe. In: Escola Politécnica de Saúde Joaquim Venâncio (org). Dicionário da educação profissional em saúde. Rio de Janeiro: EPSJV; 2006.

Peduzzi M. Trabalho em equipe de saúde no horizonte normativo da integralidade, do cuidado e da democratização das relações de trabalho. In: Pinheiro, R; Barros, MEB; Mattos, RA. Trabalho em equipe sob o eixo da integralidade: valores, saberes e práticas. Rio de Janeiro: IMS/ UERJ: CEPES: ABRASCO; 2007a.

Peduzzi M. Trabalho em equipe de saúde da perspectiva de gerentes de serviços de saúde: possibilidades da prática comunicativa orientada pelas necessidades de saúde dos usuários e da população [tese de livre-docência] São Paulo (SP): Escola de Enfermagem da Universidade de São Paulo, 2007b.

Peduzzi M; Ciampone, MHT. Trabalho em equipe e trabalho em grupo no Programa de Saúde da Família. Rev Bras Enferm. 2000;53(n.esp):143-147.

Peduzzi M, Ciampone MHT. Trabalho em equipe e processo grupal. In: Kurcgant P, organizadora. Gerenciando em enfermagem. Rio de Janeiro: Guanabara Koogan; 2005. p. 108-124.

Petersson IF. Evolution of team care and evaluation of effectiveness. Curr Opin Rheumatol. 2005;17(2):160-3.

Pinheiro R. Integralidade em saúde. In: Escola Politécnica de Saúde Joaquim Venâncio (org). Dicionário da educação profissional em saúde. Rio de Janeiro: EPSJV; 2006. 
Porter J. A psychiatric consultation-liaison service in a community hospital. Can J Psychiatry. 1988:33;271-274.

Robbins SP. Comportamento organizacional. São Paulo: Prentice Hall; 2002.

Rosa WAG, Labate RC. Programa Saúde da Família: a construção de um novo modelo de assistência. Rev Latino-am Enferm. 2005;13(6):1027-34.

Rother ET. Editorial - Revisão sistemática x revisão narrativa. Acta Paul Enferm. 2007;20(2):vi.

Rozendo CA. Liderança na enfermagem: refletindo sobre um mito. Escola de enfermagem de Ribeirão Preto [mestrado] Universidade de São Paulo. Ribeirão Preto; 1995.

Rivera FJU. A gestão situacional (em saúde) e a organização comunicante. Cad Saúde Publ. 1996;2(3):357-72.

Rudio FV. Introdução ao projeto de pesquisa científica. Petrópolis, Vozes; 2004. 32 ed.

Sadigursky D. A enfermeira na equipe de saúde mental. Rev baiana Enfermagem. 2002;17(3):45-53.

Scherer EA, Scherer ZAP, Campos MA. Percepções sobre coordenação e funcionamento de reuniões de equipe geral de um hospital-dia psiquiátrico. Rev Latino-am Enfermagem. 2007;15(1).

Schofield RF, Amodeo M. Interdisciplinary teams in health care and human services settings: are they effective? Health \& Social Work. 1999;24(3):210-9.

Schull MJ, Ferris LE, Tu JV, Hux JE, Redelmeier DA. Problems for clinical judgement: 3. thinking clearly in an emergency. JAMC. 2001:164(8);1170-1175. 
Schweikhart S, Smith-Daniels V. Reengineering the work of caregivers: role definition, team structures, and organizational redesign. Hospital \& Health Services Administration. 1996:41(1):19-53.

Sherman RO. Team nursing revisited. JONA. 1990:20(11); 43-6.

Slande-Dew N, Bigelow DA, Buckley R, Bornemann S. The greater vancouver mental health service society: 20 years' experience in urban community mental health. Can J Psychiatry. 1993:38;308-314.

Silva LIMC, Peduzzi M. Os recursos humanos de enfermagem da perspectiva da força de trabalho: análise da produção cientifica. Rev Esc Enferm USP. 2005;39(esp.):58996.

Silveira CS. Pesquisa em enfermagem oncológica no Brasil: uma revisão integrativa. Dissertação [Mestrado] Escola de Enfermagem de Ribeirão Preto. Universidade de São Paulo. 2005.

Spagnol CA. A trama dos conflitos vivenciada pela equipe de enfermagem $\mathrm{n}$ contexto da instituição hospitalar: como explicar seus "nós"? [tese]. Campinas: Faculdade de Ciências Médicas, Universidade Estadual de Campinas; 2006.

Spiri WC, Leite MMJ. O significado do trabalho em equipe na reabilitação de pessoas com malformação craniofacial congênita. Rev Esc Enferm USP. 2004;38(3):288-97.

Wasch JE. Building the occupational health team - keys to successful interdisciplinary collaboration. AAOHN Journal. 2005;53(4):166-70.

Wiecha J, Pollard T. The interdisciplinary eHealth Team: chronic care for the future. $\mathrm{J}$ Med Internet Res. 2004;6(3):e22. 


\section{Apêndices}

Publicações utilizadas no estudo

\begin{tabular}{|c|l|l|l|}
\hline \multicolumn{1}{|c|}{ Autores } & \multicolumn{1}{c|}{ Título } & \multicolumn{1}{c|}{ Periódico } \\
\hline 1 & $\begin{array}{l}\text { Abreu, Munari, } \\
\text { Fueiroz, } \\
\text { Fernandes }\end{array}$ & $\begin{array}{l}\text { O trabalho de equipe em Enfermagem: revisão } \\
\text { sistemática da literatura }\end{array}$ & $\begin{array}{l}\text { Rev Bras Enferm; 58(2):203-7, } \\
2005\end{array}$ \\
\hline 2 & Abuhab & $\begin{array}{l}\text { O trabalho em equipe multiprofissional no } \\
\text { CAPS III: um desafio }\end{array}$ & $\begin{array}{l}\text { Rev Gaúcha de } \\
\text { Enfermagem;26(3):369- } \\
80,2005\end{array}$ \\
\hline 3 & Bailey & $\begin{array}{l}\text { A triaxial model of the interdisciplinary team } \\
\text { and group process }\end{array}$ & Except child;51(1):17-25,1984 \\
\hline 4 & $\begin{array}{l}\text { Bertoncello, } \\
\text { Silva }\end{array}$ & $\begin{array}{l}\text { O processo de trabalho em ambulatório de saúde } \\
\text { mental }\end{array}$ & $\begin{array}{l}\text { Inf psiquiatr:17(4):129- } \\
34,1998\end{array}$ \\
\hline 5 & Bourghnet & Considerações sobre o processo de reabilitação & Acta fisiátrica;11(2):55-9,2004 \\
\hline 6 & Brown & $\begin{array}{l}\text { Tds in operating department nursing. The role of } \\
\text { the patient advocate }\end{array}$ & $\begin{array}{l}\text { Br J Theatre Nurs;5(2):5- } \\
6,8,1995\end{array}$ \\
\hline 7 & Câmara & Equipe - o elemento fundamental da assistência & Rev saúde Dist Fed;8(supl):10- \\
\hline
\end{tabular}




\begin{tabular}{|c|c|c|c|}
\hline & & & 1,1997 \\
\hline 8 & Campos & $\begin{array}{l}\text { O anti-Taylor: sobre a invenção de um método } \\
\text { para co-governar instituições de saúde } \\
\text { produzindo liberdade e compromisso }\end{array}$ & $\begin{array}{l}\text { Cad saúde pública;14(4):863- } \\
70,1998\end{array}$ \\
\hline 9 & Campos & $\begin{array}{l}\text { Equipes de referência e apoio especializado } \\
\text { matricial: um ensaio sobre a reorganização do } \\
\text { trabalho em saúde }\end{array}$ & $\begin{array}{l}\text { Cienc saúde coletiva;4(2):393- } \\
403,1999\end{array}$ \\
\hline 10 & Campos & $\begin{array}{l}\text { Trabalho em equipe multiprofissional: uma } \\
\text { reflexão crítica }\end{array}$ & $\begin{array}{l}\text { Jornal Brasileiro de } \\
\text { Psiquiatria;41(6):255-7,1992 }\end{array}$ \\
\hline 11 & Campos & $\begin{array}{l}\text { Experiência de trabalho em uma equipe } \\
\text { multidisciplinar de um hospital psiquiátrico } \\
\text { universitário: reflexões sobre a dinâmica de } \\
\text { grupo }\end{array}$ & $\begin{array}{l}\text { Rev ABP-APAL;10(1):30- } \\
4,1988\end{array}$ \\
\hline 12 & Catropa & $\begin{array}{l}\text { As vicissitudes no trabalho em equipe } \\
\text { multiprofissional }\end{array}$ & $\begin{array}{l}\text { Bol psiquiatr;20(1/2):17- } \\
9,1987\end{array}$ \\
\hline 13 & $\begin{array}{l}\text { Ciampone, } \\
\text { Peduzzi }\end{array}$ & Trabalho em equipe e trabalho em grupo no PSF & $\begin{array}{l}\text { Rev Bras } \\
\text { Enferm;53(n.esp):143- } \\
147,2000\end{array}$ \\
\hline 14 & Cretikos & $\begin{array}{l}\text { The medical emergency team: } 21 \text { st century } \\
\text { critical care }\end{array}$ & $\begin{array}{l}\text { Merva anestesiol;71(6):259- } \\
63,2005\end{array}$ \\
\hline 15 & Crevelim & $\begin{array}{l}\text { Participação da comunidade na equipe de saúde } \\
\text { da família: é possível estabelecer um projeto } \\
\text { comum entre trabalhadores e usuários? }\end{array}$ & $\begin{array}{l}\text { Cienc saúde } \\
\text { coletiva;10(2):323-31,2005 }\end{array}$ \\
\hline 16 & Cunha & Gestão em Enfermagem: novos rumos & $\begin{array}{l}\text { Mundo } \\
\text { saúde(1995);26(2):309- } \\
14,2002\end{array}$ \\
\hline 17 & Faustino & $\begin{array}{l}\text { Caminhos da formação de Enfermagem: } \\
\text { continuidade ou ruptura? }\end{array}$ & $\begin{array}{l}\text { Rev Brás Enfermagem } \\
\text { Brasília;56(4):343-47,2003 }\end{array}$ \\
\hline 18 & Faustino & $\begin{array}{l}\text { O trabalho de Enfermagem em saúde da família } \\
\text { na perspectiva de consolidação do SUS }\end{array}$ & $\begin{array}{l}\text { REME: Rev Mineira de } \\
\text { Enf;8(4):464-469,2004 }\end{array}$ \\
\hline 19 & $\begin{array}{l}\text { Fiander, Burns, } \\
\text { Ukoumunne, } \\
\text { Fahy, Creed, } \\
\text { Tyrer, Byford } \\
\end{array}$ & $\begin{array}{l}\text { Do care patterns change over time in a newly } \\
\text { established mental health service? A report from } \\
\text { the UK700 trial }\end{array}$ & $\begin{array}{l}\text { Eur Psychiatry;21(5):300- } \\
6,2006\end{array}$ \\
\hline 20 & $\begin{array}{l}\text { Fortuna, } \\
\text { Mishima, } \\
\text { Matumoto, } \\
\text { Pereira }\end{array}$ & $\begin{array}{l}\text { O trabalho de equipe no PSF: reflexões a partir } \\
\text { de conceitos do processo grupal e de grupos } \\
\text { operativos }\end{array}$ & $\begin{array}{l}\text { Rev latinoam } \\
\text { Enfermagem;13(2):262-8,2005 }\end{array}$ \\
\hline 21 & $\begin{array}{l}\text { Gomes, } \\
\text { Deslandes }\end{array}$ & $\begin{array}{l}\text { Interdisciplinaridade na saúde pública: um } \\
\text { campo em construção }\end{array}$ & $\begin{array}{l}\text { Rev latinoam enfem;2(2):103- } \\
14,1994\end{array}$ \\
\hline 22 & \begin{tabular}{|l|} 
Hadley, Turk, \\
Vasko, McGurrin
\end{tabular} & $\begin{array}{l}\text { Community treatment teams:an alternative to } \\
\text { state hospital }\end{array}$ & Psyquiatr Q;68(1):77-90,1997 \\
\hline 23 & Hockley & $\begin{array}{l}\text { The development of a palliative care team at the } \\
\text { Western General Hospital }\end{array}$ & $\begin{array}{l}\text { Support care cancer;4(2):77- } \\
81,1996\end{array}$ \\
\hline 24 & & $\begin{array}{l}\text { Hospitalist take on role in rapid response teams } \\
\text { withearly success }\end{array}$ & $\begin{array}{l}\text { Perform improv advis;9(6):69- } \\
71,61,2005\end{array}$ \\
\hline 25 & Irribary & $\begin{array}{l}\text { Aproximações sobre a transdisciplinaridade: } \\
\text { algumas linhas históricas, fundamentos e }\end{array}$ & $\begin{array}{l}\text { Psicol reflex crit;16(3):483- } \\
490,2003\end{array}$ \\
\hline
\end{tabular}




\begin{tabular}{|c|c|c|c|}
\hline & & princípios aplicados ao trabalho em equipe & \\
\hline 26 & $\begin{array}{l}\text { Jackson, Gater, } \\
\text { Goldberg, } \\
\text { Tantam, Loftus, } \\
\text { Taylor } \\
\end{array}$ & $\begin{array}{l}\text { A new community mental health team based in } \\
\text { primary care. A description of the service and its } \\
\text { effect on service use in the first year }\end{array}$ & $\begin{array}{l}\text { Br J Psyquiatry; } 162: 375- \\
84,1993\end{array}$ \\
\hline 27 & Lassauniere & The palliative care centre of Hotel-Dieu Hospital & $\begin{array}{l}\text { Support care cancer;3(1):7- } \\
10,1995\end{array}$ \\
\hline 28 & $\begin{array}{l}\text { Lavin, Ruebling, } \\
\text { Banks, Counte, } \\
\text { Furman, Miller, } \\
\text { Reese, } \\
\text { Viehmann, Holt } \\
\end{array}$ & $\begin{array}{l}\text { Interdisciplinary health professional education: a } \\
\text { historical review }\end{array}$ & $\begin{array}{l}\text { Adv health sci educ theory } \\
\text { pract; } 6(1): 25-47,2001\end{array}$ \\
\hline 29 & Lind & Team building & $\begin{array}{l}\text { J health mater } \\
\text { manage; } 12(10): 52,54 ; \text { quiz } \\
56,1994\end{array}$ \\
\hline 30 & Lino & $\begin{array}{l}\text { Hospital de pesquisa e reabilitação de lesões } \\
\text { lábio-palatais - USO - Bauru: trabalho em } \\
\text { equipe: responsabilidade, amor... dando certo há } \\
31 \text { anos }\end{array}$ & $\begin{array}{l}\text { Rev da sociedade brasileira de } \\
\text { psicologia hospitalar;1(1):14- } \\
16,1998\end{array}$ \\
\hline 31 & Lopes & $\begin{array}{l}\text { Modalidades de equipe na assistência à pessoa } \\
\text { especial }\end{array}$ & $\begin{array}{l}\text { Rev baiana } \\
\text { Enfermagem;6(2):103-9,1993 }\end{array}$ \\
\hline 32 & $\begin{array}{l}\text { McNamara, Mak, } \\
\text { Whyte }\end{array}$ & $\begin{array}{l}\text { Dedicated neonatal retrieval teams improve } \\
\text { delivery room ressuscitation of outborn } \\
\text { premature infants }\end{array}$ & J perinatol;25(5):309-14,2005 \\
\hline 33 & $\begin{array}{l}\text { Magalhães, } \\
\text { Tiesenhausen }\end{array}$ & $\begin{array}{l}\text { Interdisciplinaridade e terapia intensiva no } \\
\text { terceiro milênio }\end{array}$ & $\begin{array}{l}\text { Rev med Minas } \\
\text { Gerais;10(1):56-8,2000 }\end{array}$ \\
\hline 34 & Mase & Profissionalism and the health care team & J allied health;4(2):25-32,1975 \\
\hline 35 & Matheus & $\begin{array}{l}\text { O trabalho em equipe: um instrumento básico e } \\
\text { um desafio para a enfermagem }\end{array}$ & Rev EEUSP;29(1):13-25,1995 \\
\hline 36 & Matsuda, Evora & $\begin{array}{l}\text { Gestão da equipe de Enfermagem de uma UTI: a } \\
\text { satisfação profissional em foco }\end{array}$ & $\begin{array}{l}\text { Cienc cuid saúde;2(1):11- } \\
18,2003\end{array}$ \\
\hline 37 & \begin{tabular}{|l|} 
Matumoto, \\
Fortuna, \\
Mishima, Pereira, \\
Domingos \\
\end{tabular} & $\begin{array}{l}\text { Supervisão de equipes no PSF: reflexões acerca } \\
\text { do desafio da produção de cuidados }\end{array}$ & $\begin{array}{l}\text { Interface comum saúde } \\
\text { educ;9(16):9-24,2005 }\end{array}$ \\
\hline 38 & Melo, Tanaka & $\begin{array}{l}\text { Tecnologia virtual e serviços de saúde: impacto } \\
\text { sobre o trabalho em equipe }\end{array}$ & $\begin{array}{l}\text { Rev adm pública;33(1):47- } \\
54,1999\end{array}$ \\
\hline 39 & Mello & $\begin{array}{l}\text { A questão da interdisciplinaridade no dia-a-dia } \\
\text { da enfermeira que atua em centros de atenção } \\
\text { diária de saúde mental }\end{array}$ & $\begin{array}{l}\text { Rev bras } \\
\text { Enfermagem;51(1):19-34,1998 }\end{array}$ \\
\hline 40 & Mishima & $\begin{array}{l}\text { O velho trabalho em equipe pode ganhar cara } \\
\text { nova? Uma perspectiva do trabalho gerencial }\end{array}$ & $\begin{array}{l}\text { Saúde em debate;24(54):66- } \\
74,2000\end{array}$ \\
\hline 41 & \begin{tabular}{|l|} 
Monteiro, \\
Ribeiro, Souza, \\
Serafim
\end{tabular} & Habilidade para trabalhar em equipe & Aletheia;(16):7-14,2002 \\
\hline 42 & \begin{tabular}{|l} 
Moffic, \\
Patterson, Laval, \\
Adams
\end{tabular} & $\begin{array}{l}\text { Paraprofessionals and psychiatric teams: an } \\
\text { update review }\end{array}$ & $\begin{array}{l}\text { Hosp Community } \\
\text { psychiatry;35(1):61-7,1984 }\end{array}$ \\
\hline
\end{tabular}




\begin{tabular}{|c|c|c|c|}
\hline 43 & $\begin{array}{l}\text { Oliveira, Bottaro, } \\
\text { Alessi }\end{array}$ & $\begin{array}{l}\text { A reforma psiquiátrica e o processo de trabalho } \\
\text { das equipes de saúde mental }\end{array}$ & $\begin{array}{l}\text { Rev Paul } \\
\text { Enfermagem;22(1):31-42,2003 }\end{array}$ \\
\hline 44 & Oliveira, Spiri & Psf: a experiência de equipe multiprofissional & $\begin{array}{l}\text { Rev saúde pública;40(4):727- } \\
733,2006\end{array}$ \\
\hline 45 & Peduzzi & $\begin{array}{l}\text { Equipe multiprofissional de saúde: conceito e } \\
\text { tipologia: atualização }\end{array}$ & $\begin{array}{l}\text { Rev saúde pública;35(1):103- } \\
9,2001\end{array}$ \\
\hline 46 & Petersson & $\begin{array}{l}\text { Evolution of team care and evaluation of } \\
\text { effectiveness }\end{array}$ & \begin{tabular}{|l|} 
Curr Opin \\
Rheumatol;17(2):160-3,2005
\end{tabular} \\
\hline 47 & Pimenta & $\begin{array}{l}\text { Atenção básica como eixo estruturante do } \\
\text { sistema local de saúde de Amparo - SP }\end{array}$ & $\begin{array}{l}\text { Divulg saúde debate;(32):36- } \\
45,2005\end{array}$ \\
\hline 48 & Porter & $\begin{array}{l}\text { A psychiatric consultation-liaison service in a } \\
\text { community hospital }\end{array}$ & $\begin{array}{l}\text { Can J psychiatry;33(4):271- } \\
4,1988\end{array}$ \\
\hline 49 & Queiroz Filho & $\begin{array}{l}\text { Reflexões sobre a equipe psiquiátrica. } \\
\text { Sinonímia: Equipe de saúde mental, equipe } \\
\text { psiquiátrica multidisciplinar, equipe de } \\
\text { profissionais de saúde mental }\end{array}$ & $\begin{array}{l}\mathrm{J} \text { bras psiquiatr;42(9):469- } \\
81,1993 \text {, }\end{array}$ \\
\hline 50 & Rabinowitz & $\begin{array}{l}\text { Interdisciplinary breast câncer care: declaring } \\
\text { and improving the standard }\end{array}$ & $\begin{array}{l}\text { Ocology; } 18(10): 1263- \\
8 ; \text { discussion } 1268- \\
70,1275,2004\end{array}$ \\
\hline 51 & Rosa, Labate & $\begin{array}{l}\text { PSF: a construção de um novo modelo de } \\
\text { assistência }\end{array}$ & $\begin{array}{l}\text { Rev latinoam enf;13(6):1027- } \\
1034,2005\end{array}$ \\
\hline 52 & Rosen & The community psychiatrist of the future & $\begin{array}{l}\text { Curr Opin } \\
\text { psychiatry;19(4):380-8,2006 }\end{array}$ \\
\hline 53 & Sadigursky & A enfermeira na equipe de saúde mental & $\begin{array}{l}\text { Rev baiana } \\
\text { Enfermagem;17(3):45-53,2002 }\end{array}$ \\
\hline 54 & $\begin{array}{l}\text { Schull, Ferris, } \\
\text { Tu, Hux, } \\
\text { Redelmeier } \\
\end{array}$ & $\begin{array}{l}\text { Problems for clinical judgement: } 3 \text {. Tking } \\
\text { clearly in emergency }\end{array}$ & CMAJ;164(8):1170-5,2001 \\
\hline 55 & $\begin{array}{l}\text { Schweikhart, } \\
\text { Smith-Daniels }\end{array}$ & $\begin{array}{l}\text { Reengineering the work of caregivers: role } \\
\text { redefinition, team structures, and organizational } \\
\text { redesign }\end{array}$ & $\begin{array}{l}\text { Hosp health serv } \\
\text { adm;41(1):19-36,1996 }\end{array}$ \\
\hline 56 & Sherman & Team nursing revisited & J nurs adm;20(11):43-6,1990 \\
\hline 57 & $\begin{array}{l}\text { Shimizu, } \\
\text { Ciampone }\end{array}$ & $\begin{array}{l}\text { As representações dos técnicos e auxiliares de } \\
\text { Enfermagem acerca do trabalho em equipe na } \\
\text { UTI }\end{array}$ & $\begin{array}{l}\text { Rev latinoam enf;12(4):623- } \\
630,2004\end{array}$ \\
\hline 58 & Silva, Fonseca & $\begin{array}{l}\text { Repensando o trabalho em saúde mental: a } \\
\text { questão da interdisciplinaridade }\end{array}$ & $\begin{array}{l}\text { Rev bras } \\
\text { Enfermagem;48(3):212-7,1995 }\end{array}$ \\
\hline 59 & Silva & $\begin{array}{l}\text { O trabalho em equipe no PSF: investigando a } \\
\text { articulação técnica e a interação entre os } \\
\text { profissionais }\end{array}$ & $\begin{array}{l}\text { Interface comum saúde } \\
\text { educ; } 9(16): 25-38,2005\end{array}$ \\
\hline 60 & $\begin{array}{l}\text { Sladen-Dew, } \\
\text { Bigelow, } \\
\text { Buckely, } \\
\text { Bornemann }\end{array}$ & $\begin{array}{l}\text { The Greater Vancouver Mental Health Service } \\
\text { Society: } 20 \text { years' experience in urban } \\
\text { community mental health }\end{array}$ & $\begin{array}{l}\text { Can J psychiatry;38(5):308- } \\
14,1993\end{array}$ \\
\hline 61 & Spiri, Leite & $\begin{array}{l}\text { O significado do trabalho em equipe na } \\
\text { reabilitação de pessoas com malformação } \\
\text { craniofacial congênita }\end{array}$ & $\begin{array}{l}\text { Revista EEUSP;38(3):288- } \\
97,2004\end{array}$ \\
\hline 62 & Thofehrn, & Teoria dos vínculos profissionais: um novo & Texto \& contexto \\
\hline
\end{tabular}




\begin{tabular}{|c|c|c|c|}
\hline & Leopardi & modo de gestão em enfermagem & $\begin{array}{l}\text { Enfermagem:15(3):409- } \\
17,2006\end{array}$ \\
\hline 63 & Trapp & $\begin{array}{l}\text { Redefining the health care TEAM (together } \\
\text { everyone achieves more) concept }\end{array}$ & Am pharm;NS34(5):5,1994 \\
\hline 64 & & Turning teamwork into a quality car & $\begin{array}{l}\text { Qual left healthc } \\
\text { lead;15(12):2-11,1,2003 }\end{array}$ \\
\hline 65 & $\begin{array}{l}\text { Undre, Sevdalis, } \\
\text { Healey, Darzi, } \\
\text { Vincent }\end{array}$ & $\begin{array}{l}\text { Teamwork in the operating theatre: cohesion or } \\
\text { confusion? }\end{array}$ & $\begin{array}{l}\text { J eval clin pratc; } 12(2): 182- \\
9,2006\end{array}$ \\
\hline 66 & $\begin{array}{l}\text { Van den Berg, } \\
\text { Kalmijm, } \\
\text { Lindeman, } \\
\text { Veldink, de } \\
\text { Visser, Van der } \\
\text { Graaff, Wokke, } \\
\text { Van den Berg }\end{array}$ & $\begin{array}{l}\text { Multidisciplinary ALS care improves quallity of } \\
\text { life in patients with ALS }\end{array}$ & Neurology;65(8):1264-7,2005 \\
\hline 67 & $\begin{array}{l}\text { Vliet, Li, } \\
\text { MacKay, BAdley }\end{array}$ & Does everybody need a team? & J rheumatol;33(9):1897-9,2006 \\
\hline 68 & Waters & $\begin{array}{l}\text { The physician house call of the future - } \\
\text { technology and teamwork }\end{array}$ & Caring;24(8):60-1,2005 \\
\hline 69 & Wiecha, Pollard & $\begin{array}{l}\text { The interdisciplinary eHealth team: chronic care } \\
\text { for the future }\end{array}$ & $\begin{array}{l}\mathrm{J} \text { med internet } \\
\text { res;6(3):e22,2004 }\end{array}$ \\
\hline 70 & Yawm, Geier & $\begin{array}{l}\text { Should a geriatric nurse practitioner become part } \\
\text { of a multispecialty group? }\end{array}$ & Minn Med;78(7):17-21,1995 \\
\hline
\end{tabular}

Sistematização dos resultados

\begin{tabular}{|c|c|c|}
\hline 5 & Bourghuteres & reuniões de equipe são consideradâs, compesoespaço para a "construção de \\
\hline 1 & $\begin{array}{l}\text { Abreu, Munari, } \\
\text { Oueiroz. }\end{array}$ & 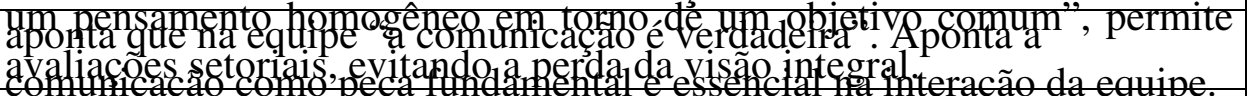 \\
\hline 6 & Brpmunides, 95005 & "As reuniões de equipe foram destacadas como instrumento importante \\
\hline 7 & Camara; 1997 & onale p \\
\hline 8 & Campos; 1998 & 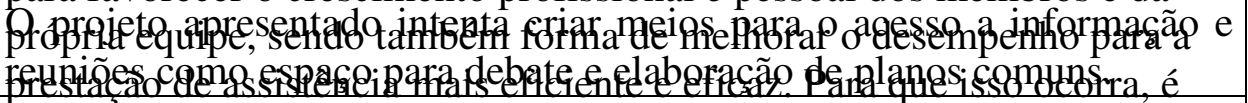 \\
\hline 9 & os; 1999 & fundamental que as reuniões sejam espaços de disc \\
\hline 10 & $\operatorname{mpos}^{2} ; 1992$ & 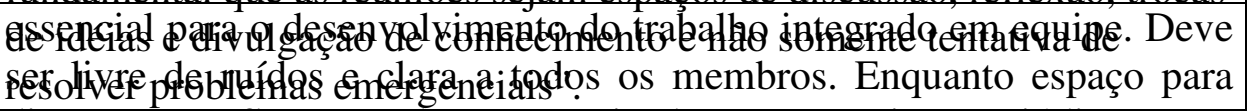 \\
\hline 2 & 005 & discussão e reflexão, pode ser organizada como reuniões periódicas entre \\
\hline 3 & 1984 & pe. Acredita que a comunicação é efetiva quando, após a troca de \\
\hline 4 & Ber & entre as diferien \\
\hline 11 & & periódicas entr \\
\hline
\end{tabular}




\begin{tabular}{|c|c|c|}
\hline 25 & ribary; 2003 & eséimentitcalizada, baseada na liderança de um profissional sobre outros, \\
\hline 12 & Catropa; 1987 & 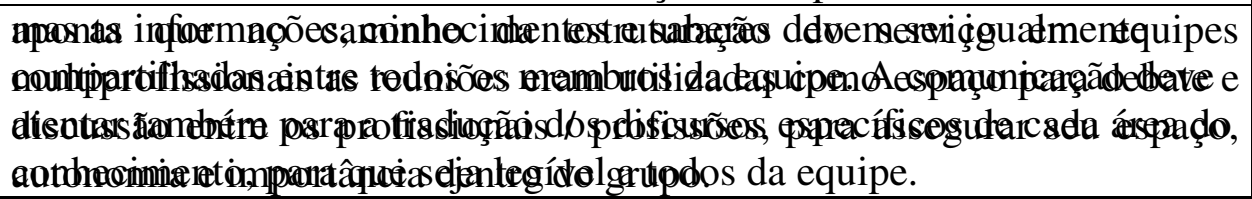 \\
\hline 26) & $\begin{array}{l}\text { Caieaksponfíater, } \\
\text { Reeddberg200atam, } \\
\text { Loftus, Taylor; } \\
1993\end{array}$ & $\begin{array}{l}\text { todo vínculo pressupõe um processo de comunicação; o projeto comum é } \\
\text { planejado e acordado a partir da comunicação dialógica entre os } \\
\text { envolvidos. A comunicação deve ser vista como intrínseca ao trabalho, } \\
\text { sendo a negociação a via de acesso a um projeto comum, questionando- }\end{array}$ \\
\hline 27 & Lassauniere; 1995 & 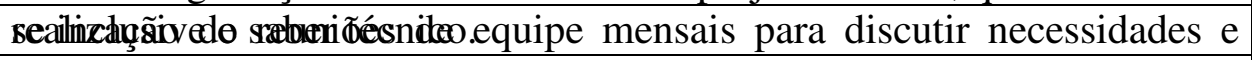 \\
\hline 14 & retikos; 2005 & ologia da info \\
\hline 28 & $\begin{array}{l}\text { Lavin, Ruebling, } \\
\text { Banks, Counte, } \\
\text { Furman, Miller, } \\
\text { Reese, Viehmann, } \\
\text { Holt; } 2001\end{array}$ & $\begin{array}{l}\text { da qualidade da assistência, na resolução de problemas de maneira mais } \\
\text { rápida e eficiente. } \\
\text { A avaliação dos programas de assistência devem incluir, além de bancos } \\
\text { de dados e planilhas, uma boa comunicação e o envolvimento de todos os } \\
\text { membros da equipe. }\end{array}$ \\
\hline 29 & Cinedellig9,42005 & 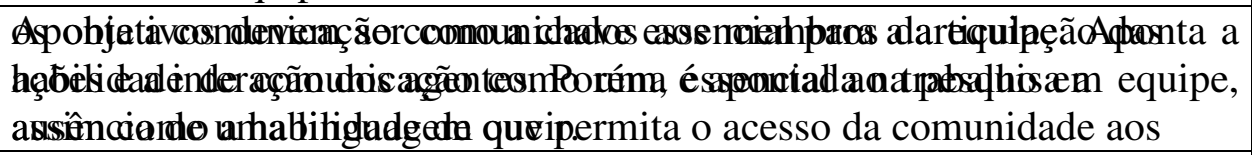 \\
\hline 30 & no; 1998 & assuntos da equipe e seus projetos, fazendo-a distanciar-se das decisões e \\
\hline 31 & 1993 & Om funciona \\
\hline 16 & unha; 2002 & 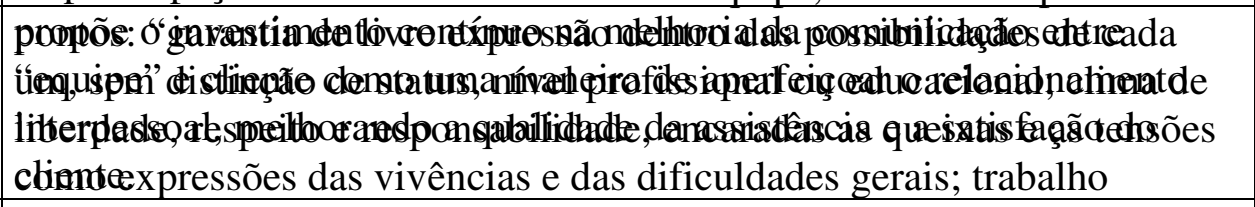 \\
\hline 17 & ; 2003 & objetivando discutir todos os elementos passíveis da realidade, \\
\hline 18 & ; 2004 & oria \\
\hline 19 & $\begin{array}{l}\text { Fiander, Burns, } \\
\text { Ukoumunne, Fahy, } \\
\text { Creed, Tyrer, } \\
\text { Byford; } 2006\end{array}$ & $\begin{array}{l}\text { como compromisso básico para garantia da unidade de ação; interesse no } \\
\text { aperfeiçoamento do trabalho; registros e avaliações sistemáticas das } \\
\text { reuniões e reflexões significativas (que levam a reformulações e novas } \\
\text { direções) do que simples memória". }\end{array}$ \\
\hline 30 & 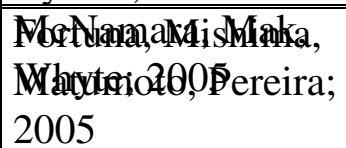 & 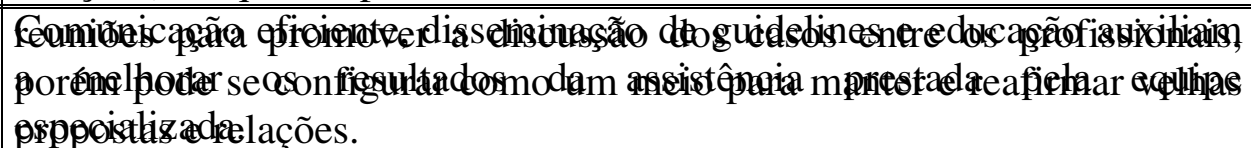 \\
\hline 33 & $\begin{array}{l}\text { Magalhães, } \\
\text { Tiesenhausen; } \\
2000\end{array}$ & $\begin{array}{l}\text { Pode representar um momento de crescimento e troca, quando ocorre de } \\
\text { maneira clara, como também pode representar um momento de paralisia, } \\
\text { quando ocorre em meio a ruídos, paralisando inclusive os processos de }\end{array}$ \\
\hline 34 & Mase; 1975 & apomtdizagemmulentaçãda equipea base do trabalho que busca c \\
\hline 35 & Matheus; 1995 & hgeferticádaslasdmàn \\
\hline 21 & $\begin{array}{l}\text { Gomes, Deslandes; } \\
1994\end{array}$ & $\begin{array}{l}\text { equipe, } \\
\text { ão e }\end{array}$ \\
\hline 22 & $\begin{array}{l}\text { Hadley, Turk, } \\
\text { Vasko, McGurrin; }\end{array}$ & $\begin{array}{l}\text { ho da equipe como um todo, e no desenvolvimento das tarefas } \\
\text { s". }\end{array}$ \\
\hline 36 & MQRষuda, Évora; & - \\
\hline 23 & dexley; 1996 & $8 a$ \\
\hline 37 & & \\
\hline 24 & & \\
\hline
\end{tabular}




\begin{tabular}{|c|c|c|}
\hline 49 & $\begin{array}{l}\text { Bereiiraz IBdhingos; } \\
2993\end{array}$ & - \\
\hline 38 & $\begin{array}{l}\text { Rhedionókraitaka,004 } \\
1999\end{array}$ & $\begin{array}{l}\text { onta a necessidade de reuniões de equipe regulares para planejar a } \\
\text { aliar o trabalho realizado com cada paciente, facilitando o fluxo de }\end{array}$ \\
\hline 39 & Mello; 1998 & 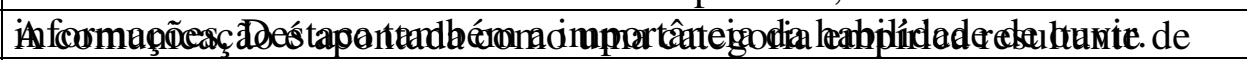 \\
\hline 51 & osa, Labate; 2005 & esquisa de campo do estudo, denominada "discutindo é que se resolvem \\
\hline 52 & osen; 2006 & problemas", e esclarece que "a discussão em equipe como um dos \\
\hline 53 & digursky; 2002 & 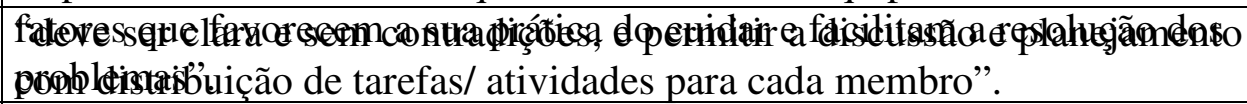 \\
\hline 40 & ishima; 2000 & 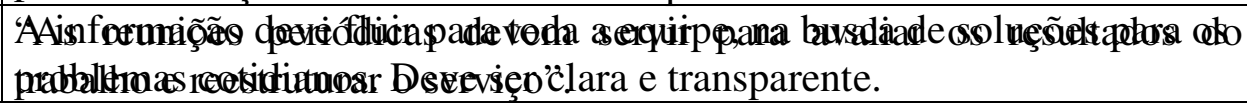 \\
\hline$\$ 4$ & 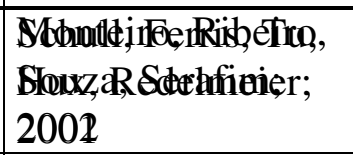 & 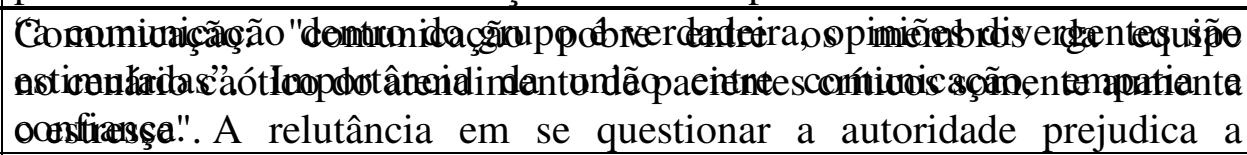 \\
\hline 42 & $\begin{array}{l}\text { Moffic, Patterson, } \\
\text { Laval, Adams; } \\
1984\end{array}$ & $\begin{array}{l}\text { €omunicação entre os membros da equipe. } \\
\text { "Barreiras para comunicar informações cruciais podem resultar, em } \\
\text { parte, da falha dos médicos e demais membros da equipe em ver a si }\end{array}$ \\
\hline 43 & $\begin{array}{l}\text { Oliveira, Bottaro, } \\
\text { Alessi; } 2003\end{array}$ & 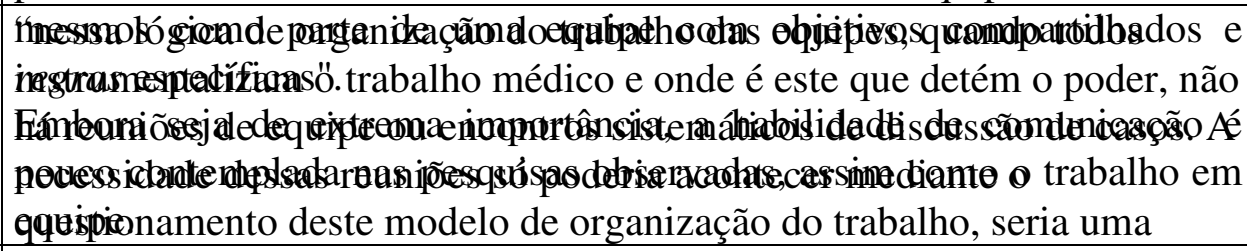 \\
\hline 55 & hweikhs & tentat \\
\hline$\$ 6$ & $\begin{array}{l}\text { OHieremiram;Slp99ic) } \\
2006\end{array}$ & 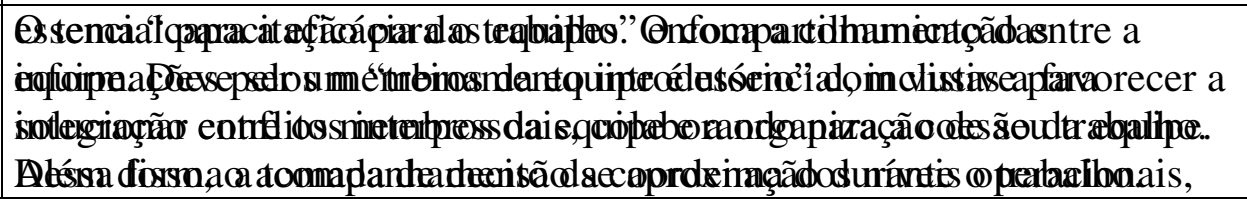 \\
\hline 45 & 01 & 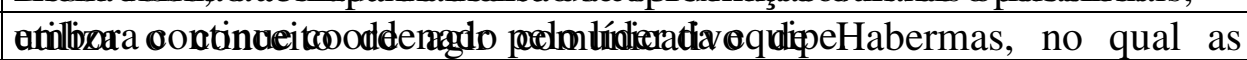 \\
\hline 57 & $\begin{array}{l}\text { Shimizu, } \\
\text { Ciampone; } 200\end{array}$ & 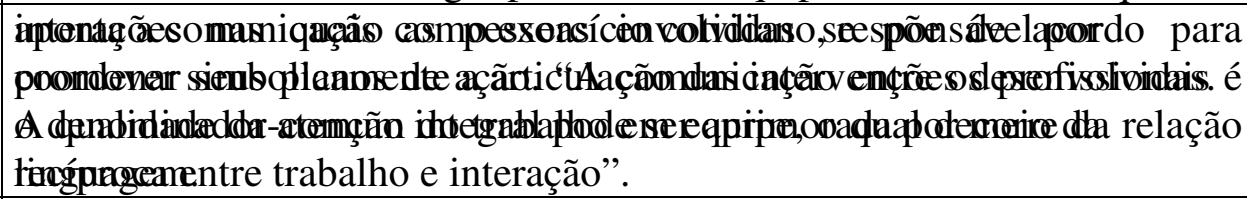 \\
\hline 58 & $\begin{array}{l}\text { Iva, Fon } \\
95\end{array}$ & $\begin{array}{l}\text { Apresenta a comunicação como a "mediação simbólica da linguagem, } \\
\text { por meio da qual se dá a articulação das ações multiprofissionais e a }\end{array}$ \\
\hline 59 & Silva; 2005 & 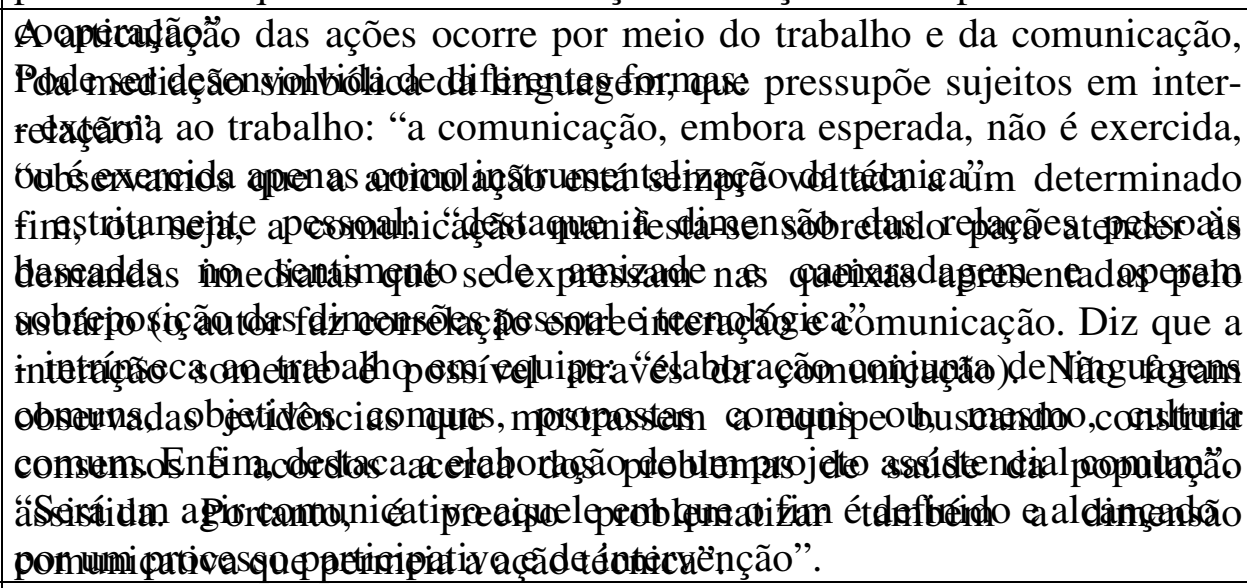 \\
\hline 46 & 05 & As reuniões semanais funcionam mais como um especo para socialização \\
\hline 47 & $\mathrm{me}$ & \\
\hline 48 & Porter; 1988 & elaboração do projeto \\
\hline
\end{tabular}




\begin{tabular}{|c|c|c|}
\hline & & $\begin{array}{l}\text { comunicativa. } \\
\text { O número elevado de profissionais que constituem a equipe se apresenta } \\
\text { como dificultador do processo de comunicação. } \\
\text { "A dimensão comunicativa que permeia a ação, chama a atenção o fato } \\
\text { de que a comunicação no interior da equipe se destine,basicamente, à } \\
\text { troca ou transmissão de informações de caráter técnico, sendo pouco } \\
\text { referidas situações em que se exercite a discussão crítica em torno de } \\
\text { problemas e necessidades da equipe e da população na busca de } \\
\text { consensos coletivos". } \\
\text { As relações de poder constituem-se como um grande dificultador da } \\
\text { comunicação. }\end{array}$ \\
\hline 60 & $\begin{array}{l}\text { Sladen-Dew, } \\
\text { Bigelow, Buckely, } \\
\text { Bornemann; } 1993 \\
\end{array}$ & - \\
\hline 61 & Spiri; 2004 & $\begin{array}{l}\text { "necessidade de comunicação, onde a expressão é fundamental e possível } \\
\text { a partir da linguagem". }\end{array}$ \\
\hline 62 & $\begin{array}{l}\text { Thofehrn, } \\
\text { Leopardi; } 2006\end{array}$ & $\begin{array}{l}\text { as reuniões regulares são apresentadas como espaço positivo de } \\
\text { crescimento social do grupo, favorecendo a criatividade, as descobertas } \\
\text { pessoais e coletivas, minimizando dificuldades. } \\
\text { "A comunicação entre as pessoas é complexa e particular", e ruídos } \\
\text { como insegurança e medo são prejudiciais a comunicação da equipe. A } \\
\text { comunicação positiva, "entendido como a ocorrência de um diálogo } \\
\text { aberto e igualitário, com uma comunicação autêntica e transparente" é } \\
\text { proposta para atenuar adversidades. }\end{array}$ \\
\hline 63 & Trapp & - \\
\hline 64 & 2003 & $\begin{array}{l}\text { apontada como uma das principais características do trabalho em equipe. } \\
\text { A comunicação é a característica responsável por permitir que todos os } \\
\text { membros da equipe estejam na mesma etapa da assistência. }\end{array}$ \\
\hline 65 & $\begin{array}{l}\text { Undre, Sevdalis, } \\
\text { Healey, Darzi, } \\
\text { Vincent; } 2006\end{array}$ & $\begin{array}{l}\text { aponta a equipe como importante estratégia para melhorar a segurança da } \\
\text { assistência, principalmente na sala cirúrgica. Estão envolvidos } \\
\text { anestesistas, cirurgiões e enfermeiros e é nesse cenário que uma } \\
\text { comunicação ineficaz predispõe ao erro humano. Requer interações } \\
\text { interdisciplinares complexas. } \\
\text { Expõe a importância de uma comunicação clara e precisa, sem lacunas, e } \\
\text { sem intimidar os demais profissionais. }\end{array}$ \\
\hline 66 & $\begin{array}{l}\text { Van den Berg, } \\
\text { Kalmijm, } \\
\text { Lindeman, } \\
\text { Veldink, de Visser, } \\
\text { Van der Graaff, } \\
\text { Wokke, Van den } \\
\text { Berg; } 2005\end{array}$ & - \\
\hline 67 & $\begin{array}{l}\text { Vliet, Li, MacKay, } \\
\text { Badley; } 2006\end{array}$ & $\begin{array}{l}\text { A comunicação é facilitada com uma equipe composta de poucas } \\
\text { pessoas. }\end{array}$ \\
\hline 68 & Waters; 2005 & - \\
\hline 69 & $\begin{array}{l}\text { Wiecha, Pollard; } \\
2004\end{array}$ & $\begin{array}{l}\text { O artigo aponta a importância da informação, principalmente com o } \\
\text { advento da internet, que permite o registro, armazenamento e troca de } \\
\text { informações. "Quando as mentes interagem, novas idéias surgem". É } \\
\text { fundamental para o sucesso das equipes interdisciplinares a interação }\end{array}$ \\
\hline
\end{tabular}




\begin{tabular}{|l|l|l|}
\hline & & $\begin{array}{l}\text { entre os diversos profissionais e a compreensão clara da sua estrutura e } \\
\text { funcionamento. }\end{array}$ \\
\hline 70 & Yawm, Geier; & $\begin{array}{l}\text { sugere que a enfermeira torna a comunicação mais clara e fácil; porém a } \\
\text { enfermagem de nível médio aponta como desvantagem a redução da } \\
\text { comunicação direta com o médico. A equipe médica é a menos } \\
\text { entusiasmada com a inclusão da enfermeira, por acreditar que terão mais } \\
\text { um profissional para supervisionar. Alguns, porém, mesmo incertos dos } \\
\text { benefícios, acreditam que a comunicação pode ser melhorada com a } \\
\text { presença da enfermeira na equipe. }\end{array}$ \\
\hline
\end{tabular}

\begin{tabular}{|c|c|c|}
\hline & Autores & Projeto assistencial comum \\
\hline 1 & $\begin{array}{l}\text { Abreu, Munari, } \\
\text { Queiroz, } \\
\text { Fernandes; } 2005\end{array}$ & - \\
\hline 2 & Abuhab; 2005 & $\begin{array}{l}\text { diz-se que a equipe multiprofissional tem o mesmo objetivo, mas com } \\
\text { consegue trabalhar de forma interdisciplinar. } \\
\text { - "a ação não condiz com as discussões da equipe e com os acordos } \\
\text { coletivos, e que existe tensão nas relações entre os profissionais". } \\
\text { - "quando há comunicação e contato mais efetivo entre os membros da } \\
\text { equipe, há melhor evolução da situação do paciente". } \\
\text { Embora exista a preocupação em promover reuniões técnica diárias para } \\
\text { se discutir a abordagem assistencial individualizada, na prática ocorrem } \\
\text { as condutas tomadas individualmente pelos profissionais. }\end{array}$ \\
\hline 3 & Bailey; 1984 & - \\
\hline 4 & $\begin{array}{l}\text { Bertoncello, Silva; } \\
1998\end{array}$ & não há proposta de trabalho claramente definida. \\
\hline 5 & Bourghnet; 2004 & - \\
\hline 6 & Brown; 1995 & - \\
\hline 7 & Camara; 1997 & - \\
\hline 8 & Campos; 1998 & - \\
\hline 9 & Campos; 1999 & $\begin{array}{l}\text { A equipe multiprofissional de referência é responsável por elaborar um } \\
\text { projeto assistencial individual para as pessoas sob sua responsabilidade, } \\
\text { de acordo com a característica de cada caso, e a disponibilidade de } \\
\text { recursos e tempo. }\end{array}$ \\
\hline 10 & Campos $^{2} ; 1992$ & - \\
\hline 11 & Campos $^{2} ; 1988$ & - \\
\hline 12 & Catropa; 1987 & - \\
\hline 13 & $\begin{array}{l}\text { Ciampone, } \\
\text { Peduzzi; } 2000\end{array}$ & $\begin{array}{l}\text { decorrente do processo comunicativo e da interação entre os agentes que } \\
\text { compõe a equipe. }\end{array}$ \\
\hline 14 & Cretikos; 2005 & - \\
\hline
\end{tabular}




\begin{tabular}{|c|c|c|}
\hline 15 & Crevelim; 2005 & $\begin{array}{l}\text { embora deixe claro a importância do projeto assistencial comum ser } \\
\text { elaborado pela equipe e pela comunidade, aponta para o fato de que a } \\
\text { comunidade é apenas comunicada do projeto, sendo este o maior desafio } \\
\text { do trabalho entre equipe e usuários. }\end{array}$ \\
\hline 16 & Cunha; 2002 & - \\
\hline 17 & Faustino; 2003 & - \\
\hline 18 & Faustino; 2004 & - \\
\hline 19 & $\begin{array}{l}\text { Fiander, Burns, } \\
\text { Ukoumunne, Fahy, } \\
\text { Creed, Tyrer, } \\
\text { Byford; } 2006\end{array}$ & - \\
\hline 20 & $\begin{array}{l}\text { Fortuna, Mishima, } \\
\text { Matumoto, Pereira; } \\
2005\end{array}$ & - \\
\hline 21 & $\begin{array}{l}\text { Gomes, Deslandes; } \\
1994\end{array}$ & - \\
\hline 22 & $\begin{array}{l}\text { Hadley, Turk, } \\
\text { Vasko, McGurrin; } \\
1997\end{array}$ & $\begin{array}{l}\text { a equipe funciona como uma unidade integrada, na qual todos os } \\
\text { membros conhecem e se preocupam com as necessidades dos } \\
\text { consumidores de seus serviços. }\end{array}$ \\
\hline 23 & Hockley; 1996 & 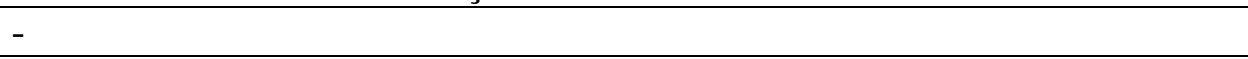 \\
\hline 24 & 2005 & - \\
\hline 25 & Irribary; 2003 & - \\
\hline 26 & $\begin{array}{l}\text { Jackson, Gater, } \\
\text { Goldberg, Tantam, } \\
\text { Loftus, Taylor; } \\
1993\end{array}$ & $\begin{array}{l}\text { A equipe discute entre si e elabora um plano assistencial comum, } \\
\text { aprovado pelo psiquiatra. }\end{array}$ \\
\hline 27 & Lassauniere; 1995 & - \\
\hline 28 & $\begin{array}{l}\text { Lavin, Ruebling, } \\
\text { Banks, Counte, } \\
\text { Furman, Miller, } \\
\text { Reese, Viehmann, } \\
\text { Holt; } 2001\end{array}$ & - \\
\hline 29 & Lind; 1994 & - \\
\hline 30 & Lino; 1998 & $\begin{array}{l}\text { sugere que os diversos profissionais elaboram o plano assistencial e cada } \\
\text { qual, a seu tempo, executa seu trabalho, de maneira que ao final, a } \\
\text { assistência tenha sido completa e o resultado o mais satisfatório possível. }\end{array}$ \\
\hline 31 & Lopes; 1993 & - \\
\hline 32 & \begin{tabular}{|l} 
McNamara, Mak, \\
Whyte; 2005
\end{tabular} & - \\
\hline 33 & $\begin{array}{l}\text { Magalhães, } \\
\text { Tiesenhausen; } \\
2000\end{array}$ & - \\
\hline 34 & Mase; 1975 & - \\
\hline 35 & Matheus; 1995 & - \\
\hline 36 & $\begin{array}{l}\text { Matsuda, Évora; } \\
2003\end{array}$ & - \\
\hline 37 & $\begin{array}{l}\text { Matumoto, } \\
\text { Fortuna, Mishima, }\end{array}$ & $\begin{array}{l}\text { a equipe tem a necessidade de conhecer e explicitar os contratos } \\
\text { formados - entre a supervisão e a equipe, e entre a equipe e os usuários - }\end{array}$ \\
\hline
\end{tabular}




\begin{tabular}{|c|c|c|}
\hline & $\begin{array}{l}\text { Pereira, Domingos; } \\
2005\end{array}$ & para elaborar de maneira efetiva o contrato terapêutico. \\
\hline 38 & $\begin{array}{l}\text { Melo, Tanaka; } \\
1999\end{array}$ & - \\
\hline 39 & Mello; 1998 & $\begin{array}{l}\text { relata que é apenas através das discussões em equipe, onde todos pensam } \\
\text { juntos, que é possível elaborar um projeto assistencial comum. }\end{array}$ \\
\hline 40 & Mishima; 2000 & - \\
\hline 41 & $\begin{array}{l}\text { Monteiro, Ribeiro, } \\
\text { Souza, Serafim; } \\
2002\end{array}$ & - \\
\hline 42 & $\begin{array}{l}\text { Moffic, Patterson, } \\
\text { Laval, Adams; } \\
1984\end{array}$ & - \\
\hline 43 & $\begin{array}{l}\text { Oliveira, Bottaro, } \\
\text { Alessi; } 2003\end{array}$ & - \\
\hline 44 & $\begin{array}{l}\text { Oliveira, Spiri; } \\
2006\end{array}$ & $\begin{array}{l}\text { "A integração entre os membros da equipe permite que os profissionais } \\
\text { troquem informações relacionadas aos pacientes para tomar a conduta } \\
\text { adequada de acordo com cada necessidade identificada pela equipe". }\end{array}$ \\
\hline 45 & Peduzzi; 2001 & $\begin{array}{l}\text { a elaboração de um projeto assistencial comum é o sinalizador de } \\
\text { integração da equipe. Dentro de um leque de condutas possíveis, os } \\
\text { membros da equipe se colocam em acordo sobre quais serão utilizados } \\
\text { para atender a demanda. "É por meio dessa prática comunicativa, } \\
\text { caracterizada pela busca de consensos, que os profissionais podem argüir } \\
\text { mutuamente o trabalho cotidiano executado e construir um projeto } \\
\text { comum, pertinente às necessidades de saúde dos usuários, além de } \\
\text { reiterar o projeto técnico já dado, no que se fizer necessário". }\end{array}$ \\
\hline 46 & Petersson; 2005 & - \\
\hline 47 & Pimenta; 2005 & - \\
\hline 48 & Porter; 1988 & - \\
\hline 49 & $\begin{array}{l}\text { Queiroz Filho; } \\
1993\end{array}$ & - \\
\hline 50 & Rabinowitz; 2004 & $\begin{array}{l}\text { o planejamento comum está no coração do trabalho em equipe } \\
\text { interdisciplinar, promovendo a discussão das bases para o planejamento } \\
\text { da assistência de cada paciente de maneira individual, por todos os } \\
\text { membros da equipe. }\end{array}$ \\
\hline 51 & Rosa, Labate; 2005 & - \\
\hline 52 & Rosen; 2006 & - \\
\hline 53 & Sadigursky; 2002 & A equipe transdisciplinar deve ter um "objetivo único". \\
\hline 54 & $\begin{array}{l}\text { Schull, Ferris, Tu, } \\
\text { Hux, Redelmeier; } \\
2001\end{array}$ & - \\
\hline 55 & $\begin{array}{l}\text { Schweikhart, } \\
\text { Smith-Daniels; } \\
1996\end{array}$ & - \\
\hline 56 & Sherman; 1990 & - \\
\hline 57 & $\begin{array}{l}\text { Shimizu, } \\
\text { Ciampone; } 2004\end{array}$ & $\begin{array}{l}\text { percebe que na instituição pesquisada não há a preocupação na } \\
\text { elaboração de um plano assistencial comum. }\end{array}$ \\
\hline 58 & Silva, Fonseca; & - \\
\hline
\end{tabular}




\begin{tabular}{|c|c|c|}
\hline & 1995 & \\
\hline 59 & Silva; 2005 & $\begin{array}{l}\text { A interação é entendida no artigo como a "construção de consensos", que } \\
\text { mediada pela comunicação auxilia os profissionais na busca e construção } \\
\text { de um projeto assistencial comum, que seja pertinente às demandas dos } \\
\text { usuários. } \\
\text { Apresenta como dificultador na elaboração do projeto assistencial } \\
\text { comum a sobrecarga de trabalho dos profissionais. } \\
\text { São apontados como facilitadores do projeto assistencial comum: } \\
\text { "flexibilização da divisão do trabalho, uma vez que, além das ações } \\
\text { específicas os profissionais também participam de ações comuns a outros } \\
\text { membros da equipe; a partilha de decisões de problemas relacionados à } \\
\text { dinâmica da unidade". }\end{array}$ \\
\hline 60 & $\begin{array}{l}\text { Sladen-Dew, } \\
\text { Bigelow, Buckely, } \\
\text { Bornemann; } 1993 \\
\end{array}$ & - \\
\hline 61 & Spiri; 2004 & - \\
\hline 62 & $\begin{array}{l}\text { Thofehrn, } \\
\text { Leopardi; } 2006\end{array}$ & - \\
\hline 63 & Trapp; 1994 & - \\
\hline 64 & 2003 & - \\
\hline 65 & $\begin{array}{l}\text { Undre, Sevdalis, } \\
\text { Healey, Darzi, } \\
\text { Vincent; } 2006 \\
\end{array}$ & - \\
\hline 66 & $\begin{array}{l}\text { Van den Berg, } \\
\text { Kalmijm, } \\
\text { Lindeman, } \\
\text { Veldink, de Visser, } \\
\text { Van der Graaff, } \\
\text { Wokke, Van den } \\
\text { Berg; 2005 }\end{array}$ & - \\
\hline 67 & $\begin{array}{l}\text { Vliet, Li, MacKay, } \\
\text { Badley; } 2006\end{array}$ & - \\
\hline 68 & Waters; 2005 & - \\
\hline 69 & $\begin{array}{l}\text { Wiecha, Pollard; } \\
2004\end{array}$ & - \\
\hline 70 & $\begin{array}{l}\text { Yawm, Geier; } \\
1995\end{array}$ & - \\
\hline
\end{tabular}




\begin{tabular}{|c|l|l|}
\hline \multicolumn{1}{|c|}{ Autores } & \multicolumn{1}{c|}{ Especificidade dos trabalhos especializados } \\
\hline 1 & $\begin{array}{l}\text { Abreu, Munari, } \\
\text { Fueiroz, }\end{array}$ & - \\
\hline 2 & Abuhab; 2005 & $\begin{array}{l}\text { necessidade de olhares diversos sobre a mesma questão. Porém, fica } \\
\text { claro que a maior dificuldade do trabalho em equipe é a articulação e } \\
\text { interação dos diferentes profissionais "devido ao fato de cada } \\
\text { profissional manter-se nas suas especificidades, isolado na realização ou } \\
\text { no cumprimento de tarefas". }\end{array}$ \\
\hline 3 & Bailey; 1984 & - \\
\hline 4 & $\begin{array}{l}\text { Bertoncello, Silva; } \\
1998\end{array}$ & - \\
\hline 5 & Bourghnet; 2004 & - \\
\hline 6 & Brown; 1995 & - \\
\hline 7 & Camara; 1997 & - \\
\hline 8 & Campos; 1998 & - \\
\hline 9 & Campos; 1999 & $\begin{array}{l}\text { as equipes de referência contam com o suporte do apoio matricial; dessa } \\
\text { forma, atende-se a atenção integral a saúde e a re-composição dos } \\
\text { trabalhos especializados segundo sua especificidade técnica. }\end{array}$ \\
\hline 10 & Campos ${ }^{2} ; 1992$ & - \\
\hline 11 & Campos $; 1988$ & - \\
\hline 12 & Catropa; 1987 & $\begin{array}{l}\text { resgatando as especificidades de cada profissão é possível prestar } \\
\text { assistência integral. }\end{array}$ \\
\hline 13 & $\begin{array}{l}\text { Ciampone, } \\
\text { Peduzzi; } 2000\end{array}$ & $\begin{array}{l}\text { "a articulação refere-se a recomposição de processos de trabalhos } \\
\text { distintos, e portanto, a consideração das conexões e interfaces existentes } \\
\text { entre as intervenções técnicas peculiares de cada área profissional, bem } \\
\text { como a preservação das respectivas especificidades". Preservar } \\
\text { diferenças técnicas e flexibilizar fronteiras. }\end{array}$ \\
\hline 15 & Crevelim; 2005 & - \\
\hline 16 & Cunha; 2002 & - \\
\hline
\end{tabular}




\begin{tabular}{|c|c|c|}
\hline 17 & Faustino; 2003 & - \\
\hline 18 & Faustino; 2004 & - \\
\hline 19 & $\begin{array}{l}\text { Fiander, Burns, } \\
\text { Ukoumunne, Fahy, } \\
\text { Creed, Tyrer, } \\
\text { Byford; } 2006\end{array}$ & - \\
\hline 20 & $\begin{array}{l}\text { Fortuna, Mishima, } \\
\text { Matumoto, Pereira; } \\
2005\end{array}$ & - \\
\hline 21 & $\begin{array}{l}\text { Gomes, Deslandes; } \\
1994\end{array}$ & $\begin{array}{l}\text { a interdisciplinaridade busca a integração dos trabalhos especializados, } \\
\text { entendendo, porém, que não se pode negar a importância da } \\
\text { especialização, mas algumas questões complexas exigem olhares que } \\
\text { contemplem diversos recortes. }\end{array}$ \\
\hline 22 & $\begin{array}{l}\text { Hadley, Turk, } \\
\text { Vasko, McGurrin; } \\
1997\end{array}$ & - \\
\hline 23 & Hockley; 1996 & - \\
\hline 24 & 2005 & - \\
\hline 25 & Irribary; 2003 & $\begin{array}{l}\text { É preciso que haja interação entre as disciplinas, "cada profissional } \\
\text { descubra um interesse e uma curiosidade pela área de seu colega". }\end{array}$ \\
\hline 26 & $\begin{array}{l}\text { Jackson, Gater, } \\
\text { Goldberg, Tantam, } \\
\text { Loftus, Taylor; } \\
1993 \\
\end{array}$ & - \\
\hline 27 & Lassauniere; 1995 & - \\
\hline 28 & $\begin{array}{l}\text { Lavin, Ruebling, } \\
\text { Banks, Counte, } \\
\text { Furman, Miller, } \\
\text { Reese, Viehmann, } \\
\text { Holt; } 2001\end{array}$ & - \\
\hline 29 & Lind; 1994 & $\begin{array}{l}\text { a principal força do trabalho em equipe é a variedade das habilidades de } \\
\text { seus membros. }\end{array}$ \\
\hline 30 & Lino; 1998 & - \\
\hline 31 & Lopes; 1993 & - \\
\hline 32 & $\begin{array}{l}\text { McNamara, Mak, } \\
\text { Whyte; } 2005\end{array}$ & - \\
\hline 33 & $\begin{array}{l}\text { Magalhães, } \\
\text { Tiesenhausen; } \\
2000\end{array}$ & - \\
\hline 34 & Mase; 1975 & $\begin{array}{l}\text { o autor aponta o trabalho em equipe como uma alternativa frente à hiper- } \\
\text { especialização da assistência à saúde, diz que os próprios profissionais } \\
\text { estão percebendo essa alternativa, na medida em que passaram a discutir } \\
\text { propostas comuns e uma linguagem comum. }\end{array}$ \\
\hline 35 & Matheus; 1995 & - \\
\hline 36 & $\begin{array}{l}\text { Matsuda, Évora; } \\
2003\end{array}$ & - \\
\hline 37 & $\begin{array}{l}\text { Matumoto, } \\
\text { Fortuna, Mishima, }\end{array}$ & - \\
\hline
\end{tabular}




\begin{tabular}{|c|c|c|}
\hline & $\begin{array}{l}\text { Pereira, Domingos; } \\
2005\end{array}$ & \\
\hline 38 & $\begin{array}{l}\text { Melo, Tanaka; } \\
1999\end{array}$ & - \\
\hline 39 & Mello; 1998 & $\begin{array}{l}\text { A legislação assegura que o atendimento seja integral, a partir das } \\
\text { equipes interdisciplinares. }\end{array}$ \\
\hline 40 & Mishima; 2000 & - \\
\hline 41 & $\begin{array}{l}\text { Monteiro, Ribeiro, } \\
\text { Souza, Serafim; } \\
2002\end{array}$ & - \\
\hline 42 & $\begin{array}{l}\text { Moffic, Patterson, } \\
\text { Laval, Adams; } \\
1984\end{array}$ & - \\
\hline 43 & $\begin{array}{l}\text { Oliveira, Bottaro, } \\
\text { Alessi; } 2003\end{array}$ & - \\
\hline 44 & $\begin{array}{l}\text { Oliveira, Spiri; } \\
2006\end{array}$ & - \\
\hline 45 & Peduzzi; 2001 & - \\
\hline 46 & Petersson; 2005 & - \\
\hline 47 & Pimenta; 2005 & - \\
\hline 48 & Porter; 1988 & - \\
\hline 49 & $\begin{array}{l}\text { Queiroz Filho; } \\
1993\end{array}$ & - \\
\hline 50 & Rabinowitz; 2004 & - \\
\hline 51 & Rosa, Labate; 2005 & - \\
\hline 52 & Rosen; 2006 & - \\
\hline 53 & Sadigursky; 2002 & - \\
\hline 54 & $\begin{array}{l}\text { Schull, Ferris, Tu, } \\
\text { Hux, Redelmeier; } \\
2001\end{array}$ & - \\
\hline 55 & $\begin{array}{l}\text { Schweikhart, } \\
\text { Smith-Daniels; } \\
1996\end{array}$ & - \\
\hline 56 & Sherman; 1990 & - \\
\hline 57 & $\begin{array}{l}\text { Shimizu, } \\
\text { Ciampone; } 2004\end{array}$ & - \\
\hline 58 & $\begin{array}{l}\text { Silva, Fonseca; } \\
1995\end{array}$ & - \\
\hline 59 & Silva; 2005 & $\begin{array}{l}\text { A equipe traz a possibilidade de se recompor os trabalhos especializados, } \\
\text { seja numa mesma área profissional, seja nas relações interprofissionais. }\end{array}$ \\
\hline 60 & $\begin{array}{l}\text { Sladen-Dew, } \\
\text { Bigelow, Buckely, } \\
\text { Bornemann; } 1993\end{array}$ & - \\
\hline 61 & Spiri; 2004 & - \\
\hline 62 & $\begin{array}{l}\text { Thofehrn, } \\
\text { Leopardi; } 2006\end{array}$ & - \\
\hline 63 & Trapp; 1994 & - \\
\hline 64 & 2003 & - \\
\hline
\end{tabular}




\begin{tabular}{|c|c|c|}
\hline 65 & $\begin{array}{l}\text { Undre, Sevdalis, } \\
\text { Healey, Darzi, } \\
\text { Vincent; } 2006 \\
\end{array}$ & - \\
\hline 66 & $\begin{array}{l}\text { Van den Berg, } \\
\text { Kalmijm, } \\
\text { Lindeman, } \\
\text { Veldink, de Visser, } \\
\text { Van der Graaff, } \\
\text { Wokke, Van den } \\
\text { Berg; 2005 }\end{array}$ & - \\
\hline 67 & $\begin{array}{l}\text { Vliet, Li, MacKay, } \\
\text { Badley; } 2006\end{array}$ & - \\
\hline 68 & Waters; 2005 & - \\
\hline 69 & $\begin{array}{l}\text { Wiecha, Pollard; } \\
2004\end{array}$ & - \\
\hline 70 & $\begin{array}{l}\text { Yawm, Geier; } \\
1995\end{array}$ & - \\
\hline & Autores & Flexibilização da divisão do trabalho \\
\hline 1 & $\begin{array}{l}\text { Abreu, Munari, } \\
\text { Queiroz, } \\
\text { Fernandes; } 2005\end{array}$ & - \\
\hline 2 & Abuhab; 2005 & - \\
\hline 3 & Bailey; 1984 & - \\
\hline 4 & $\begin{array}{l}\text { Bertoncello, Silva; } \\
1998\end{array}$ & - \\
\hline 5 & Bourghnet; 2004 & - \\
\hline 6 & Brown; 1995 & - \\
\hline 7 & Camara; 1997 & - \\
\hline 8 & Campos; 1998 & - \\
\hline 9 & Campos; 1999 & - \\
\hline 10 & Campos $^{2} ; 1992$ & - \\
\hline 11 & Campos $^{2} ; 1988$ & - \\
\hline 12 & Catropa; 1987 & - \\
\hline 13 & \begin{tabular}{|l|} 
Ciampone, \\
Peduzzi; 2000 \\
\end{tabular} & - \\
\hline 14 & Cretikos; 2005 & - \\
\hline 15 & Crevelim; 2005 & - \\
\hline 16 & Cunha; 2002 & - \\
\hline 17 & Faustino; 2003 & - \\
\hline 18 & Faustino; 2004 & - \\
\hline 19 & $\begin{array}{l}\text { Fiander, Burns, } \\
\text { Ukoumunne, Fahy, } \\
\text { Creed, Tyrer, } \\
\text { Byford; } 2006\end{array}$ & - \\
\hline 20 & $\begin{array}{l}\text { Fortuna, Mishima, } \\
\text { Matumoto, Pereira; } \\
2005\end{array}$ & $\begin{array}{l}\text { o trabalho em saúde deve ser dividido, pois cada profissional possui um } \\
\text { saber específico pertinente a sua formação. }\end{array}$ \\
\hline 21 & Gomes, Deslandes; & - \\
\hline
\end{tabular}




\begin{tabular}{|c|c|c|}
\hline & 1994 & \\
\hline 22 & $\begin{array}{l}\text { Hadley, Turk, } \\
\text { Vasko, McGurrin; } \\
1997\end{array}$ & - \\
\hline 23 & Hockley; 1996 & - \\
\hline 24 & 2005 & - \\
\hline 25 & Irribary; 2003 & - \\
\hline 26 & $\begin{array}{l}\text { Jackson, Gater, } \\
\text { Goldberg, Tantam, } \\
\text { Loftus, Taylor; } \\
1993\end{array}$ & - \\
\hline 27 & Lassauniere; 1995 & - \\
\hline 28 & $\begin{array}{l}\text { Lavin, Ruebling, } \\
\text { Banks, Counte, } \\
\text { Furman, Miller, } \\
\text { Reese, Viehmann, } \\
\text { Holt; } 2001\end{array}$ & - \\
\hline 29 & Lind; 1994 & - \\
\hline 30 & Lino; 1998 & - \\
\hline 31 & Lopes; 1993 & - \\
\hline 32 & $\begin{array}{l}\text { McNamara, Mak, } \\
\text { Whyte; } 2005\end{array}$ & - \\
\hline 33 & $\begin{array}{l}\text { Magalhães, } \\
\text { Tiesenhausen; } \\
2000\end{array}$ & - \\
\hline 34 & Mase; 1975 & - \\
\hline 35 & Matheus; 1995 & - \\
\hline 36 & $\begin{array}{l}\text { Matsuda, Évora; } \\
2003\end{array}$ & - \\
\hline 37 & $\begin{array}{l}\text { Matumoto, } \\
\text { Fortuna, Mishima, } \\
\text { Pereira, Domingos; } \\
2005\end{array}$ & - \\
\hline 38 & $\begin{array}{l}\text { Melo, Tanaka; } \\
1999\end{array}$ & - \\
\hline \begin{tabular}{|l|}
39 \\
\end{tabular} & Mello; 1998 & - \\
\hline 40 & Mishima; 2000 & $\begin{array}{l}\text { aponta a divisão técnica e social do trabalho como condição condenável, } \\
\text { na medida em que gera a alienação do trabalhador. }\end{array}$ \\
\hline 41 & $\begin{array}{l}\text { Monteiro, Ribeiro, } \\
\text { Souza, Serafim; } \\
2002\end{array}$ & - \\
\hline 42 & $\begin{array}{l}\text { Moffic, Patterson, } \\
\text { Laval, Adams; } \\
1984\end{array}$ & - \\
\hline 43 & $\begin{array}{l}\text { Oliveira, Bottaro, } \\
\text { Alessi; } 2003\end{array}$ & - \\
\hline 44 & $\begin{array}{l}\text { Oliveira, Spiri; } \\
2006\end{array}$ & - \\
\hline
\end{tabular}




\begin{tabular}{|c|c|c|}
\hline 45 & Peduzzi; 2001 & $\begin{array}{l}\text { "flexibilidade foi entendida como a coexistência de ações privativas das } \\
\text { respectivas áreas profissionais e ações que são executadas, } \\
\text { indistintamente, por agentes de diferentes campos de atuação". "A } \\
\text { flexibilidade convive com as especificidades de cada área profissional"- } \\
\text { borrar as fronteiras. A equipe integração está mais próxima da } \\
\text { flexibilidade da divisão do trabalho. }\end{array}$ \\
\hline 46 & Petersson; 2005 & equipes mais flexíveis atendem melhor às mudanças e demandas. \\
\hline 47 & Pimenta; 2005 & - \\
\hline 48 & Porter; 1988 & - \\
\hline 49 & $\begin{array}{l}\text { Queiroz Filho; } \\
1993\end{array}$ & - \\
\hline 50 & Rabinowitz; 2004 & - \\
\hline 51 & Rosa, Labate; 2005 & - \\
\hline 52 & Rosen; 2006 & - \\
\hline 53 & Sadigursky; 2002 & - \\
\hline 54 & $\begin{array}{l}\text { Schull, Ferris, Tu, } \\
\text { Hux, Redelmeier; } \\
2001\end{array}$ & - \\
\hline 55 & $\begin{array}{l}\text { Schweikhart, } \\
\text { Smith-Daniels; } \\
1996 \\
\end{array}$ & - \\
\hline 56 & Sherman; 1990 & - \\
\hline 57 & $\begin{array}{l}\text { Shimizu, } \\
\text { Ciampone; } 2004\end{array}$ & - \\
\hline 58 & $\begin{array}{l}\text { Silva, Fonseca; } \\
1995\end{array}$ & - \\
\hline 59 & Silva; 2005 & $\begin{array}{l}\text { A divisão técnica e social do trabalho acaba por gerar dificuldades na } \\
\text { interação e atenção integral, assim como a hierarquia. Nem todos os } \\
\text { membros opinam durante o planejamento, o que prejudica o projeto } \\
\text { comum. }\end{array}$ \\
\hline 60 & $\begin{array}{l}\text { Sladen-Dew, } \\
\text { Bigelow, Buckely, } \\
\text { Bornemann; } 1993 \\
\end{array}$ & - \\
\hline 61 & Spiri; 2004 & $\begin{array}{l}\text { aponta a divisão social do trabalho intelectual e manual, principalmente } \\
\text { entre medicina e enfermagem. Apresenta que os trabalhadores partem de } \\
\text { uma "escala social que tem valor agregado" na divisão social do } \\
\text { trabalho, na qual os trabalhos mais simples são menos valorizados. }\end{array}$ \\
\hline 62 & $\begin{array}{l}\text { Thofehrn, } \\
\text { Leopardi; } 2006\end{array}$ & $\begin{array}{l}\text { aponta a importância da divisão do trabalho em enfermagem, sem perder } \\
\text { de vista a sua flexibilidade. }\end{array}$ \\
\hline 63 & Trapp; 1994 & - \\
\hline 64 & 2003 & - \\
\hline 65 & $\begin{array}{l}\text { Undre, Sevdalis, } \\
\text { Healey, Darzi, } \\
\text { Vincent; } 2006 \\
\end{array}$ & - \\
\hline 66 & $\begin{array}{l}\text { Van den Berg, } \\
\text { Kalmijm, } \\
\text { Lindeman, } \\
\text { Veldink, de Visser, }\end{array}$ & - \\
\hline
\end{tabular}




\begin{tabular}{|l|l|l|}
\hline & $\begin{array}{l}\text { Van der Graaff, } \\
\text { Wokke, Van den } \\
\text { Berg; 2005 }\end{array}$ & \\
\hline 67 & $\begin{array}{l}\text { Vliet, Li, MacKay, } \\
\text { Badley; 2006 }\end{array}$ & - \\
\hline 68 & Waters; 2005 & - \\
\hline 69 & $\begin{array}{l}\text { Wiecha, Pollard; } \\
2004\end{array}$ & - \\
\hline 70 & $\begin{array}{l}\text { Yawm, Geier; } \\
1995\end{array}$ & - \\
\hline
\end{tabular}

\begin{tabular}{|c|c|c|}
\hline & Autores & Autonomia profissional \\
\hline 1 & $\begin{array}{l}\text { Abreu, Munari, } \\
\text { Queiroz, } \\
\text { Fernandes; } 2005\end{array}$ & - \\
\hline 2 & Abuhab; 2005 & $\begin{array}{l}\text { diz-se da hegemonia do trabalho médico como dificultador do trabalho } \\
\text { em equipe. }\end{array}$ \\
\hline 3 & Bailey; 1984 & - \\
\hline 4 & $\begin{array}{l}\text { Bertoncello, Silva; } \\
1998\end{array}$ & - \\
\hline 5 & Bourghnet; 2004 & $\begin{array}{l}\text { "a técnica a ser utilizada é de domínio do profissional, mas de } \\
\text { conhecimento de todos e a tática de abordagem de cada paciente é } \\
\text { elaborada pela equipe. }\end{array}$ \\
\hline 6 & Brown; 1995 & 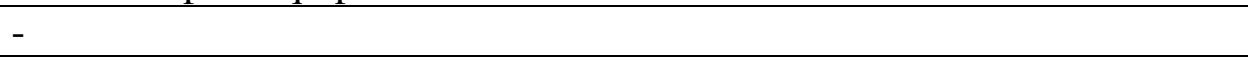 \\
\hline 7 & Camara; 1997 & - \\
\hline 8 & Campos; 1998 & A autonomia é sempre parcial, assim como a liberdade. \\
\hline 9 & Campos; 1999 & $\begin{array}{l}\text { O sistema de equipes de referência e apoio matricial valorizam a } \\
\text { autonomia das diferentes profissões, uma vez que cada qual entra no } \\
\text { projeto da equipe de referência para atender particularidades específicas } \\
\text { de sua área de atuação. }\end{array}$ \\
\hline 10 & Campos $^{2} ; 1992$ & - \\
\hline 11 & Campos $^{2} ; 1988$ & - \\
\hline 12 & Catropa; 1987 & "Na equipe acaba se diluindo o que seria peculiar a cada profissão". \\
\hline 13 & \begin{tabular}{|l|} 
Ciampone, \\
Peduzzi; 2000 \\
\end{tabular} & - \\
\hline 14 & Cretikos; 2005 & - \\
\hline 15 & Crevelim; 2005 & - \\
\hline 16 & Cunha; 2002 & - \\
\hline 17 & Faustino; 2003 & - \\
\hline 18 & Faustino; 2004 & - \\
\hline 19 & Fiander, Burns, & - \\
\hline
\end{tabular}




\begin{tabular}{|c|c|c|}
\hline & $\begin{array}{l}\text { Ukoumunne, Fahy, } \\
\text { Creed, Tyrer, } \\
\text { Byford; } 2006\end{array}$ & \\
\hline 20 & $\begin{array}{l}\text { Fortuna, Mishima, } \\
\text { Matumoto, Pereira; } \\
2005\end{array}$ & - \\
\hline 21 & $\begin{array}{l}\text { Gomes, Deslandes; } \\
1994\end{array}$ & - \\
\hline 22 & $\begin{array}{l}\text { Hadley, Turk, } \\
\text { Vasko, McGurrin; } \\
1997\end{array}$ & - \\
\hline 23 & Hockley; 1996 & - \\
\hline 24 & 2005 & - \\
\hline 25 & Irribary; 2003 & $\begin{array}{l}\text { A tomada de decisão compartilhada e horizontal, sem que nenhum saber } \\
\text { prevaleça sobre outro. }\end{array}$ \\
\hline 26 & $\begin{array}{l}\text { Jackson, Gater, } \\
\text { Goldberg, Tantam, } \\
\text { Loftus, Taylor; } \\
1993\end{array}$ & $\begin{array}{l}\text { aponta que embora os diferentes profissionais compartilhem o trabalho } \\
\text { em equipe, eles mantém seu papel profissional e contribuem com suas } \\
\text { habilidades específicas. }\end{array}$ \\
\hline 27 & Lassauniere; 1995 & - \\
\hline 28 & $\begin{array}{l}\text { Lavin, Ruebling, } \\
\text { Banks, Counte, } \\
\text { Furman, Miller, } \\
\text { Reese, Viehmann, } \\
\text { Holt; } 2001\end{array}$ & - \\
\hline 29 & Lind; 1994 & - \\
\hline 30 & Lino; 1998 & - \\
\hline 31 & Lopes; 1993 & - \\
\hline 32 & $\begin{array}{l}\text { McNamara, Mak, } \\
\text { Whyte; } 2005\end{array}$ & - \\
\hline 33 & $\begin{array}{l}\text { Magalhães, } \\
\text { Tiesenhausen; } \\
2000\end{array}$ & - \\
\hline 34 & Mase; 1975 & $\begin{array}{l}\text { quanto mais especializado o profissional, mais interdependente dos } \\
\text { demais profissionais ele se torna. }\end{array}$ \\
\hline 35 & Matheus; 1995 & - \\
\hline 36 & $\begin{array}{l}\text { Matsuda, Évora; } \\
2003\end{array}$ & - \\
\hline 37 & $\begin{array}{l}\text { Matumoto, } \\
\text { Fortuna, Mishima, } \\
\text { Pereira, Domingos; } \\
2005\end{array}$ & - \\
\hline 38 & $\begin{array}{l}\text { Melo, Tanaka; } \\
1999\end{array}$ & - \\
\hline 39 & Mello; 1998 & - \\
\hline 40 & Mishima; 2000 & $\begin{array}{l}\text { aponta que é preciso haver uma horizontalização das relações } \\
\text { preservando e compartilhando a autonomia profissional na busca pelo } \\
\text { trabalho inter. }\end{array}$ \\
\hline
\end{tabular}




\begin{tabular}{|c|c|c|}
\hline 41 & $\begin{array}{l}\text { Monteiro, Ribeiro, } \\
\text { Souza, Serafim; } \\
2002\end{array}$ & - \\
\hline 42 & $\begin{array}{l}\text { Moffic, Patterson, } \\
\text { Laval, Adams; } \\
1984\end{array}$ & - \\
\hline 43 & $\begin{array}{l}\text { Oliveira, Bottaro, } \\
\text { Alessi; } 2003\end{array}$ & - \\
\hline 44 & $\begin{array}{l}\text { Oliveira, Spiri; } \\
2006\end{array}$ & - \\
\hline 45 & Peduzzi; 2001 & $\begin{array}{l}\text { "concebida como a esfera de liberdade de julgamento e de tomada de } \\
\text { decisão frente às necessidades de saúde". A autonomia dos profissionais } \\
\text { é legitimada pela maior ou menos autonomia técnica que expõe } \\
\text { Apresenta as concepções de autonomia plena - independência na } \\
\text { execução de suas atuações -, alienação - ignora a autonomia de seu } \\
\text { trabalho - e interdependência - caráter interdependente da autonomia } \\
\text { técnica do conjunto de agentes. A equipe integração está mais próxima } \\
\text { da autonomia técnica com interdependência dos projetos. }\end{array}$ \\
\hline 46 & Petersson; 2005 & - \\
\hline 47 & Pimenta; 2005 & - \\
\hline 48 & Porter; 1988 & - \\
\hline 49 & $\begin{array}{l}\text { Queiroz Filho; } \\
1993\end{array}$ & - \\
\hline 50 & Rabinowitz; 2004 & - \\
\hline 51 & Rosa, Labate; 2005 & - \\
\hline 52 & Rosen; 2006 & - \\
\hline 53 & Sadigursky; 2002 & - \\
\hline 54 & $\begin{array}{l}\text { Schull, Ferris, Tu, } \\
\text { Hux, Redelmeier; } \\
2001\end{array}$ & - \\
\hline 55 & $\begin{array}{l}\text { Schweikhart, } \\
\text { Smith-Daniels; } \\
1996\end{array}$ & $\begin{array}{l}\text { considera que o grau de autonomia dos membros da equipe está } \\
\text { diretamente relacionado com o grau de integração entre eles. Reforça que } \\
\text { as mudanças organizacionais proporcionam o aumento da integração e } \\
\text { consequentemente da autonomia profissional. }\end{array}$ \\
\hline 56 & Sherman; 1990 & - \\
\hline 57 & \begin{tabular}{|l} 
Shimizu, \\
Ciampone; 2004
\end{tabular} & - \\
\hline 58 & $\begin{array}{l}\text { Silva, Fonseca; } \\
1995\end{array}$ & - \\
\hline 59 & Silva; 2005 & $\begin{array}{l}\text { O estudo aponta que cada profissional planeja individualmente suas } \\
\text { ações, que são comunicadas ao grupo nas reuniões semanais, e ainda que } \\
\text { cada profissional atua com ampla independência no planejamento de } \\
\text { suas ações. O que difere do conceito de articulação das açôes } \\
\text { apresentado, assim como do projeto assistencial comum. }\end{array}$ \\
\hline 60 & $\begin{array}{l}\text { Sladen-Dew, } \\
\text { Bigelow, Buckely, } \\
\text { Bornemann; 1993 } \\
\end{array}$ & - \\
\hline 61 & Spiri; 2004 & "a autonomia necessita ser continuamente conquistada". "A mudança \\
\hline
\end{tabular}




\begin{tabular}{|l|l|l|}
\hline & & $\begin{array}{l}\text { dessa situação requer que cada profissional repense seu trabalho e } \\
\text { compreenda que a autonomia técnica não se encontra no isolamento ou } \\
\text { independência profissional, mas sim na colaboração entre os } \\
\text { profissionais que buscam construir e compartilhar o projeto comum da } \\
\text { intervenção, utilizando formas cooperativas, solidárias ao invés de } \\
\text { concorrência ou competição individual”. }\end{array}$ \\
\hline 62 & $\begin{array}{l}\text { Thofehrn, } \\
\text { Leopardi; 2006 }\end{array}$ & - \\
\hline 63 & Trapp; 1994 & - \\
\hline 64 & 2003 & - \\
\hline 65 & $\begin{array}{l}\text { Undre, Sevdalis, } \\
\text { Healey, Darzi, } \\
\text { Vincent; 2006 }\end{array}$ & - \\
\hline 66 & $\begin{array}{l}\text { Van den Berg, } \\
\text { Kalmijm, } \\
\text { Lindeman, } \\
\text { Veldink, de Visser, } \\
\text { Van der Graaff, } \\
\text { Wokke, Van den } \\
\text { Berg; 2005 }\end{array}$ & \\
\hline 67 & $\begin{array}{l}\text { Vliet, Li, MacKay, } \\
\text { Badley; 2006 }\end{array}$ & \\
\hline 68 & Waters; 2005 & - \\
\hline 69 & $\begin{array}{l}\text { Wiecha, Pollard; } \\
\text { 2004 }\end{array}$ & \\
\hline 70 & $\begin{array}{l}\text { Yawm, Geier; } \\
\text { 1995 }\end{array}$ & \\
\hline
\end{tabular}




\begin{tabular}{|c|c|c|}
\hline & Autores & Concepção de equipe \\
\hline 1 & $\begin{array}{l}\text { Abreu, Munari, } \\
\text { Queiroz, } \\
\text { Fernandes; } 2005\end{array}$ & $\begin{array}{l}\text { "equipe gera sinergia positiva através de um esforço coordenado". } \\
\text { "Nesse caso, o desempenho é coletivo e o resultado é maior que a soma } \\
\text { das partes individuais. A responsabilidade é tanto individual quanto } \\
\text { coletiva e as habilidades são complementares. Na equipe há uma } \\
\text { integração gerencial de habillidades e talentos individuais em uma } \\
\text { habilidade coletiva de produzir serviços de maneira mais eficiente e } \\
\text { efetiva". }\end{array}$ \\
\hline 2 & Abuhab; 2005 & 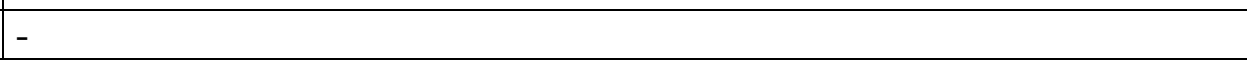 \\
\hline 3 & Bailey; 1984 & $\begin{array}{l}\text { A unidade funcional equipe se faz presente quando todos os membros } \\
\text { têm plena consciência do papel da equipe, assim como dos papéis } \\
\text { individuais. }\end{array}$ \\
\hline 4 & $\begin{array}{l}\text { Bertoncello, Silva; } \\
1998\end{array}$ & - \\
\hline 5 & Bourghnet; 2004 & - \\
\hline 6 & Brown; 1995 & $\begin{array}{l}\text { "pode ser definido como um grupo de duas ou mais pessoas que } \\
\text { reconhecem objetivos comuns e coordenam seus esforços para atingi- } \\
\text { los". }\end{array}$ \\
\hline 7 & Camara; 1997 & - \\
\hline 8 & Campos; 1998 & - \\
\hline 9 & Campos; 1999 & - \\
\hline 10 & Campos $^{2} ; 1992$ & $\begin{array}{l}\text { "Um grupo de profissionais só configura uma equipe quando opera de } \\
\text { modo cooperativo, convergindo seus objetivos para uma dada situação, } \\
\text { de forma a haver complementaridade e não soma ou superposição". }\end{array}$ \\
\hline 11 & Campos $^{2} ; 1988$ & - \\
\hline 12 & Catropa; 1987 & - \\
\hline 13 & $\begin{array}{l}\text { Ciampone, } \\
\text { Peduzzi; } 2000\end{array}$ & $\begin{array}{l}\text { "é justamente a relação recíproca entre essas duas dimensões } \\
\text { complementares - trabalho e interação - que caracteriza o que } \\
\text { denominamos trabalho em equipe. Assim, o trabalho em equipe } \\
\text { constituiria uma prática em que a comunicação entre os profissionais faz } \\
\text { parte de um exercício cotidiano do trabalho e os agentes operam a }\end{array}$ \\
\hline
\end{tabular}




\begin{tabular}{|c|c|c|}
\hline & & $\begin{array}{l}\text { articulação das intervenções técnicas por meio da mediação simbólica da } \\
\text { linguagem. Nesse sentido, há que se considerar duas dimensões inerentes } \\
\text { ao trabalho em equipe: a articulação das ações e a interação dos } \\
\text { profissionais". }\end{array}$ \\
\hline 14 & Cretikos; 2005 & Aponta o trabalho em equipe como uma solução em potencial. \\
\hline 15 & Crevelim; 2005 & $\begin{array}{l}\text { "A noção de trabalho em equipe está associada à interação entre os } \\
\text { agentes, integralidade da atenção à saúde, co-responsabilidade e } \\
\text { planejamento compartilhado pelo diálogo entre os trabalhadores } \\
\text { integrantes da equipe". "A equipe emerge dos depoimentos como divisão } \\
\text { do trabalho, como espaço para dividir e buscar soluções". }\end{array}$ \\
\hline 16 & Cunha; 2002 & $\begin{array}{l}\text { "trabalhar em equipe é uma questão de competências, em que a } \\
\text { cooperação é um valor profissional". }\end{array}$ \\
\hline 17 & Faustino; 2003 & - \\
\hline 18 & Faustino; 2004 & - \\
\hline 19 & $\begin{array}{l}\text { Fiander, Burns, } \\
\text { Ukoumunne, Fahy, } \\
\text { Creed, Tyrer, } \\
\text { Byford; } 2006 \\
\end{array}$ & - \\
\hline 20 & $\begin{array}{l}\text { Fortuna, Mishima, } \\
\text { Matumoto, Pereira; } \\
2005\end{array}$ & $\begin{array}{l}\text { considera o trabalho em equipe "como possibilidade de 'recomposição' } \\
\text { do trabalho em saúde numa outra direção, a da interdisciplinaridade". } \\
\text { "Um processo de relações a serem permanentemente olhadas". "... uma } \\
\text { rede de relações entre pessoas, rede de relações de poderes, saberes, } \\
\text { afetos, interesses e desejos, onde é possível identificar processos grupais. } \\
\text { Trabalhar em equipe equivale a se relacionar". Não é um processo } \\
\text { harmonioso, mas local onde ocorrem conflitos inerentes às relações, que } \\
\text { se bem trabalhados podem funcionar como possibilidades de } \\
\text { crescimento. }\end{array}$ \\
\hline 21 & $\begin{array}{l}\text { Gomes, Deslandes; } \\
1994\end{array}$ & - \\
\hline 22 & $\begin{array}{l}\text { Hadley, Turk, } \\
\text { Vasko, McGurrin; } \\
1997\end{array}$ & - \\
\hline 23 & Hockley; 1996 & - \\
\hline 24 & 2005 & - \\
\hline 25 & Irribary; 2003 & $\begin{array}{l}\text { "a origem da transdisciplinaridade está situada no trabalho em equipe". } \\
\text { Quando um problema não é solucionado por uma área do conhecimento, } \\
\text { surge como solução viável o diálogo entre áreas diferentes do } \\
\text { conhecimento. Daí surge o desafio, e a necessidade, de se trabalhar em } \\
\text { equipe. }\end{array}$ \\
\hline 26 & $\begin{array}{l}\text { Jackson, Gater, } \\
\text { Goldberg, Tantam, } \\
\text { Loftus, Taylor; } \\
1993\end{array}$ & - \\
\hline 27 & Lassauniere; 1995 & - \\
\hline 28 & $\begin{array}{l}\text { Lavin, Ruebling, } \\
\text { Banks, Counte, } \\
\text { Furman, Miller, } \\
\text { Reese, Viehmann, } \\
\text { Holt; } 2001\end{array}$ & - \\
\hline
\end{tabular}




\begin{tabular}{|c|c|c|}
\hline 29 & Lind; 1994 & $\begin{array}{l}\text { "um grupo de pessoas atuando juntas", o artigo diz que é uma definição } \\
\text { curta, porém acurada. Uma equipe de saúde é um grupo atuando junto } \\
\text { para promover saúde frente a doenças e injúrias. Cada membro da equipe } \\
\text { é a menor parte da equipe, trabalhando na intenção de alcançar seus } \\
\text { objetivos comuns. }\end{array}$ \\
\hline 30 & Lino; 1998 & - \\
\hline 31 & Lopes; 1993 & $\begin{array}{l}\text { "mais de uma pessoa com proposta de trabalho e normas de ação } \\
\text { comuns, tudo isso por necessidade de maior compreensão de situaçôes, } \\
\text { complementação e realimentação do trabalho para se atingir objetivos } \\
\text { também comuns". }\end{array}$ \\
\hline 32 & $\begin{array}{l}\text { McNamara, Mak, } \\
\text { Whyte; } 2005\end{array}$ & - \\
\hline 33 & $\begin{array}{l}\text { Magalhães, } \\
\text { Tiesenhausen; } \\
2000\end{array}$ & - \\
\hline 34 & Mase; 1975 & $\begin{array}{l}\text { embora o termo equipe esteja se banalizando (O ARTIGO FOI } \\
\text { PUBLICADO EM 1975!), equipe significa um plano de ação } \\
\text { cooperativo, democrático e íntimo entre vários indivíduos. Deve criar } \\
\text { uma sinergia positiva. }\end{array}$ \\
\hline 35 & Matheus; 1995 & $\begin{array}{l}\text { "modelo de trabalho, não só visando o alcance de objetivos, mas, } \\
\text { também, como meio de satisfazer as necessidades das pessoas que } \\
\text { compõe o grupo". Na enfermagem, conceitua o trabalho em equipe como } \\
\text { "um dos instrumentos básicos de enfermagem, como a 'atividade } \\
\text { coordenada e sincronizada sem atritos, desenvolvida por um grupo } \\
\text { estritamente unido". }\end{array}$ \\
\hline 36 & $\begin{array}{l}\text { Matsuda, Évora; } \\
2003\end{array}$ & - \\
\hline 37 & $\begin{array}{l}\text { Matumoto, } \\
\text { Fortuna, Mishima, } \\
\text { Pereira, Domingos; } \\
2005\end{array}$ & $\begin{array}{l}\text { "implica a interação constante e intensa de um conjunto de trabalhadores } \\
\text { para a realização da tarefa assistencial, do atendimento integral, da } \\
\text { reconstrução dos modos de lidar com os saberes e disciplinas necessários } \\
\text { para o atendimento em saúde". Considera o trabalho em equipe como } \\
\text { "uma rede de relações entre pessoas, produzidas permanentemente no } \\
\text { dia-a-dia, com múltiplas possibilidades de significados. É gerido e } \\
\text { concretizado no mesmo instante do ato do trabalho. A equipe torna-se } \\
\text { equipe enquanto produz o cuidado do usuário". }\end{array}$ \\
\hline 38 & $\begin{array}{l}\text { Melo, Tanaka; } \\
1999\end{array}$ & - \\
\hline 39 & Mello; 1998 & - \\
\hline 40 & Mishima; 2000 & $\begin{array}{l}\text { "a equipe de saúde é uma microorganização que reconstrói a unidade } \\
\text { perdida - através das sucessivas divisões do trabalho que geram outras } \\
\text { tantas profissões diferentes - do trabalho social cujo objetivo é a atenção } \\
\text { à saúde". }\end{array}$ \\
\hline 41 & $\begin{array}{l}\text { Monteiro, Ribeiro, } \\
\text { Souza, Serafim; } \\
2002\end{array}$ & $\begin{array}{l}\text { "equipe é um grupo que compreende seus objetivos e está engajado em } \\
\text { alcançá-los, de forma compartilhada". "Respeito, mente aberta e } \\
\text { cooperação são elevados. O grupo investe constantemente em seu } \\
\text { próprio crescimento". "Na equipe todos trabalham em uníssono, } \\
\text { envolvidos cada um na tarefa de todos, fazendo com que haja um } \\
\text { comprometimento total dos resultados gerais". }\end{array}$ \\
\hline 42 & Moffic, Patterson, & "uma equipe psiquiátrica geralmente se refere a um grupo de \\
\hline
\end{tabular}




\begin{tabular}{|c|c|c|}
\hline & $\begin{array}{l}\text { Laval, Adams; } \\
1984\end{array}$ & profissionais de saúde mental voltados a uma tarefa terapêutica comum". \\
\hline 43 & \begin{tabular}{|l|} 
Oliveira, Bottaro, \\
Alessi; 2003 \\
\end{tabular} & - \\
\hline 44 & $\begin{array}{l}\text { Oliveira, Spiri; } \\
2006\end{array}$ & $\begin{array}{l}\text { no PSF "deve ser remunerado e reconhecido como meio de construção } \\
\text { social de acordo com as necessidades sociais". }\end{array}$ \\
\hline 45 & Peduzzi; 2001 & $\begin{array}{l}\text { "consiste numa modalidade de trabalho coletivo que se configura na } \\
\text { relação recíproca entre as intervenções técnicas e a interação dos } \\
\text { agentes". Equipe: integração dos trabalhos especializados. }\end{array}$ \\
\hline 46 & Petersson; 2005 & $\begin{array}{l}\text { apresenta sinergia positiva, na qual o resultado é maior que a soma } \\
\text { individual, sendo alcançada quando se alcança um trabalho integrado em } \\
\text { equipe. } \\
\text { O conceito básico é a utilização das diferentes habilidades para atender } \\
\text { os problemas do paciente. }\end{array}$ \\
\hline 47 & Pimenta; 2005 & - \\
\hline 48 & Porter; 1988 & - \\
\hline 49 & $\begin{array}{l}\text { Queiroz Filho; } \\
1993\end{array}$ & - \\
\hline 50 & Rabinowitz; 2004 & aponta que o trabalho em equipe deve resultar em sinergia positiva. \\
\hline 51 & Rosa, Labate; 2005 & - \\
\hline 52 & Rosen; 2006 & $\begin{array}{l}\text { equipe interdisciplinar eficiente em saúde mental envolve a conservação } \\
\text { dos diferentes papéis disciplinares e o desenvolvimento de tarefas } \\
\text { compartilhadas, exige a figura do líder como supervisor e gerente da } \\
\text { equipe. }\end{array}$ \\
\hline 53 & Sadigursky; 2002 & - \\
\hline 54 & $\begin{array}{l}\text { Schull, Ferris, Tu, } \\
\text { Hux, Redelmeier; } \\
2001\end{array}$ & - \\
\hline 55 & $\begin{array}{l}\text { Schweikhart, } \\
\text { Smith-Daniels; } \\
1996\end{array}$ & - \\
\hline 56 & Sherman; 1990 & $\begin{array}{l}\text { "team nursing is a group endeavour. Cooperation is vital to team } \\
\text { effectiveness. A cohesion and effective team will not develop without } \\
\text { specific team building strategies. Organizational development concepts } \\
\text { involving team communication, goal achievement, and accountability } \\
\text { offer a theoretical framework for the practice of nursing team". }\end{array}$ \\
\hline 57 & $\begin{array}{l}\text { Shimizu, } \\
\text { Ciampone; } 2004\end{array}$ & $\begin{array}{l}\text { concebe equipe a partir de uma organização formal dentro da instituição, } \\
\text { provavelmente desenvolvida por ela para garantir a qualidade e } \\
\text { produtividade da assistência. }\end{array}$ \\
\hline 58 & $\begin{array}{l}\text { Silva, Fonseca; } \\
1995\end{array}$ & - \\
\hline 59 & Silva; 2005 & - \\
\hline 60 & $\begin{array}{l}\text { Sladen-Dew, } \\
\text { Bigelow, Buckely, } \\
\text { Bornemann; } 1993 \\
\end{array}$ & - \\
\hline 61 & Spiri; 2004 & - \\
\hline 62 & $\begin{array}{l}\text { Thofehrn, } \\
\text { Leopardi; } 2006\end{array}$ & - \\
\hline
\end{tabular}




\begin{tabular}{|c|c|c|}
\hline 63 & Trapp; 1994 & $\begin{array}{l}\text { "TEAM: together everyone achieves more". O objetivo da equipe é ter } \\
\text { resultados maiores do que a soma dos resultados individuais. }\end{array}$ \\
\hline 64 & 2003 & "a única coisa que você pode fazer sem uma equipe é jogar golf" \\
\hline 65 & $\begin{array}{l}\text { Undre, Sevdalis, } \\
\text { Healey, Darzi, } \\
\text { Vincent; } 2006\end{array}$ & - \\
\hline 66 & $\begin{array}{l}\text { Van den Berg, } \\
\text { Kalmijm, } \\
\text { Lindeman, } \\
\text { Veldink, de Visser, } \\
\text { Van der Graaff, } \\
\text { Wokke, Van den } \\
\text { Berg; 2005 }\end{array}$ & - \\
\hline 67 & $\begin{array}{l}\text { Vliet, Li, MacKay, } \\
\text { Badley; } 2006\end{array}$ & $\begin{array}{l}\text { "grupo de profissionais de saúde de diferentes disciplinas que } \\
\text { compartilham valores e objetivos comuns". }\end{array}$ \\
\hline 68 & Waters; 2005 & $\begin{array}{l}\text { aponta que a assistência em saúde atual é dependente do trabalho em } \\
\text { equipe. }\end{array}$ \\
\hline 69 & $\begin{array}{l}\text { Wiecha, Pollard; } \\
2004\end{array}$ & $\begin{array}{l}\text { embora muito se fale em trabalho em equipe na saúde, a literatura } \\
\text { referente ao tema ainda é pobre. "a team with a small number of } \\
\text { consistent people committed to a relevant shared purpose, with common } \\
\text { performance goals, complementary and overlapping skills, and a } \\
\text { common approach to their work. Team members hold themselves } \\
\text { mutually accountable, team results are outcomes". }\end{array}$ \\
\hline 70 & $\begin{array}{l}\text { Yawm, Geier; } \\
1995\end{array}$ & - \\
\hline
\end{tabular}




\begin{tabular}{|c|c|c|}
\hline & Autores & Características do trabalho em equipe \\
\hline 1 & $\begin{array}{l}\text { Abreu, Munari, } \\
\text { Queiroz, } \\
\text { Fernandes; } 2005\end{array}$ & $\begin{array}{l}\text { enfatiza que o trabalho em equipe não é automático, mas uma habilidade } \\
\text { a ser desenvolvida. }\end{array}$ \\
\hline 2 & Abuhab; 2005 & ao mesmo tempo visto como força de coesão e inoperante. \\
\hline 3 & Bailey; 1984 & $\begin{array}{l}\text { Propõe um modelo triaxial para compreensão do trabalho em equipe, } \\
\text { baseado em três premissas: crescimento da equipe é um processo } \\
\text { comportamental; equipes são formadas por indivíduos e a equipe é uma } \\
\text { unidade funcional. } \\
\text { Aponta que as equipes estão em constante processo de mudança e } \\
\text { aprendizado, "escalando" na busca pela abordagem transdisciplinar } \\
\text { (perspectiva), pelo consenso (processo) e pelo planejamento comum } \\
\text { (procedimento). } \\
\text { Sugere como equipe ideal aquela na qual existe um líder que é presente, } \\
\text { mas que respeita a opinião dos demais, cada membro é relativamente } \\
\text { igual em poder e influência e os conflitos estão fortemente embasados, e } \\
\text { não se restringem a questões pessoais. }\end{array}$ \\
\hline 4 & $\begin{array}{l}\text { Bertoncello, Silva; } \\
1998\end{array}$ & $\begin{array}{l}\text { os profissionais de nível superior apontaram diversos dificultadores do } \\
\text { trabalho em equipe, como diversidade de horários, formação diferente, } \\
\text { problemas de comunicação e relacionamento. Para os profissionais de } \\
\text { nível médio, o trabalho em equipe é considerado como um bom } \\
\text { relacionamento interpessoal. }\end{array}$ \\
\hline 5 & Bourghnet; 2004 & - \\
\hline 6 & Brown; 1995 & - \\
\hline 7 & Camara; 1997 & - \\
\hline 8 & Campos; 1998 & - \\
\hline 9 & Campos; 1999 & - \\
\hline 10 & Campos $^{2} ; 1992$ & - \\
\hline 11 & Campos $^{2} ; 1988$ & $\begin{array}{l}\text { finaliza o artigo apontando para a necessidade de trabalho articulado, } \\
\text { objetivos claros, liderança, interesse e envolvimento da instituição; sendo } \\
\text { a ausência ou presença desses elementos o diferencial para um }\end{array}$ \\
\hline
\end{tabular}




\begin{tabular}{|c|c|c|}
\hline 31 & Lopes; 1993 & . \\
\hline 12 & Catropa; 1987 & er significante ao grupo, agentes são planejadores, ter oportunidades a \\
\hline 13 & $\begin{array}{l}\text { Ciampone, } \\
\text { Peduzzi; } 2000\end{array}$ & 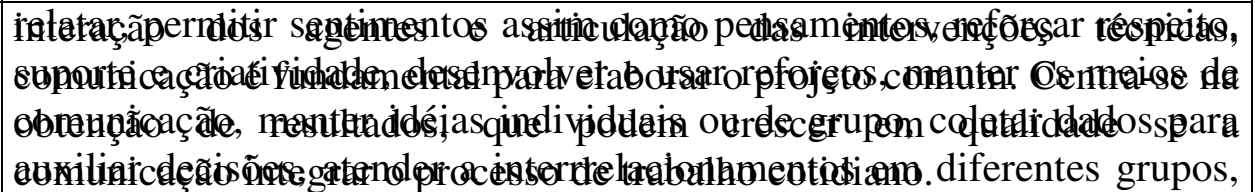 \\
\hline 14 & etikos; 2005 & speitar diferenças individuais, basear a assistênci \\
\hline 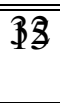 & $\begin{array}{l}\text { eNelinaradowk, } \\
\text { hyte; } 2005\end{array}$ & $\begin{array}{l}\text { Omunicação entre os agentes do trabalho, articulação das ações, } \\
\text { conhecimento das diferenças técnicas entre os trabalhos especializados, }\end{array}$ \\
\hline 33 & $\begin{array}{l}\text { Magalhães, } \\
\text { Tiesenhausen; } \\
2000\end{array}$ & $\begin{array}{l}\text { uestionamento das desigualdades estabelecidas entre os diversos } \\
\text { abalhos e o reconhecimento do caráter interdependente da autonomia } \\
\text { énica, tendência a construir projetos comum que integrem os trabalhos }\end{array}$ \\
\hline 34 & ase; 1975 & especializados. \\
\hline$\overline{B 6}$ & 2009295 & rganização e inte \\
\hline 17 & ustino; 2003 & motivação e percepção, orientadas para a eficiência e o bem-estar das \\
\hline 18 & $0 ; 2004$ & soais. \\
\hline 19 & $\begin{array}{l}\text { r, Burns, } \\
\text { nunne, Fahy, } \\
\text { Tyrer, } \\
; 2006\end{array}$ & $\begin{array}{l}\text { "A organização implica na existência de papéis definidos, de divisão do } \\
\text { trabalho que convergem para uma causa comum". } \\
\text { "A interação significa que cada membro partilhe, converse e troque } \\
\text { idéias do que fazem e até de seus sentimentos". }\end{array}$ \\
\hline 20 & $\begin{array}{l}\text { Fortuna, Mishima, } \\
\text { Matumoto, Pereira; } \\
2005\end{array}$ & 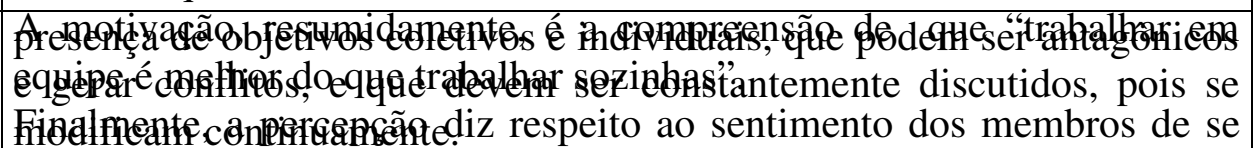 \\
\hline 21 & omes, Deslandes; & $\begin{array}{l}\text { e identificarem com ela, todos os membros } \\
\text { izados. }\end{array}$ \\
\hline 36 & allsed, T, trimera; & e \\
\hline 37 & to, & 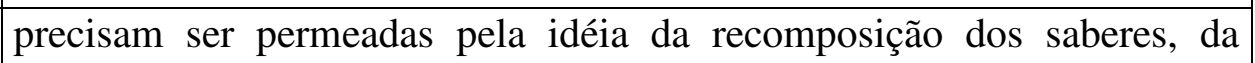 \\
\hline 23 & ay; Mosgim & perfeita é apenas \\
\hline 24 & a, Domin & $\overline{\mathrm{ma}}$ \\
\hline 25 & $y ; 2003$ & i \\
\hline 38 & Tanaka; & $\begin{array}{l}\text { de e respeito por } \\
\text { movimento de }\end{array}$ \\
\hline 39 & Tello; 1998 & ahiestho ebjequipe \\
\hline 26 & n, Gater, & $\begin{array}{l}\text { '. Para o trabalho em } \\
\text { o do usuário. }\end{array}$ \\
\hline 40 & $\mathrm{a} ; 2000$ & d \\
\hline 27 & infere,ipej & $\operatorname{tar}$ \\
\hline 28 & 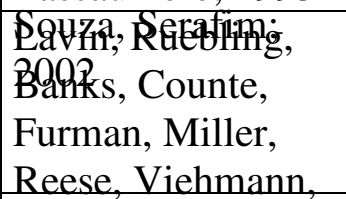 & $\begin{array}{l}\text { preocupado com o grupo, ter características de liderança, saber se } \\
\text { comunicar, ter preocupação com a tarefa do grupo e com o fator humano. } \\
\text { O alicerce fundamental do trabalho em equipe é o desenvolvimento } \\
\text { interpessoal. }\end{array}$ \\
\hline 42 & obqtterson, & - \\
\hline 29 & ,1999ms; & . \\
\hline 43 & liveira, Bottar & ntạtiva de superação da organização \\
\hline 30 & 196963 & $\begin{array}{l}\text { édica do trabalho, a distribuição democrática de poder, } \\
\text { óis entre os profissionais da equipe e a racionalização }\end{array}$ \\
\hline
\end{tabular}




\begin{tabular}{|c|c|c|}
\hline & & do tempo para uma priorização da atenção ao usuário. \\
\hline 44 & $\begin{array}{l}\text { Oliveira, Spiri; } \\
2006\end{array}$ & - \\
\hline 45 & Peduzzi; 2001 & $\begin{array}{l}\text { comunicação entre os agentes, diferenças técnicas e desigual valoração } \\
\text { social dos trabalhos especializados, formulação de um projeto } \\
\text { assistencial comum, especificidade de cada área profissional, } \\
\text { flexibilidade da divisão do trabalho e autonomia técnica. }\end{array}$ \\
\hline 46 & Petersson; 2005 & - \\
\hline 47 & Pimenta; 2005 & - \\
\hline 48 & Porter; 1988 & $\begin{array}{l}\text { necessidade de se conhecer o papel específico de cada membro para } \\
\text { encontrar o caminho para cada um interagir de maneira a melhorar o } \\
\text { trabalho da equipe. } \\
\text { São chaves para o sucesso da equipe a forte compreensão da contribuição } \\
\text { de cada disciplina, assim como um alto grau de flexibilidade e interação } \\
\text { para o atendimento das inúmeras demandas em saúde mental. }\end{array}$ \\
\hline 49 & $\begin{array}{l}\text { Queiroz Filho; } \\
1993\end{array}$ & - \\
\hline 50 & Rabinowitz; 2004 & $\begin{array}{l}\text { a interação entre os profissionais é fundamental para o trabalho em } \\
\text { equipe, incluindo o paciente nesse processo. }\end{array}$ \\
\hline 51 & Rosa, Labate; 2005 & 9 \\
\hline 52 & Rosen; 2006 & $\begin{array}{l}\text { O líder não precisa necessariamente ser o médico, mas o membro melhor } \\
\text { qualificado na equipe, aquele que melhor conheça a equipe, seus } \\
\text { objetivos e recursos. O líder representa a equipe perante o restante na } \\
\text { instituição, e os serviços de apoio. Tem ainda a responsabilidade de } \\
\text { equilibrar emoções, papéis, valores e visões dos membros da equipe. }\end{array}$ \\
\hline 53 & Sadigursky; 2002 & $\begin{array}{l}\text { conhecimento, responsabilidade e afetividade, distribuição do poder, } \\
\text { com quebra da hegemonia de um sobre os demais, a escolha de um líder, } \\
\text { periodicamente, para coordenar administrativamente as tarefas. }\end{array}$ \\
\hline 56 & $\begin{array}{l}\text { Schull, Ferris, Tu, } \\
\text { Hux, Redelmeier; } \\
2001\end{array}$ & - \\
\hline 55 & $\begin{array}{l}\text { Schweikhart, } \\
\text { Smith-Daniels; } \\
1996\end{array}$ & $\begin{array}{l}\text { aponta que as dimensões estruturais de uma equipe relacionam-se com o } \\
\text { grau de interação e integração entre ações e agentes operacionais e } \\
\text { gerenciais. } \\
\text { Considera que é a organização que escolhe o grau de integração entre } \\
\text { seus agentes. }\end{array}$ \\
\hline 56 & Sherman; 1990 & $\begin{array}{l}\text { objetivo nas necessidades individuais do paciente, sendo este incluído no } \\
\text { planejamento da assistência, responsabilidade do líder frente a equipe, } \\
\text { utilização de liderança participativa, responsabilidade da equipe por um } \\
\text { número de pacientes, utilização de todas as habilidades dos membros na } \\
\text { assistência, aceitação do líder pelos demais membros, comunicação } \\
\text { efetiva. }\end{array}$ \\
\hline 57 & $\begin{array}{l}\text { Shimizu, } \\
\text { Ciampone; } 2004\end{array}$ & articulação das ações e interação dos agentes. \\
\hline 58 & $\begin{array}{l}\text { Silva, Fonseca; } \\
1995\end{array}$ & - \\
\hline 59 & Silva; 2005 & - \\
\hline 60 & $\begin{array}{l}\text { Sladen-Dew, } \\
\text { Bigelow, Buckely, }\end{array}$ & - \\
\hline
\end{tabular}




\begin{tabular}{|c|c|c|}
\hline & Bornemann; 1993 & \\
\hline 61 & Spiri; 2004 & - \\
\hline 62 & $\begin{array}{l}\text { Thofehrn, } \\
\text { Leopardi; } 2006\end{array}$ & - \\
\hline 63 & Trapp; 1994 & - \\
\hline 64 & 2003 & $\begin{array}{l}\text { aponta a equipe côo alternativa para reduzir custos, aumentar a qualidade } \\
\text { da assistência, incluindo o paciente na equipe, como um dos membros } \\
\text { mais importantes, e utilizando-se da liderança. } \\
\text { Aponta como características: apoio, construção de um relacionamento, e } \\
\text { comunicação. }\end{array}$ \\
\hline 65 & $\begin{array}{l}\text { Undre, Sevdalis, } \\
\text { Healey, Darzi, } \\
\text { Vincent; } 2006\end{array}$ & - \\
\hline 66 & $\begin{array}{l}\text { Van den Berg, } \\
\text { Kalmijm, } \\
\text { Lindeman, } \\
\text { Veldink, de Visser, } \\
\text { Van der Graaff, } \\
\text { Wokke, Van den } \\
\text { Berg; 2005 }\end{array}$ & - \\
\hline 67 & $\begin{array}{l}\text { Vliet, Li, MacKay, } \\
\text { Badley; } 2006\end{array}$ & - \\
\hline 68 & Waters; 2005 & - \\
\hline 69 & $\begin{array}{l}\text { Wiecha, Pollard; } \\
2004\end{array}$ & $\begin{array}{l}\text { cita como dimensões essenciais ao trabalho em equipe a estrutura, o } \\
\text { contexto, o processo (no qual a comunicação é essencial) e a } \\
\text { produtividade. São condições para o trabalho em equipe: comunicação, } \\
\text { cooperação, coesão, compromisso, colaboração, enfrentamento e } \\
\text { resolução de conflitos, esforços coordenados, tomada de decisão por } \\
\text { compartilhada, foco no paciente, consistência, contribuição. Tais } \\
\text { condições são responsáveis por permitir a criação de novas idéias, } \\
\text { habilidades e inovação, assim como por permitir a sinergia. }\end{array}$ \\
\hline 70 & $\begin{array}{l}\text { Yawm, Geier; } \\
1995\end{array}$ & - \\
\hline
\end{tabular}




\begin{tabular}{|c|c|c|}
\hline & Autores & Enfoque gerencial \\
\hline 1 & $\begin{array}{l}\text { Abreu, Munari, } \\
\text { Queiroz, } \\
\text { Fernandes; } 2005\end{array}$ & - \\
\hline 2 & Abuhab; 2005 & $\begin{array}{l}\text { estrutura organizacional gera sobrecarga de trabalho, impedindo que os } \\
\text { profissionais cooperem entre si e amparem projetos e ações, uma vez que } \\
\text { estão presos a demanda da realização de tarefas, deixando em segundo } \\
\text { plano o "lendário projeto terapêutico". Falta de apoio do órgão gestor às } \\
\text { necessidades especiais do serviço. "Não é a regulamentação do serviço } \\
\text { que define seu perfil, mas sua organização e os compromissos sociais } \\
\text { assumidos pelos atores envolvidos". }\end{array}$ \\
\hline 3 & Bailey; 1984 & - \\
\hline 4 & $\begin{array}{l}\text { Bertoncello, Silva; } \\
1998\end{array}$ & - \\
\hline 5 & Bourghnet; 2004 & $\begin{array}{l}\text { Coordenador da equipe: com as atribuições de garantir que cada } \\
\text { profissional conheça o pensamento dos outros em relação ao } \\
\text { atendimento, otimizando esforços, organizando a terapêutica, } \\
\text { multiplicando talentos individuais, gerenciando conflitos, buscando a } \\
\text { construção de uma cultura comum entre os membros, na qual } \\
\text { competitividade se transforma em cooperação, e garantindo o melhor } \\
\text { planejamento comum para o paciente. }\end{array}$ \\
\hline 6 & Brown; 1995 & \\
\hline 7 & Camara; 1997 & - \\
\hline 8 & Campos; 1998 & $\begin{array}{l}\text { gerência a partir de unidades de produção = coletivos multiprofissionais. } \\
\text { Todos participam, mas ninguém decide sozinho. }\end{array}$ \\
\hline 9 & Campos; 1999 & $\begin{array}{l}\text { "o estilo de governo e a estrutura de poder das organizações condicionam } \\
\text { e determinam comportamentos e posturas. Um sistema de poder } \\
\text { altamente verticalizado, com tomada centralizada de decisões, tende a } \\
\text { estimular descompromisso e alienação entre a maioria dos } \\
\text { trabalhadores". A lógica de organização do trabalho, seus valores e } \\
\text { processos não é nunca inócua, ela reflete interesses, diretrizes e valores }\end{array}$ \\
\hline
\end{tabular}




\begin{tabular}{|c|c|c|}
\hline & & $\begin{array}{l}\text { dominantes. } \\
\text { A estrutura organizacional tradicional não favorece tomadas de decisão } \\
\text { horizontais, compartilhadas. }\end{array}$ \\
\hline 10 & Campos $^{2} ; 1992$ & - \\
\hline 11 & Campos $^{2} ; 1988$ & - \\
\hline 12 & Catropa; 1987 & - \\
\hline 13 & $\begin{array}{l}\text { Ciampone, } \\
\text { Peduzzi; } 2000 \\
\end{array}$ & - \\
\hline 14 & Cretikos; 2005 & - \\
\hline 15 & Crevelim; 2005 & $\begin{array}{l}\text { traduz a importância na participação do usuário no gerenciamento dos } \\
\text { serviços de saúde oferecidos, inclusive na tomada de decisão dentro dos } \\
\text { conselhos gestores. Aponta, porém, que embora essa importância seja } \\
\text { dada, a elaboração do projeto assistencial é realizada pelos profissionais } \\
\text { que compõe a equipe, isto é, essa elaboração é realizada para dentro da } \\
\text { equipe, excluindo-se o usuário do serviço, servindo este apenas para } \\
\text { legitimar as decisões tomadas pela equipe. }\end{array}$ \\
\hline 16 & Cunha; 2002 & - \\
\hline 17 & Faustino; 2003 & - \\
\hline 18 & Faustino; 2004 & - \\
\hline 19 & $\begin{array}{l}\text { Fiander, Burns, } \\
\text { Ukoumunne, Fahy, } \\
\text { Creed, Tyrer, } \\
\text { Byford; } 2006\end{array}$ & - \\
\hline 20 & $\begin{array}{l}\text { Fortuna, Mishima, } \\
\text { Matumoto, Pereira; } \\
2005\end{array}$ & - \\
\hline 21 & $\begin{array}{l}\text { Gomes, Deslandes; } \\
1994\end{array}$ & - \\
\hline 22 & $\begin{array}{l}\text { Hadley, Turk, } \\
\text { Vasko, McGurrin; } \\
1997\end{array}$ & - \\
\hline 23 & Hockley; 1996 & - \\
\hline 24 & 2005 & - \\
\hline 25 & Irribary; 2003 & - \\
\hline 26 & $\begin{array}{l}\text { Jackson, Gater, } \\
\text { Goldberg, Tantam, } \\
\text { Loftus, Taylor; } \\
1993\end{array}$ & - \\
\hline 27 & Lassauniere; 1995 & - \\
\hline 28 & $\begin{array}{l}\text { Lavin, Ruebling, } \\
\text { Banks, Counte, } \\
\text { Furman, Miller, } \\
\text { Reese, Viehmann, } \\
\text { Holt; } 2001\end{array}$ & - \\
\hline 29 & Lind; 1994 & - \\
\hline 30 & Lino; 1998 & - \\
\hline 31 & Lopes; 1993 & $\begin{array}{l}\text { trabalha as características do líder da equipe, como forma de estabelecer } \\
\text { um canal efetivo de comunicação, definir objetivos comuns e tornar }\end{array}$ \\
\hline
\end{tabular}




\begin{tabular}{|c|c|c|}
\hline & & $\begin{array}{l}\text { possível a existência de atitudes investigatórias. É aquele capaz de } \\
\text { coordenar, facilitar a cooperação, manter a organização, facilitar e } \\
\text { controlar o desenvolvimento das atividades. }\end{array}$ \\
\hline 32 & $\begin{array}{l}\text { McNamara, Mak, } \\
\text { Whyte; } 2005 \\
\end{array}$ & - \\
\hline 33 & $\begin{array}{l}\text { Magalhães, } \\
\text { Tiesenhausen; } \\
2000\end{array}$ & - \\
\hline 34 & Mase; 1975 & - \\
\hline 35 & Matheus; 1995 & $\begin{array}{l}\text { aborda a importância da liderança no desenvolvimento do trabalho em } \\
\text { equipe; aponta os diferentes estilos de liderança e discute que a utilização } \\
\text { deste ou daquele estilo depende do momento e da necessidade da equipe. }\end{array}$ \\
\hline 36 & $\begin{array}{l}\text { Matsuda, Évora; } \\
2003\end{array}$ & - \\
\hline 37 & $\begin{array}{l}\text { Matumoto, } \\
\text { Fortuna, Mishima, } \\
\text { Pereira, Domingos; } \\
2005\end{array}$ & $\begin{array}{l}\text { analisa a atividade de supervisão das equipes do PSF, sua importância na } \\
\text { facilitação da auto-análise e auto-gestão das equipes, e elaboração do } \\
\text { contrato terapêutico e na análise da divisão técnica-social do trabalho. A } \\
\text { supervisão auxilia também para que as equipes adquiram a flexibilidade } \\
\text { necessária aos processos de mudança. O supervisor deve atentar-se para } \\
\text { o fato da equipe não torna-se dependente de suas condutas. }\end{array}$ \\
\hline 38 & $\begin{array}{l}\text { Melo, Tanaka; } \\
1999\end{array}$ & - \\
\hline 39 & Mello; 1998 & - \\
\hline 40 & Mishima; 2000 & $\begin{array}{l}\text { "seu trabalho implicava, portanto, procura permanente de integração e } \\
\text { articulação entre diferentes níveis de poder". }\end{array}$ \\
\hline 41 & $\begin{array}{l}\text { Monteiro, Ribeiro, } \\
\text { Souza, Serafim; } \\
2002\end{array}$ & - \\
\hline 42 & $\begin{array}{l}\text { Moffic, Patterson, } \\
\text { Laval, Adams; } \\
1984\end{array}$ & - \\
\hline 43 & $\begin{array}{l}\text { Oliveira, Bottaro, } \\
\text { Alessi; } 2003\end{array}$ & - \\
\hline 44 & $\begin{array}{l}\text { Oliveira, Spiri; } \\
2006\end{array}$ & - \\
\hline 45 & Peduzzi; 2001 & - \\
\hline 46 & Petersson; 2005 & - \\
\hline 47 & Pimenta; 2005 & $\begin{array}{l}\text { embora considere que as equipes têm autonomia para procurar e decidir } \\
\text { sobre seus melhores caminhos, a gestão do PSF de Amparo conta com } \\
\text { um colegiado, formado apenas por médicos e enfermeiros, com a } \\
\text { responsabilidade de gerir o programa, sedo considerado "espaço de } \\
\text { poder compartilhado para discutir problemas de saúde e tomar decisões } \\
\text { referentes à rede básica e ao sistema municipal de saúde. Esse colegiado } \\
\text { passou a ser um espaço coletivo com papel decisivo no processo de } \\
\text { mudança do modelo de gestão". }\end{array}$ \\
\hline 48 & Porter; 1988 & - \\
\hline 49 & $\begin{array}{l}\text { Queiroz Filho; } \\
1993\end{array}$ & - \\
\hline
\end{tabular}




\begin{tabular}{|c|c|c|}
\hline 50 & Rabinowitz; 2004 & $\begin{array}{l}\text { necessidade de um supervisor da equipe, que seja capaz de apoiar os } \\
\text { membros e promover a educação e a melhoria na utilização dos recursos } \\
\text { disponíveis. }\end{array}$ \\
\hline 51 & Rosa, Labate; 2005 & - \\
\hline 52 & Rosen; 2006 & - \\
\hline 53 & Sadigursky; 2002 & - \\
\hline 54 & $\begin{array}{l}\text { Schull, Ferris, Tu, } \\
\text { Hux, Redelmeier; } \\
2001\end{array}$ & - \\
\hline 55 & $\begin{array}{l}\text { Schweikhart, } \\
\text { Smith-Daniels; } \\
1996\end{array}$ & $\begin{array}{l}\text { aponta que as dimensões operacional e gerencial estão unidas num } \\
\text { processo interativo no qual um planeja e o outro executa. }\end{array}$ \\
\hline 56 & Sherman; 1990 & - \\
\hline 57 & $\begin{array}{l}\text { Shimizu, } \\
\text { Ciampone; } 2004\end{array}$ & - \\
\hline 58 & $\begin{array}{l}\text { Silva, Fonseca; } \\
1995\end{array}$ & - \\
\hline 59 & Silva; 2005 & - \\
\hline 60 & $\begin{array}{l}\text { Sladen-Dew, } \\
\text { Bigelow, Buckely, } \\
\text { Bornemann; } 1993 \\
\end{array}$ & - \\
\hline 61 & Spiri; 2004 & - \\
\hline 62 & $\begin{array}{l}\text { Thofehrn, } \\
\text { Leopardi; } 2006\end{array}$ & - \\
\hline 63 & Trapp; 1994 & - \\
\hline 64 & 2003 & $\begin{array}{l}\text { o artigo aponta o sistema Toyota de produção como o modelo para a } \\
\text { organização do trabalho em equipe na instituição apresentada. Diz que } \\
\text { esse sistema tem como característica trabalhar como "uma sinfonia" e } \\
\text { busca a qualidade, segurança, satisfação da equipe, satisfação do } \\
\text { paciente e economia. }\end{array}$ \\
\hline 65 & $\begin{array}{l}\text { Undre, Sevdalis, } \\
\text { Healey, Darzi, } \\
\text { Vincent; } 2006\end{array}$ & - \\
\hline 66 & $\begin{array}{l}\text { Van den Berg, } \\
\text { Kalmijm, } \\
\text { Lindeman, } \\
\text { Veldink, de Visser, } \\
\text { Van der Graaff, } \\
\text { Wokke, Van den } \\
\text { Berg; 2005 }\end{array}$ & - \\
\hline 67 & $\begin{array}{l}\text { Vliet, Li, MacKay, } \\
\text { Badley; } 2006\end{array}$ & - \\
\hline 68 & Waters; 2005 & - \\
\hline 69 & $\begin{array}{l}\text { Wiecha, Pollard; } \\
2004\end{array}$ & - \\
\hline 70 & $\begin{array}{l}\text { Yawm, Geier; } \\
1995\end{array}$ & - \\
\hline
\end{tabular}




\begin{tabular}{|c|l|l|}
\hline & \multicolumn{1}{|c|}{ Autores } & \multicolumn{1}{|c|}{ Integralidade da atenção à saúde } \\
\hline 1 & $\begin{array}{l}\text { Abreu, Munari, } \\
\text { Queiroz, } \\
\text { Fernandes; } 2005\end{array}$ & - \\
\hline 2 & Abuhab; 2005 & $\begin{array}{l}\text { O trabalho em equipe é visto como essencial para transformar a aprender } \\
\text { com as diversas práticas para possibilitar um atendimento integral. }\end{array}$ \\
\hline 3 & Bailey; 1984 & - \\
\hline 4 & $\begin{array}{l}\text { Bertoncello, Silva; } \\
1998\end{array}$ & $\begin{array}{l}\text { "nesse tipo de atendimento, oferecido no ambulatório, não havia } \\
\text { preocupação com a pessoa de forma integral e o objeto de trabalho era a } \\
\text { doença mental". }\end{array}$ \\
\hline 5 & Bourghnet; 2004 & - \\
\hline 6 & Brown; 1995 & - \\
\hline 7 & Camara; 1997 & - \\
\hline 8 & Campos; 1998 & - \\
\hline 9 & Campos; 1999 & $\begin{array}{l}\text { O número de pessoas adscritas a uma equipe de referência garantiria a } \\
\text { atenção integral. }\end{array}$ \\
\hline 10 & Campos ; 1992 & - \\
\hline 11 & Campos ; 1988 & - \\
\hline 12 & Catropa; 1987 & $\begin{array}{l}\text { resgatando as especificidades de cada profissão é possível prestar } \\
\text { assistência integral. }\end{array}$ \\
\hline 13 & $\begin{array}{l}\text { Ciampone, } \\
\text { Peduzzi; } 2000\end{array}$ & - \\
\hline 14 & Cretikos; 2005 & - \\
\hline 15 & Crevelim; 2005 & $\begin{array}{l}\text { na perspectiva da atenção integral a saúde, o usuário é agente } \\
\text { participante do processo. }\end{array}$ \\
\hline 16 & Cunha; 2002 & - \\
\hline 17 & Faustino; 2003 & - \\
\hline 18 & Faustino; 2004 & a busca pela integralidade da assistência traz o desafio do trabalho \\
\hline
\end{tabular}




\begin{tabular}{|c|c|c|}
\hline & & multiprofissional, através da complementaridade das ações. \\
\hline 19 & $\begin{array}{l}\text { Fiander, Burns, } \\
\text { Ukoumunne, Fahy, } \\
\text { Creed, Tyrer, } \\
\text { Byford; } 2006\end{array}$ & - \\
\hline 20 & $\begin{array}{l}\text { Fortuna, Mishima, } \\
\text { Matumoto, Pereira; } \\
2005\end{array}$ & - \\
\hline 21 & $\begin{array}{l}\text { Gomes, Deslandes; } \\
1994\end{array}$ & - \\
\hline 22 & $\begin{array}{l}\text { Hadley, Turk, } \\
\text { Vasko, McGurrin; } \\
1997\end{array}$ & $\begin{array}{l}\text { apresenta a equipe multidisciplinar como uma necessidade ao alcance da } \\
\text { atenção integral. }\end{array}$ \\
\hline 23 & Hockley; 1996 & - \\
\hline 24 & 2005 & - \\
\hline 25 & Irribary; 2003 & - \\
\hline 26 & $\begin{array}{l}\text { Jackson, Gater, } \\
\text { Goldberg, Tantam, } \\
\text { Loftus, Taylor; } \\
1993\end{array}$ & $\begin{array}{l}\text { sugere que a abordagem em equipe permite estender a assistência } \\
\text { especializada a pacientes que não eram atendidos. }\end{array}$ \\
\hline 27 & Lassauniere; 1995 & - \\
\hline 28 & $\begin{array}{l}\text { Lavin, Ruebling, } \\
\text { Banks, Counte, } \\
\text { Furman, Miller, } \\
\text { Reese, Viehmann, } \\
\text { Holt; } 2001\end{array}$ & - \\
\hline 29 & Lind; 1994 & - \\
\hline 30 & Lino; 1998 & - \\
\hline 31 & Lopes; 1993 & - \\
\hline 32 & $\begin{array}{l}\text { McNamara, Mak, } \\
\text { Whyte; } 2005\end{array}$ & - \\
\hline 33 & $\begin{array}{l}\text { Magalhães, } \\
\text { Tiesenhausen; } \\
2000\end{array}$ & - \\
\hline 34 & Mase; 1975 & - \\
\hline 35 & Matheus; 1995 & - \\
\hline 36 & $\begin{array}{l}\text { Matsuda, Évora; } \\
2003\end{array}$ & - \\
\hline 37 & $\begin{array}{l}\text { Matumoto, } \\
\text { Fortuna, Mishima, } \\
\text { Pereira, Domingos; } \\
2005\end{array}$ & $\begin{array}{l}\text { aponta que a divisão técnica e social do trabalho pode funcionar como } \\
\text { dificultador da elaboração do projeto assistencial comum, inclusive } \\
\text { durante as reuniões, onde aqueles cujo trabalho é mais valorizado têm } \\
\text { mais tempo de exposição de suas idéias, assim como a decisão final do } \\
\text { projeto. }\end{array}$ \\
\hline 38 & $\begin{array}{l}\text { Melo, Tanaka; } \\
1999\end{array}$ & - \\
\hline 39 & Mello; 1998 & $\begin{array}{l}\text { É através desses saberes "mais estruturados, mais humanizados e } \\
\text { renovados" que surge a assistência integral em saúde mental. "Frente ao }\end{array}$ \\
\hline
\end{tabular}




\begin{tabular}{|c|c|c|}
\hline & & $\begin{array}{l}\text { enigma da saúde mental não há saber único, como também não há } \\
\text { resposta única". }\end{array}$ \\
\hline 40 & Mishima; 2000 & - \\
\hline 41 & $\begin{array}{l}\text { Monteiro, Ribeiro, } \\
\text { Souza, Serafim; } \\
2002\end{array}$ & - \\
\hline 42 & $\begin{array}{l}\text { Moffic, Patterson, } \\
\text { Laval, Adams; } \\
1984\end{array}$ & - \\
\hline 43 & $\begin{array}{l}\text { Oliveira, Bottaro, } \\
\text { Alessi; } 2003\end{array}$ & - \\
\hline 44 & $\begin{array}{l}\text { Oliveira, Spiri; } \\
2006\end{array}$ & $\begin{array}{l}\text { vê o trabalho em equipe multiprofissional como uma maneira de } \\
\text { compensar a ultraespecialização da saúde, "recompõe, em uma } \\
\text { assistência integral, as ações parciais que nem sempre solucionam as } \\
\text { necessidades de saúde em seu todo". } \\
\text { "O trabalho em equipe é a base para ações integrais na saúde e para } \\
\text { atender com qualidade as necessidades dos usuários". Aponta que a } \\
\text { abordagem é facilitada porque o usuários são atendidos por toda a } \\
\text { equipe, o que incentiva sua autonomia para o auto-cuidado. } \\
\text { "A equipe presta assistência integral, efetiva, contínua e com qualidade, } \\
\text { considerando a perspectiva da família, por meio da abordagem } \\
\text { interdisciplinar, planejamento de ações, organização do trabalho, } \\
\text { compartilhamento de decisões". Porém reforça que a equipe } \\
\text { multiprofissional não garante o atendimento integral. } \\
\text { "O trabalho em equipe é muito importante para dispensar assistência } \\
\text { integral ao paciente e família". }\end{array}$ \\
\hline 45 & Peduzzi; 2001 & $\begin{array}{l}\text { os diferentes trabalhos se agregam ou se separam na busca pelo cuidado } \\
\text { integral, porém além de tecnicamente diferentes, também são diferentes } \\
\text { em valoração social. }\end{array}$ \\
\hline 46 & Petersson; 2005 & - \\
\hline 47 & Pimenta; 2005 & $\begin{array}{l}\text { foi através da atuação das equipes que o programa identificou nós } \\
\text { críticos na busca pela integralidade da assistência a saúde, sendo os } \\
\text { principais a oferta de medicamentos e a atenção a grupos de risco } \\
\text { específicos. }\end{array}$ \\
\hline 48 & Porter; 1988 & - \\
\hline 49 & $\begin{array}{l}\text { Queiroz Filho; } \\
1993\end{array}$ & - \\
\hline 50 & Rabinowitz; 2004 & - \\
\hline 51 & Rosa, Labate; 2005 & - \\
\hline 52 & Rosen; 2006 & $\begin{array}{l}\text { observa a equipe interdisciplinar é o principal veículo para se alcançar a } \\
\text { atenção integral }\end{array}$ \\
\hline 53 & Sadigursky; 2002 & - \\
\hline 54 & $\begin{array}{l}\text { Schull, Ferris, Tu, } \\
\text { Hux, Redelmeier; } \\
2001\end{array}$ & - \\
\hline 55 & $\begin{array}{l}\text { Schweikhart, } \\
\text { Smith-Daniels; } \\
1996\end{array}$ & $\begin{array}{l}\text { O atendimento será mais integral quanto maior for o grau de integração } \\
\text { entre os membros de uma mesma equipe de saúde. }\end{array}$ \\
\hline 56 & Sherman; 1990 & - \\
\hline
\end{tabular}




\begin{tabular}{|c|c|c|}
\hline 57 & \begin{tabular}{|l|} 
Shimizu, \\
Ciampone; 2004 \\
\end{tabular} & A atenção integral é a finalidade do trabalho em equipe eficiente. \\
\hline 58 & $\begin{array}{l}\text { Silva, Fonseca; } \\
1995\end{array}$ & - \\
\hline 59 & Silva; 2005 & $\begin{array}{l}\text { aponta o trabalho em equipe como um dos pressupostos básicos mais } \\
\text { fortes do PSF, responsável por uma abordagem mais resolutiva e } \\
\text { integral. Porém aponta que o trabalho em equipe por si só não resolve o } \\
\text { problema da integralidade. A atenção integral é buscada através da } \\
\text { interação e articulação dos agentes e suas ações técnicas, na busca de um } \\
\text { projeto assistencial comum. } \\
\text { "a articulação das ações ou dos trabalhos requer que cada agente tenha } \\
\text { um dado conhecimento do trabalho do outro e o reconhecimento de sua } \\
\text { necessidade para a atenção integral à saúde". }\end{array}$ \\
\hline 60 & \begin{tabular}{|l} 
Sladen-Dew, \\
Bigelow, Buckely, \\
Bornemann; 1993
\end{tabular} & - \\
\hline 61 & Spiri; 2004 & - \\
\hline 62 & $\begin{array}{l}\text { Thofehrn, } \\
\text { Leopardi; } 2006\end{array}$ & - \\
\hline 63 & Trapp; 1994 & - \\
\hline 64 & 2003 & - \\
\hline 65 & $\begin{array}{l}\text { Undre, Sevdalis, } \\
\text { Healey, Darzi, } \\
\text { Vincent; } 2006 \\
\end{array}$ & - \\
\hline 66 & $\begin{array}{l}\text { Van den Berg, } \\
\text { Kalmijm, } \\
\text { Lindeman, } \\
\text { Veldink, de Visser, } \\
\text { Van der Graaff, } \\
\text { Wokke, Van den } \\
\text { Berg; 2005 }\end{array}$ & - \\
\hline 67 & $\begin{array}{l}\text { Vliet, Li, MacKay, } \\
\text { Badley; } 2006\end{array}$ & - \\
\hline 68 & Waters; 2005 & - \\
\hline 69 & $\begin{array}{l}\text { Wiecha, Pollard; } \\
2004\end{array}$ & - \\
\hline 70 & $\begin{array}{l}\text { Yawm, Geier; } \\
1995\end{array}$ & - \\
\hline
\end{tabular}




\begin{tabular}{|c|c|c|}
\hline & Autores & Multidisciplinaridade, interdisciplinaridade, transdisciplinaridade \\
\hline 1 & $\begin{array}{l}\text { Abreu, Munari, } \\
\text { Queiroz, } \\
\text { Fernandes; } 2005\end{array}$ & $\begin{array}{l}\text { a interdisciplinaridade é caracterizada pela intensidade das trocas entre os } \\
\text { profissionais e o grau de relação real entre as disciplinas frente aos } \\
\text { problemas. } \\
\text { Reuniões multidisciplinares "são apontadas como espaço privilegiado } \\
\text { para a troca de informações e conhecimento", que favorecem tanto o } \\
\text { crescimento profissional quanto a qualidade da assistência. }\end{array}$ \\
\hline 2 & Abuhab; 2005 & $\begin{array}{l}\text { multi e inter aparecem como uma necessidade para viabilizar o trabalho } \\
\text { do CAPS. Não demonstra compreensão na diferenciação dos termos. } \\
\text { Sobre a articulação do trabalho multiprofissional, "torna-se mais } \\
\text { organizado e ágil quando realizado em equipe, onde cada profissional } \\
\text { assume e se apropria de seu papel. No entender de alguns técnicos, } \\
\text { quando a equipe se disponibiliza para uma atividade interdisciplinar, } \\
\text { indica que os profissionais estão ali porque gostam". }\end{array}$ \\
\hline 3 & Bailey; & $\begin{array}{l}\text { aponta o trabalho multidisciplinar como um grupo com vários } \\
\text { profissionais atuando conjuntamente, sem apresentarem interdependência } \\
\text { em seus processos e ações. Já o trabalho interdisciplinar apresenta como } \\
\text { característica principal o fato de que o resultado somente é alcançado a } \\
\text { partir da contribuição de todas as disciplinas envolvidas, a partir da } \\
\text { interação dos esforços. O trabalho transdisciplinar apresenta, segundo o } \\
\text { autor, três características: a equipe deve desenvolver vários serviços, os } \\
\text { conhecimentos específicos de um membro são utilizados para treinar e } \\
\text { capacitar os demais e papeis e responsabilidades são compartilhados entre } \\
\text { os membros da equipe. } \\
\text { Aponta que cada "fase" do trabalho apresenta dificuldades específicas } \\
\text { que devem ser sanadas de acordo com o momento do grupo. }\end{array}$ \\
\hline 4 & o, Silva; & - \\
\hline 5 & Bourghnet; 2004 & $\begin{array}{l}\text { aponta a escolha pela equipe multiprofissional com metodologia } \\
\text { interdisciplinar como chave para a avaliação e reabilitação, de maneira } \\
\text { integrada, como forma de observar as partes sem perder a noção do todo. }\end{array}$ \\
\hline
\end{tabular}




\begin{tabular}{|c|c|c|}
\hline & & $\begin{array}{l}\text { Esse conceito de multiprofissionalidade e interdiscipinaridade sugere a } \\
\text { "possibilidade de interpretação do conhecimento para suprir as } \\
\text { necessidades do conhecimento (...) uma necessidade do paciente pode ser } \\
\text { atendida por mais de um setor". } \\
\text { "O trabalho em equipe interdisciplinar exige uma postura madura do } \\
\text { profissional, que deve estar preparado para expor claramente suas idéias, } \\
\text { ter a capacidade de absorver críticas e transformá-las em estímulo para } \\
\text { seu crescimento pessoal, além de poder defender com tranqüilidade suas } \\
\text { convicções". } \\
\text { Características do trabalho em equipe interdisciplinar: "permite a } \\
\text { interpretação do conhecimento, conscientização que o todo é maior que } \\
\text { as partes, produção conjunta do conhecimento, recomposição do } \\
\text { conhecimento fragmentado, compreensão do todo dimensiona a ação das } \\
\text { partes, fortalecimento das partes beneficia o todo, exige boa estruturação } \\
\text { das partes, precisa ser construída". }\end{array}$ \\
\hline 6 & Brown; 1995 & - \\
\hline 7 & Camara; 1997 & $\begin{array}{l}\text { trabalha com o atendimento interdisciplinar, a partir de uma "abordagem } \\
\text { multiprofissional de uma forma a mais integrada possível, permitindo ao } \\
\text { paciente usufruir o máximo das qualificações individuais, ao mesmo } \\
\text { tempo que se evita visões múltiplas e fragmentadas de sua problemática } \\
\text { sócio-psíquico-existencial e favorece o convívio entre técnicos e } \\
\text { pacientes como um elemento terapêutico". }\end{array}$ \\
\hline 8 & Campos; 1998 & - \\
\hline 9 & 1999 & $\begin{array}{l}\text { encara a transdisciplinaridade como um objetivo audacioso, na medida } \\
\text { em que "implica na abertura e articulação de campos disciplinares e } \\
\text { campos de responsabilidade bastante distintos entre si". Audacioso } \\
\text { também por ser pouco utilizado, sendo a tomada de decisão e a } \\
\text { responsabilidade pela terapêutica um processo isolado e fragmentado de } \\
\text { cada profissional envolvido no caso. }\end{array}$ \\
\hline 10 & ; 1992 & utiliza todos os termos como sinônimos, e aponta esse recorte. \\
\hline 11 & Campos $^{2} ; 1988$ & - \\
\hline 12 & Catropa; 1987 & $\begin{array}{l}\text { aponta que na equipe multiprofissional "as diversas funções se } \\
\text { coordenam e integram", sendo cada qual uma parte interdependente do } \\
\text { todo. }\end{array}$ \\
\hline 13 & $\begin{array}{l}\text { Ciampone, } \\
\text { Peduzzi; } 2000\end{array}$ & - \\
\hline 14 & Cretikos; 2005 & - \\
\hline 15 & Crevelim; 2005 & - \\
\hline 16 & Cunha; 2002 & - \\
\hline 17 & Faustino; 2003 & $\begin{array}{l}\text { aponta a transdisciplinaridade como de particular interesse para a } \\
\text { formação em enfermagem, embora não discuta seu conceito ou aplicação. }\end{array}$ \\
\hline 18 & Faustino; 2004 & $\begin{array}{l}\text { a multiprofissionalidade representa a necessidade de integração de } \\
\text { diversas categorias profissionais, promovendo uma intervenção conjunta } \\
\text { na abordagem familiar. }\end{array}$ \\
\hline 19 & $\begin{array}{l}\text { Fiander, Burns, } \\
\text { Ukoumunne, } \\
\text { Fahy, Creed, } \\
\text { Tyrer, Byford; } \\
2006\end{array}$ & - \\
\hline
\end{tabular}




\begin{tabular}{|c|c|c|}
\hline 20 & $\begin{array}{l}\text { Fortuna, Mishima, } \\
\text { Matumoto, } \\
\text { Pereira; 2005 }\end{array}$ & \\
\hline 21 & $\begin{array}{l}\text { Gomes, } \\
\text { Deslandes; } 1994\end{array}$ & $\begin{array}{l}\text { interdisciplinaridade é a busca de uma alternativa para as limitações dos } \\
\text { enfoques unidisciplinares. } \\
\text { a interdisciplinaridade é vista como a busca pela recomposição do } \\
\text { conhecimento, frente à fragmentação e crescente especialização do } \\
\text { conhecimento. Responde também aos desafios impostos pelos complexos } \\
\text { problemas modernos, que não são respondidos de maneira unidisciplinar, } \\
\text { ou pela simples justaposição das disciplinas. } \\
\text { "o desafio interdisciplinar deve basear-se numa perspectiva de diálogo e } \\
\text { interação das disciplinas, para além das tentativas multidisciplinares que } \\
\text { apenas produzem conhecimentos justapostos em torno de um mesmo } \\
\text { problema, cada qual a partir de seu próprio e inviolável ponto de vista". } \\
\text { Obstáculos da interdisciplinaridade: forte tradição positivista e } \\
\text { biocêntrica; espaços de poder que a disciplinarização significa; } \\
\text { estruturação do ensino e pesquisa em departamentos; dificuldades } \\
\text { inerentes ao trabalho em equipe. } \\
\text { "Para que se avance na questão da interdisciplinaridade, é importante } \\
\text { lembrarmos que essa não anula a disciplinaridade. Assim como não } \\
\text { significa a justaposição dos saberes, também não anula a especificidade } \\
\text { de cada campo de saber. Ela, antes de tudo, implica numa consciência dos } \\
\text { limites e das potencialidades de cada campo de saber para que possa } \\
\text { haver uma abertura em direção a um fazer coletivo". }\end{array}$ \\
\hline 22 & $\begin{array}{l}\text { Hadley, Turk, } \\
\text { Vasko, McGurrin; } \\
1997\end{array}$ & $\begin{array}{l}\text { a literatura sobre multidisciplinaridade entra como princípio diretivo no } \\
\text { modelo apresentado. }\end{array}$ \\
\hline 23 & Hockley; 1996 & linar. \\
\hline 24 & 2005 & - \\
\hline 25 & Irribary; 2003 & $\begin{array}{l}\text { Multidisciplinaridade: "uma gama de disciplinas propostas } \\
\text { simultaneamente. Não há nenhuma cooperação entre elas. Vários } \\
\text { profissionais estão reunidos, mas trabalham isoladamente". } \\
\text { Pruridisciplinaridade: "envolve a justaposição de diversas disciplinas } \\
\text { situadas geralmente no mesmo nível hierárquico e agrupadas de modo } \\
\text { que apareçam as relações existentes entre elas. Há cooperação, mas sem } \\
\text { coordenação". A finalidade é manter o objeto sempre inscrito no quadro } \\
\text { de sua pesquisa original. } \\
\text { Interdisciplinaridade: "envolve uma axiomática comum a um grupo de } \\
\text { disciplinas conexas e definidas em um nível hierárquico imediatamente } \\
\text { superior, o que introduz a noção de finalidade. É um tipo de sistema de } \\
\text { dois níveis e de objetos múltiplos com a coordenação procedendo de } \\
\text { nível superior". Introduz a noção de finalidade e coordenação do } \\
\text { trabalho. "O objeto é levado a um novo campo, mas ainda permanece } \\
\text { ligado a suas características essenciais. } \\
\text { Transdisciplinaridade: "a descrição geral envolve uma coordenação de } \\
\text { das as disciplinas e interdisciplinas em um sistema de ensino inovado, } \\
\text { sobre a base de um axiomática geral. É um tipo de sistema de níveis e } \\
\text { objetivos múltiplos. A coordenação propõe uma finalidade comum dos } \\
\text { sistemas. Para que a configuração transdisciplinar seja alcançada é }\end{array}$ \\
\hline
\end{tabular}




\begin{tabular}{|c|c|c|}
\hline & & $\begin{array}{l}\text { preciso que esses profissionais, fundamentalmente, estejam } \\
\text { reciprocamente situados em sua área de origem e na área de cada um dos } \\
\text { colegas. A noção de cada profissional, em sua especificidade, contribui } \\
\text { para uma visão global do espaço transdisciplinar". "Diálogo e cooperação } \\
\text { entre diferentes áreas do conhecimento". } \\
\text { "disciplinaridade significará, então, a exploração científica e } \\
\text { especializada de determinado domínio homogêneo de estudo. O que nos } \\
\text { permite evocar um conjunto sistemático e organizado de conhecimentos } \\
\text { com características próprias em seus planos de ensino, de formação, dos } \\
\text { métodos e das matérias". Toda disciplina precisa de outra para interagir. } \\
\text { A interdisciplinaridade é um passo para que a equipe atinja a } \\
\text { transdisciplinaridade. } \\
\text { "Cada um entra na disciplina do colega e olha pela luneta do outro } \\
\text { pesquisador, interrogando os dispositivos práticos e teóricos utilizados } \\
\text { pelo pesquisador anfitrião e com os quais ele vê aquilo que diz ver". } \\
\text { "A transdisciplinaridade procura ultrapassar a modernidade. Por } \\
\text { definição não pode haver especialistas transdisciplinares, mas } \\
\text { pesquisadores animados por uma atitude transdisciplinar. O desafio da } \\
\text { transdisciplinaridade é gerar uma civilização, em escala planetária, } \\
\text { movida pela força de um diálogo intercultural". } \\
\text { "a transdisciplinaridade como um esforço para integrar ao conhecimento } \\
\text { tudo aquilo que não pode ser explicado pelo domínio de uma única } \\
\text { disciplina, de modo a se recolocar o homem no centro do conhecimento". }\end{array}$ \\
\hline 26 & \begin{tabular}{|l} 
Jackson, Gater, \\
Goldberg, Tantam, \\
Loftus, Taylor; \\
1993 \\
\end{tabular} & 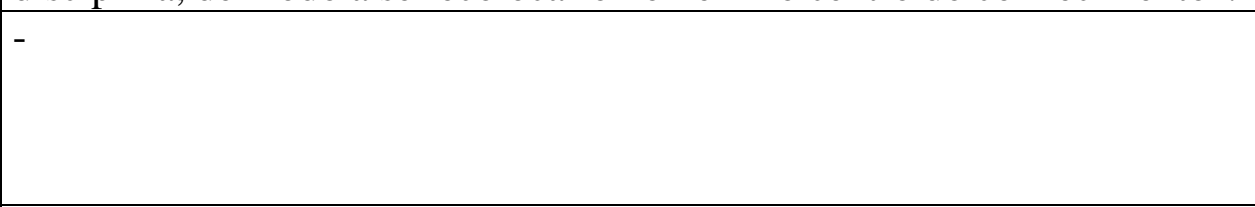 \\
\hline 27 & Lassauniere; 1995 & - \\
\hline 28 & $\begin{array}{l}\text { Lavin, Ruebling, } \\
\text { Banks, Counte, } \\
\text { Furman, Miller, } \\
\text { Reese, Viehmann, } \\
\text { Holt; } 2001\end{array}$ & $\begin{array}{l}\text { Aponta o trabalho em equipe interdisciplinar como a grande tendência do } \\
\text { século } 21 \text {, sendo que os investimentos devem ir na direção da melhoria da } \\
\text { educação referente ao trabalho em equipe interdisciplinar. } \\
\text { A partir de } 1970 \text { é possível perceber na literatura o crescente interesse em } \\
\text { relação à interdisciplinaridade. } \\
\text { Na década de 1990, o advento da AIDS trouxe uma mudança de atitude e } \\
\text { alavancou o trabalho em equipe interdisciplinar na saúde. } \\
\text { 1960: percebe-se uma preocupação em preservar o papel profissional, } \\
\text { para a seguir promover uma discussão interdisciplinar. } \\
\text { 1970: crescente interesse no trabalho interdisciplinar em decorrência da } \\
\text { grande variação de disciplinas. } \\
\text { 1980: identificação de competências, objetivos e conteúdo do trabalho } \\
\text { interdisciplinar, e teste de vários métodos. } \\
\text { Encerra dizendo que o trabalho interdisciplinar é um movimento global, } \\
\text { na busca por um melhor cuidado a pacientes com doenças crônicas ou } \\
\text { complexas. Fatores socioeconômicos interferem na distribuição de } \\
\text { recursos. }\end{array}$ \\
\hline 29 & Lind; 1994 & - \\
\hline 30 & Lino; 1998 & - \\
\hline 31 & Lopes; 1993 & $\begin{array}{l}\text { procura diferenciar conceitualmente equipes multidisciplinares - "uma } \\
\text { integração daqueles profissionais eliminados os preconceitos, orientando }\end{array}$ \\
\hline
\end{tabular}




\begin{tabular}{|c|c|c|}
\hline & & $\begin{array}{l}\text { seus esforços no sentido de se ajudarem mutuamente, a fim de } \\
\text { alcançarem os objetivos comuns de diagnosticar, orientar e prevenir" - } \\
\text { interdisciplinar - "cada integrante da equipe, em sua especialidade, } \\
\text { procederá a observação do cliente, emitindo pareceres em laudos } \\
\text { individuais, para, em conjunto com os demais, obter a formulação da } \\
\text { hipótese diagnóstica, etiológica e prognostica do caso em estudo" - e } \\
\text { transdisciplinar - "trabalhar através da fronteiras disciplinares } \\
\text { tradicionais, na direção da 'liberdade de papéis', tomar todas as decisões } \\
\text { com consenso da equipe". }\end{array}$ \\
\hline 32 & $\begin{array}{l}\text { McNamara, Mak, } \\
\text { Whyte; } 2005\end{array}$ & ( \\
\hline 33 & $\begin{array}{l}\text { Magalhães, } \\
\text { Tiesenhausen; } \\
2000\end{array}$ & $\begin{array}{l}\text { conceito de interdisciplinaridade de Japiassu: "quando nos situamos ao } \\
\text { nível do simples multidisciplinar a solução de um problema só exige } \\
\text { informações tomadas de empréstimo a duas ou mais especialidades ou } \\
\text { setores do conhecimento, sem que as disciplinas levadas a contribuir por } \\
\text { aquele que se utiliza sejam modificadas ou enriquecidas. Já na ótica } \\
\text { interdisciplinar as trocas de conhecimento almejam incorporar os } \\
\text { resultados de várias especialidades tomando de empréstimo das outras } \\
\text { disciplinas técnicas metodológicas, fazendo uso dos esquemas } \\
\text { conceituais e das análises que se encontram nos diversos ramos do saber, } \\
\text { a fim de fazê-los integrar e convergir, depois de terem sido comparados e } \\
\text { julgados". }\end{array}$ \\
\hline 34 & Mase; 1975 & - \\
\hline 35 & Matheus; 1995 & - \\
\hline 36 & $\begin{array}{l}\text { Matsuda, Évora; } \\
2003\end{array}$ & - \\
\hline 37 & $\begin{array}{l}\text { Matumoto, } \\
\text { Fortuna, Mishima, } \\
\text { Pereira, } \\
\text { Domingos; } 2005\end{array}$ & $\begin{array}{l}\text { aponta a organização da produção em saúde de maneira transdisciplinar, } \\
\text { para que "os gestores sejam responsáveis pelos seus resultados e, à } \\
\text { medida que a produção do cuidado em saúde se faz nesses termos, vai-se } \\
\text { construindo 'a figura do gestor do cuidado, que pode ou não ser um } \\
\text { médico, mas que sempre será um cuidador'". }\end{array}$ \\
\hline 38 & $\begin{array}{l}\text { Melo, Tanaka; } \\
1999\end{array}$ & - \\
\hline 39 & Mello; 1998 & $\begin{array}{l}\text { O tratamento interdisciplinar possibilita uma visão ampla do usuário, } \\
\text { favorecendo os profissionais envolvidos através da ampliação de seu } \\
\text { conhecimento técnico e a otimização do atendimento. "Afirma que as } \\
\text { relações interdisciplinares permitem uma melhor compreensão da } \\
\text { realidade e auxiliam na resolução dos problemas", favorecendo as trocas, } \\
\text { os processos de crescimento e transformação, as descobertas e o } \\
\text { crescimento dos profissionais na direção de uma formação polivalente. } \\
\text { "É caracterizada pela intensidade das trocas entre os profissionais e pelo } \\
\text { grau de integração real das disciplinas, durante o entendimento e a } \\
\text { resolução de problemas comuns". } \\
\text { São exigências do trabalho interdisciplinar: a competência específica de } \\
\text { cada especialista e o reconhecimento deste especialista "do caráter parcial } \\
\text { e relativo de sua disciplina". }\end{array}$ \\
\hline 40 & Mishima; 2000 & $\begin{array}{l}\text { "na busca da integralidade da assistência, a atuação de um único } \\
\text { profissional não é suficiente". }\end{array}$ \\
\hline 41 & Monteiro, Ribeiro, & observa a interdisciplinaridade a partir da lente de que um trabalho \\
\hline
\end{tabular}




\begin{tabular}{|c|c|c|}
\hline & $\begin{array}{l}\text { Souza, Serafim; } \\
2002\end{array}$ & somente é integralizado através da complementaridade dos outros. \\
\hline 42 & $\begin{array}{l}\text { Moffic, Patterson, } \\
\text { Laval, Adams; } \\
1984\end{array}$ & $\begin{array}{l}\text { nas equipes multidisciplinares se observa um pequeno intercâmbio de } \\
\text { habilidades entre os membros da equipe, enquanto que nas equipes } \\
\text { interdisciplinares pode-se observar que algumas funções são } \\
\text { compartilhadas por membros das diferentes disciplinas. }\end{array}$ \\
\hline 43 & $\begin{array}{l}\text { Oliveira, Bottaro, } \\
\text { Alessi; } 2003\end{array}$ & $\begin{array}{l}\text { equipe multidisciplinar é conceituada como a "justaposição de um } \\
\text { conjunto de agentes que operam, parcelada ou isoladamente, saberes e } \\
\text { práticas com diferentes recortes de objeto, comumente ordenados sob } \\
\text { uma coordenação administrativa e mantendo uma relação de poder } \\
\text { vertical"; já a equipe interdisciplinar, "as práticas se relacionam, são } \\
\text { recíprocas, interagem, há uma identificação comum de objeto e uma } \\
\text { tendência a horizontalização das relações de poder entre todos os saberes } \\
\text { relacionados e um enriquecimento mútuo". }\end{array}$ \\
\hline 44 & $\begin{array}{l}\text { Oliveira, Spiri; } \\
2006\end{array}$ & $\begin{array}{l}\text { aponta que o PSF trabalha com equipe multiprofissionais, numa } \\
\text { perspectiva e interdisciplinaridade, na qual "os membros da equipe } \\
\text { articulam suas práticas e saberes no enfrentamento de cada situação } \\
\text { identificada para propor soluções conjuntamente e intervir de maneira } \\
\text { adequada já que todos conhecem a problemática". }\end{array}$ \\
\hline 45 & Peduzzi; 2001 & $\begin{array}{l}\text { "trabalho em equipe multiprofissional consiste numa modalidade de } \\
\text { trabalho coletivo que se configura na relação recíproca entre as múltiplas } \\
\text { intervenções técnicas e a interação dos agentes de diferentes áreas } \\
\text { profissionais". }\end{array}$ \\
\hline 46 & Petersson; 2005 & - \\
\hline 47 & Pimenta; 2005 & $\begin{array}{l}\text { propõe que o trabalho das equipes do PSF é interdisciplinar, mas } \\
\text { apresenta que "o saber individualizado dos diversos profissionais que } \\
\text { compõe a equipe de saúde, a visão biologicista, a hegemonia do saber } \\
\text { médico e a disputa de poder dentro da equipe impedem uma abordagem } \\
\text { interdisciplinar no cuidado em saúde". }\end{array}$ \\
\hline 48 & 1988 & $\begin{array}{l}\text { o trabalho em equipe multidisciplinar promove uma redução do número } \\
\text { de visitas médicas, do tempo de internação, assim como a detecção } \\
\text { precoce e um melhor gerenciamento dos problemas. }\end{array}$ \\
\hline 49 & $\begin{array}{l}\text { Queiroz Filho; } \\
1993\end{array}$ & - \\
\hline 50 & Rabinowitz; 2004 & $\begin{array}{l}\text { o autor utiliza os termos interdisciplinar e multidisciplinar como } \\
\text { sinônimos. }\end{array}$ \\
\hline 51 & $\begin{array}{l}\text { Rosa, Labate; } \\
2005\end{array}$ & $\begin{array}{l}\text { aponta a equipe multiprofissional e interdisciplinar como responsável } \\
\text { pelo compromisso de "prestar assistência integral e resolutiva a toda } \\
\text { população (...) de acordo com as reais necessidades dessa população". }\end{array}$ \\
\hline 52 & Rosen; 2006 & $\begin{array}{l}\text { muitos problemas em saúde são multicausais e exigem uma abordagem } \\
\text { com múltiplos olhares; dessa forma, mais resolvidos com mais rapidez e } \\
\text { competência se utilizar uma abordagem interdisciplinar. } \\
\text { A abordagem interdisciplinar pode ser prejudicada pela hegemonia } \\
\text { médica. A legislação aponta o médico como responsável pelos atos de } \\
\text { toda a equipe. }\end{array}$ \\
\hline 53 & Sadigursky; 2002 & $\begin{array}{l}\text { equipe transdisciplinar "impõe socialização de papéis, com redução da } \\
\text { organização hierarquizada de poder de um sobre os demais em prol de } \\
\text { um trabalho coletivo e integrado". } \\
\text { Transdisciplinaridade pode ser conceituada como "um trabalho grupal, }\end{array}$ \\
\hline
\end{tabular}




\begin{tabular}{|c|c|c|}
\hline & & $\begin{array}{l}\text { composto por vários profissionais, mas que extrapola sua área de atuação, } \\
\text { ou seja, é um fluxo de atividades/ práticas e saberes que transita entre os } \\
\text { vários ramos do conhecimento. São práticas articuladas entre si (...) } \\
\text { dando uma visão global da natureza e da realidade, caracterizando-se } \\
\text { como uma prática transformadora do conhecimento". }\end{array}$ \\
\hline 54 & $\begin{array}{l}\text { Schull, Ferris, Tu, } \\
\text { Hux, Redelmeier; } \\
2001\end{array}$ & 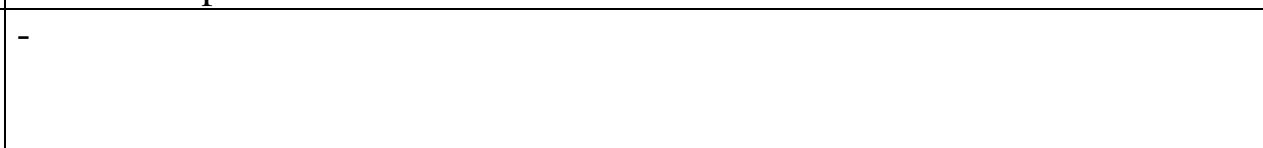 \\
\hline 55 & $\begin{array}{l}\text { Schweikhart, } \\
\text { Smith-Daniels; } \\
1996\end{array}$ & $\begin{array}{l}\text { não faz distinção entre abordagem interdisciplinar e multidisciplinar, } \\
\text { utilizando os dois termos como sinônimos. }\end{array}$ \\
\hline 56 & Sherman; 1990 & - \\
\hline 57 & \begin{tabular}{|l|} 
Shimizu, \\
Ciampone; 2004
\end{tabular} & - \\
\hline 58 & $\begin{array}{l}\text { Silva, Fonseca; } \\
1995\end{array}$ & $\begin{array}{l}\text { apresenta a diferenciação acerca da interdisciplinaridade segundo dois } \\
\text { referenciais teóricos distintos: positivismo e materialismo histórico } \\
\text { dialético. } \\
\text { Aponta a visão do positivismo, que orienta as políticas atuais de saúde, } \\
\text { como permeada filosoficamente pelo idealismo, e no qual a hegemonia } \\
\text { médica é observada. } \\
\text { A visão do materialismo histórico dialético não coloca uma profissão } \\
\text { como superior a outra, mas acredita que todas, sendo o todo de si } \\
\text { mesmas, fazem parte de uma realidade maior, determinada } \\
\text { historicamente, e em constante processo de construção e mudança. }\end{array}$ \\
\hline 59 & Silva; 2005 & - \\
\hline 60 & $\begin{array}{l}\text { Sladen-Dew, } \\
\text { Bigelow, Buckely, } \\
\text { Bornemann; } 1993\end{array}$ & $\begin{array}{l}\text { o programa desenvolvido para crianças também é referenciado, com } \\
\text { abordagem multidisciplinar, e inclui além do paciente e da família, a } \\
\text { comunidade e a escola. Alguns projetos têm abordagem transdisciplinar. }\end{array}$ \\
\hline 61 & Spiri; 2004 & $\begin{array}{l}\text { a postura interdisciplinar é exigida frente à complexidade das } \\
\text { necessidades de atenção em reabilitação. Aponta como dificuldade o fato } \\
\text { de que "as fronteiras entre as disciplinas não são rompidas, permitindo } \\
\text { que haja um voltar-se para a área específica sem a integração com as } \\
\text { demais". } \\
\text { O trabalho interdisciplinar exige antes de tudo uma atitude } \\
\text { interdisciplinar, de se perceber, e perceber o outro interdisciplinar, o que } \\
\text { inclui a reciprocidade, a humildade diante das próprias limitações de } \\
\text { saber, a perplexidade diante de novos saberes, assim como os desafios da } \\
\text { renovação, do compromisso e da responsabilidade. }\end{array}$ \\
\hline 62 & $\begin{array}{l}\text { Thofehrn, } \\
\text { Leopardi; } 2006\end{array}$ & - \\
\hline 63 & Trapp; 1994 & - \\
\hline 64 & 2003 & - \\
\hline 65 & $\begin{array}{l}\text { Undre, Sevdalis, } \\
\text { Healey, Darzi, } \\
\text { Vincent; } 2006\end{array}$ & - \\
\hline 66 & $\begin{array}{l}\text { Van den Berg, } \\
\text { Kalmijm, } \\
\text { Lindeman, } \\
\text { Veldink, de }\end{array}$ & $\begin{array}{l}\text { define equipe multidisciplinar como um conjunto completo de } \\
\text { profissionais com experiência e conhecimento suficientes para concentrar } \\
\text { grande número de pacientes e recursos para o tratamento da esclerose } \\
\text { amniotrófica lateral. }\end{array}$ \\
\hline
\end{tabular}




\begin{tabular}{|l|l|l|}
\hline & $\begin{array}{l}\text { Visser, Van der } \\
\text { Graaff, Wokke, } \\
\text { Van den Berg; } \\
2005\end{array}$ & \\
\hline 67 & $\begin{array}{l}\text { Vliet, Li, MacKay, } \\
\text { Badley; 2006 }\end{array}$ & - \\
\hline 68 & Waters; 2005 & - \\
\hline 69 & $\begin{array}{l}\text { Wiecha, Pollard; } \\
2004\end{array}$ & $\begin{array}{l}\text { diferencia interdisciplinaridade - onde cada membro participa das } \\
\text { atividades de maneira compartilhada, com um nível mais elevado de } \\
\text { colaboração - e multidisciplinaridade - onde cada qual participa de } \\
\text { maneira independente, apenas compartilhando as informações necessárias } \\
\text { ao seu próprio trabalho. } \\
\text { Uma equipe interdisciplinar moderna é um grupo consistente de pessoas } \\
\text { de disciplinas clínicas relevantes, incluindo o paciente, que interagem } \\
\text { guiadas pelas condições que garante o sucesso dos resultados favoráveis } \\
\text { ao paciente. }\end{array}$ \\
\hline 70 & $\begin{array}{l}\text { Yawm, Geier; } \\
1995\end{array}$ & \begin{tabular}{l} 
- \\
\hline
\end{tabular} \\
\hline
\end{tabular}

